$\hat{3}$
$\frac{0}{2}$
$\frac{0}{4}$
$\frac{1}{4}$

\title{
AEROSPACE SYSTEM \\ UNIFIED LIFE CYCLE ENGINEERING: PRODUCIBILITY MEASUREMENT ISSUES
}

Dale E. Calkins, University of Washington

Richard S. Gaevert, University of Washington

Frederick J. Michel, Consultant

Karen J. Richter

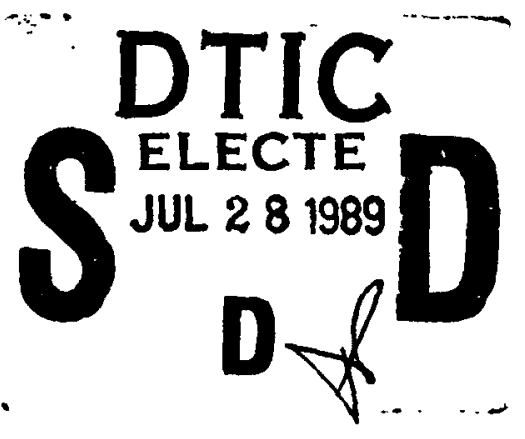

May 1989

\section{DESTREDURON STATEMENT $A$ Approved for public releaser \\ Dienribution Unlionited}

Prepared for

Office of the Under Secretary of Defense for Acquisition

(Research and Advanced Technology)

Supported by

Air Force Human Resources Laboratory

Wright-Patterson AFB, Ohio

INSTITUTE FOR DEFENSE ANALYSES

1801 N. Beauregand Street, Alexandria, Vinginia 22311-177.2 


\section{DEFINITIONS

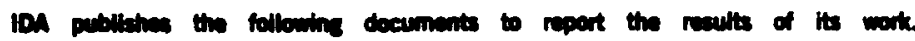 \\ Reports}

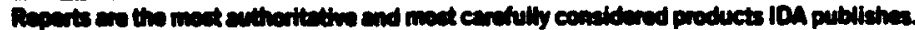

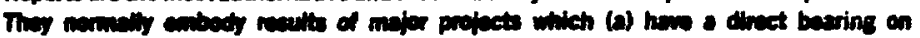

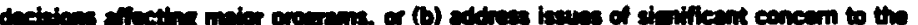

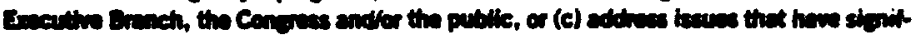

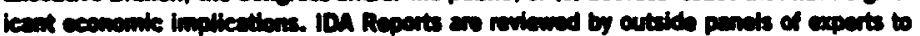

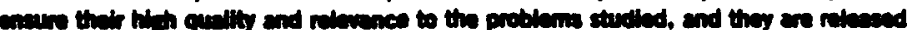
by the Pronidint of IDA

\section{Croup Reports}

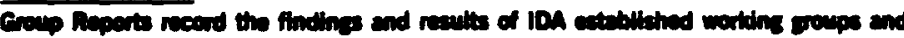

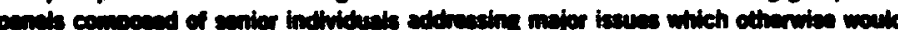

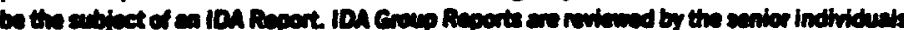

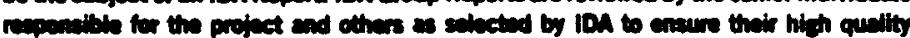

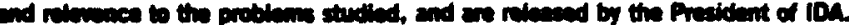

\section{Papers}

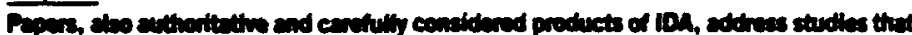

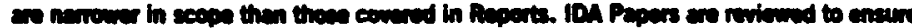

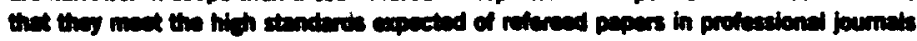

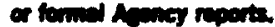

\section{Documants}

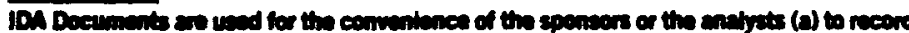

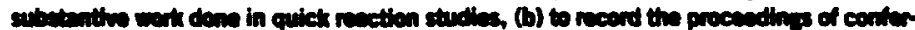

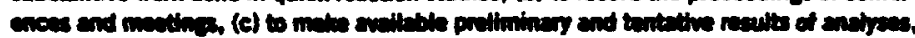

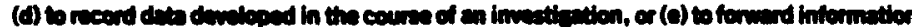

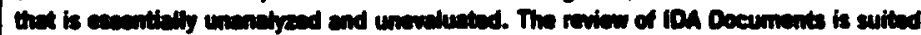

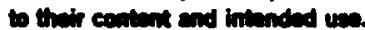

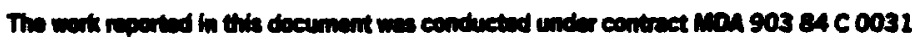

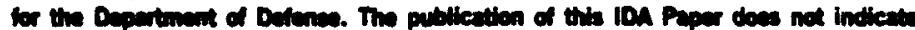

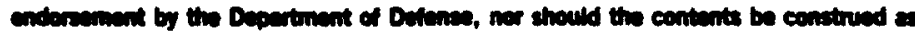

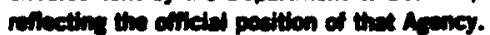

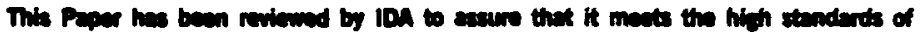

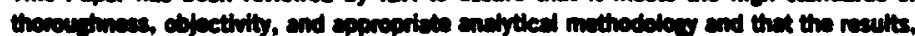

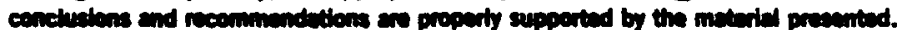


UNCLASSIFIED

SECURTY CLASGFICATION OF THIS PAOE

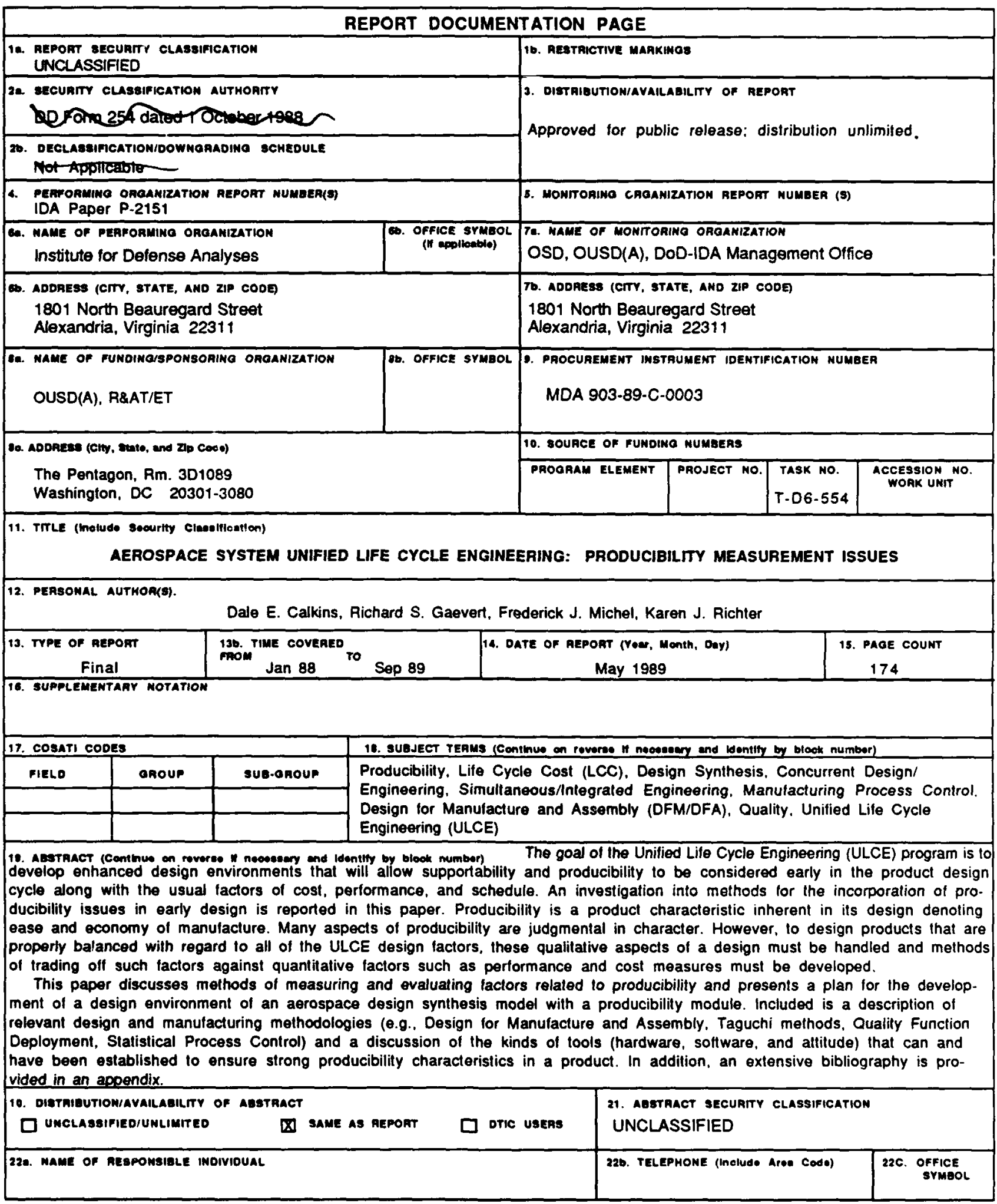

DO FOAN 1473. SA MAA

C.S. $5-1-89$

UNCLASSIFIED

SECURTY CLASSIFICATION OF THIS PAOE 
IDA PAPER P-2151

\section{AEROSPACE SYSTEM \\ UNIFIED LIFE CYCLE ENGINEERING: PRODUCIBILITY MEASUREMENT ISSUES}

Dale E. Calkins, University of Washington Richard S. Gaevert, University of Washington Frederick J. Michel, Consultant Karen J. Richter

May 1989

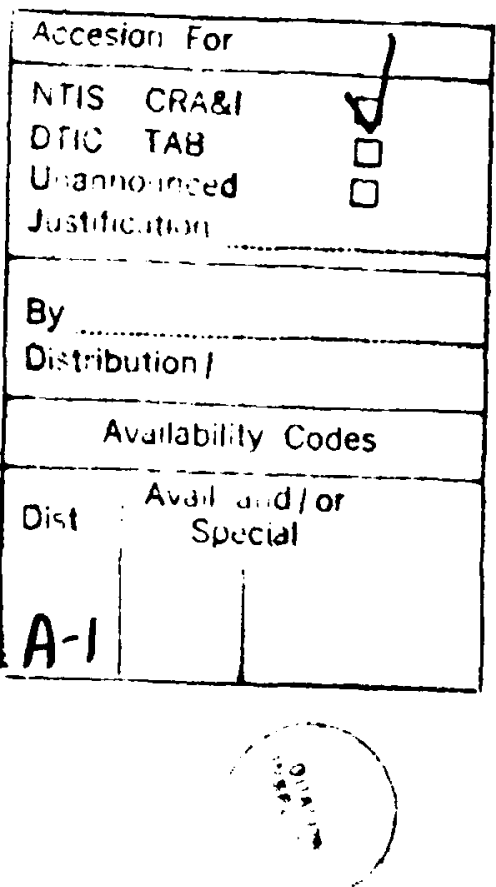

INSTITUTE FOR DEFENSE ANALYSES

Contract MDA 90389 C 0003

Task T.D6-554 


\section{PREFACE}

This report is the result of work performed by the Institute for Defense Analyses (IDA) under contract number MDA $90389 \mathrm{C} 0003$, task order T-D6-554, "Measurements Issues in Unified Life Cycle Engineering." This work was performed for the Air Force Human Resources Laboratory, Logistics and Human Factors Division, and the Under Secretary of Defense for Acquisition (USD(A)). The two general areas being investigated under the task are supportability and producibility. This report covers the issues on the measurement of producibility and specifically addresses subtasks 1-4.

This paper was reviewed by Dr. Jeffrey H. Grotte of IDA; Dr. Daniel P. Schrage of the Georgia Institute of Technology, a consultant to IDA; and Mr. Frederick J. Michel, a consultant to IDA formerly with the Army Materiel Command. Subsequent to his review, Mr. Michel added substantial material to the text. 


\section{CONTENTS}

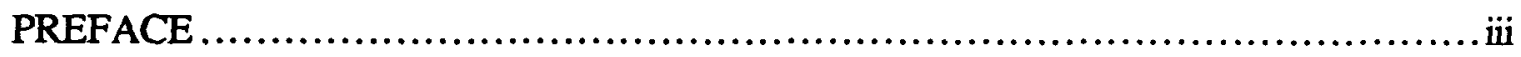

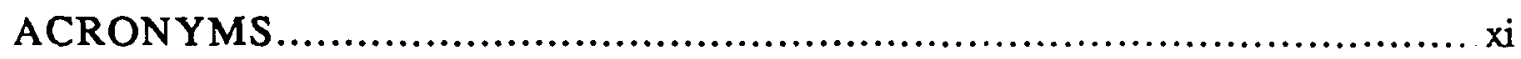

EXECUTIVE SUMMARY .............................................................

A. Producibility Definition ............................................... ES-2

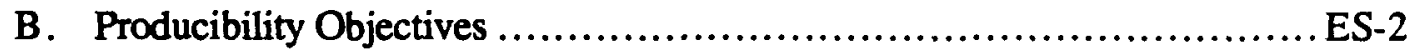

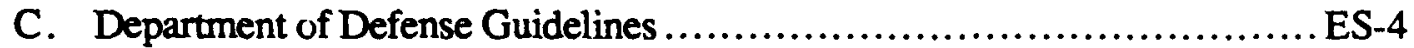

D. Producibility Methodologies and Tools........................................... ES-6

E. Producibility Synthesis Model Development Plan..............................ES-7

1. Life Cycle Cost Model ........................................... ES-7

2. Proposed Synthesis Model ........................................ ES-8

3. Hardware Requirements ........................................... ES-9

4. Software Requirements ............................................

5. System Integration................................................ 10

F. Conclusions and Recommendations ..................................

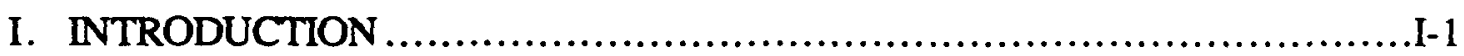

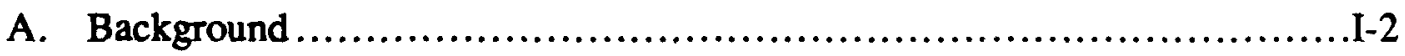

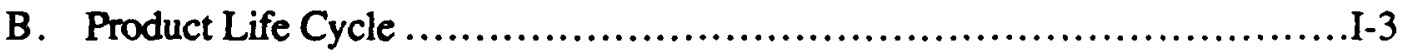

C. Producibility Definition....................................................

II. PRODUCIBILITY CONCEPT .....................................................

A. Producibility Elements...................................................

1. Manufacturing Processes .........................................

2. Geometry ...........................................................

3. Structural Design Concepts...........................................II-9

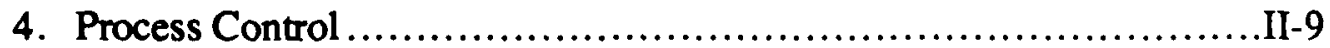

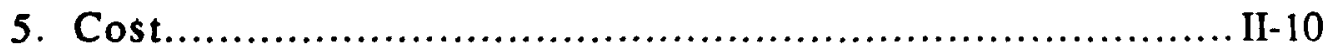


B. Procedural and Heuristic Issues .................................... II-1 1

C. Design Level Detail.............................................................. 11

1. Conceptual Design Level............................................... II-12

2. Preliminary Design Level ........................................ II-13

3. Detail Design Level .............................................. II-13

D. Decomposition................................................ II-13

1. Aerospace System Decomposition............................... II-13

2. Geometry Decomposition...................................... ח-14

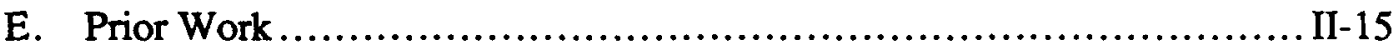

1. Producibility at the Mechanical Design Level ........................ II-15

2. Producibility at the System Design Level ........................... II-18

III. RELEVANT DESIGN AND MANUFACTURING METHODOLOGIES........II-1

A. Concurrent Design and Simultaneous/Integrated Engineering ................III-1

B. Design for Manufacture and Assembly (DFM/DFA).............................III-3

C. Taguchi Measurement Theory .............................................II-4

D. Group Technology ..................................................... III

E. Quality Function Deployment...................................... III-12

F. Environmental Stress Screening..................................... III-15

G. Statistical Process Control....................................................III-15

H. Pareto Analysis ........................................................... III-19

I. Pugh Concept Selection .............................................. III 19

J. Design With Features .............................................III-20

IV. PRODUCIBILITY MEASUREMENT ......................................

A. Evaluation Techniques (Guidelines and Checklists) ......................IV-1

B. Department of Defense Guidelines ..........................................IV-7

C. Producibility Measurement Tools .................................... IV -12

1. Boothroyd and Dewhurst Design for Assembly ................... IV-12

2. Hitachi Assemblability Evaluation Method ........................ IV-14

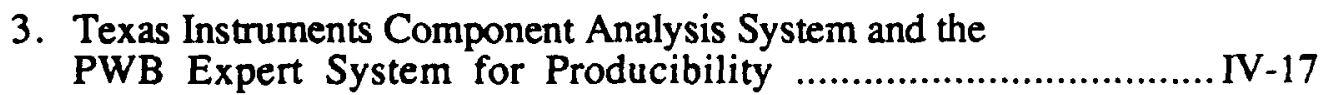

4. Casper: A Designing with Features Software Aid........................ IV-17

5. Process Planning Software ..................................... IV -19 
V. PRODUCIBILITY SYNTHESIS MODEL DEVELOPMENT PLAN. V-1

A. Life Cycle Cost Model ..............................................

B. Supersonic Transport Producibility Studies.................................V-2

C. Proposed Transport Synthesis Model..........................................V-7

1. Knowledge Base.............................................

2. Hardware Requirements ......................................... V-7

3. Software Requirements ........................................ V-10

4. System Integration .......................................... V-12

VI. CONCLUSIONS AND RECOMMENDATIONS ............................. VI-1

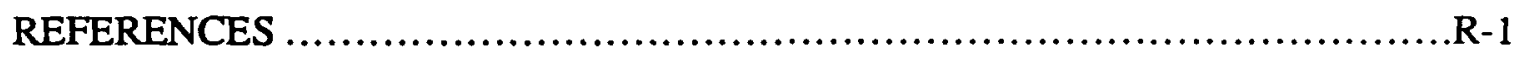

\section{Appendices}
A. DESIGN SYNTHESIS
B. ANNOTATED BIBLIOGRAPHY 


\section{LIST OF TABLES}

II-1. Key Producibility Elements II-3

II-2. Conventional and Nonconventional Manufacturing Processes for Metal and Plastic. II-4

III-1. Potential Savings Using Group Technology Principles. III-12

A-1. Aeronautical Synthesis Model Architecture. A-8

\section{LIST OF FIGURES}

II-1. Costs for Manual and Automatic Assembly Methods . II-6

II-2. Near Net Shape Forging .II-7

II-3. Design for Producibility Components

II-4. Producibility at Various Levels. II -12

II-5. Aerospace Vehicle Decomposition II-14

II-6. Geometry Decomposition II-15

II-7. Geometry Decomposition of Aerospace Vehicle II-16

II-8. Example of Design Simplification

III-1. Degree of Difficulty of Design Change Vs. Time III-2

III-2. Decreasing Cost Savings Leverage as Program Progresses III-2

III-3. Design for Simple Alignment. III-5

III-4. Current and Desired Design Flow for DFA. III-5

III-5. Taguchi Theory and the Quadratic Loss Function III-7

III-6. Traditional Step-Type Loss Function. III-7

III-7. Noise Factors and Loss .III-9

III-8. QFD and Traditional Product Development. III-12

III-9. Fault Tree III-14

III-10. Geometry Knowledge III-21 
IV-1. Critical Path Templates.............................................. IV 10

IV-2. Referenced Material....................................................... IV-11

IV-3. Hitachi Assemblability Procedure............................................. IV-15

IV-4. Producibility Tools Integration Within a PWB Design Environment.......... IV-18

V-1. Johnson's LCC Model .....................................................

V-2. Supersonic Transport Cruise Aircraft ......................................

V-3. Supersonic Cruise Aircraft Producibility Study ............................... -6

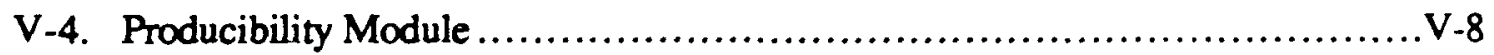

V-5. Design Environment for the Designer ........................................

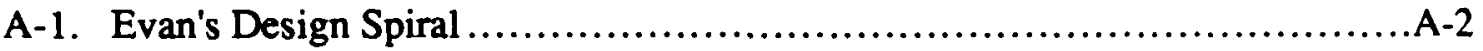

A-2. Andrews' Three-Dimensional Design Spiral ...............................

A-3. Aeronautical and Marine Synthesis Models.........................................

A-4. Design Environment for the Designer ................................... A-16

A-5. Proposed Marine Generic Synthesis Model ............................ A-17

A-6. Hybrid Expert System Environment............................................... A-19 


\section{ACRONYMS}

AEM

AGARD

CAD

CAE

CAS

CFD

CIM

$\mathrm{CNC}$

$\mathrm{COQ}$

DFA

DFM

DOC

DoD

DOMINIC

DSS

$\mathrm{EE}$

FEM

FLOPS

FMEA

FMS

FTA

FY

GT

HLCG
Assemblability Evaluation Method (Hitachi)

Advisory Group for Aerospace Research and Development

Computer-Aided Design

Computer-Aided Engineering

Component Analysis System (Texas Instruments)

Computational Fluid Dynamics

Computer-Integrated Manufacturing

Computer Numerical Control

Cost of Quality

Design for Assembly

Design for Manufacture

Direct Operating Costs

Department of Defense

Domain Independent Redesign Program

Decision Support Systems

Executive Expert

Finite Element Module

Flight Optimization System

Failure Mode and Effects Analysis

Flexible Manufacturing System

Fault Tree Analysis

Fiscal Year

Group Technology

High Level Computer Graphics 
IDA Institute for Defense Analyses

IMIP Industrial Modernization Incentives Program

IOC Indirect Operating Costs

JT Just in Time

LCC Life Cycle Cost

MIPS Million Instrutions per Second

MMT Manufacturing Method and Technology

MRP Manufacturing Resources Planning

MT Manufacturing Technology

NASA National Aeronautics and Space Administration

NATO North Atlantic Treaty Organization

NC Numerical Control

PESP Printed Wiring Board Expert System for Producibility

PWB Printed Wiring Board

QC Quality Control

QFD Quality Function Deployment

RDT\&E Research, Development, Test and Evaluation

RFI Radio Frequency Interference

RISC Reduced Instruction Set Computer

ROI Return on Investment

SAE Society of Automotive Engineers

SAI Science Applications Incorporated

SPC Statistical Process Control

ULCE Unified Life Cycle Engineering

UPC Unit Production Cost

USD(A) Under Secretary of Defense for Acquisition 


\section{EXECUTIVE SUMMARY}

Traditional weapon system design has always concentrated on function and performance. During the past few decades, defense systems have become exceedingly sophisticated, causing engineering to become more functionalized and specialized. Consequently, the design groups that have evolved have drifted apart from manufacturing groups, resulting in equipment that is not always designed for economical production.

Too often designers formulate the new and elegant solutions that cannot be produced and deployed economically [Ref. 2]. As a result, deliveries are often late and costs exceed expectations. For these reasons, the United States must refine its engineering and management techniques and focus on new design and manufacturing methodologies that will increase production efficiency and product quality.

Defense products usually pass through three design phases before entering production--the Conceptual phase, the Demonstration/Validation phase, and Full Scale Development. In recent years, investigations have been conducted to discover where in the life cycle of a product the greatest opportunities exist to significantly influence cost and to what degree cost can be influenced. Evidence clearly shows that these opportunities diminish with each step in the life cycle. The early design phases are the most sensitive, and producibility concepts should be integrated into these phases.

The goal of the Unified Life Cycle Engineering (ULCE) program is to develop enhanced design environments that will encourage producibility and supportability to be considered early in the product design cycle along with the usual factors of cost, performance, and schedule. This paper discusses methods of measuring and evaluating factors related to producibility and presents a plan for the development of a design environment for an aerospace design synthesis model that includes a producibility module. 


\section{A. PRODUCIBILITY DEFINITION}

A major portion of Life Cycle Cost (LCC) and ULCE evaluation is the determination of the product's producibility characteristics while it is being designed. All too often, a product is designed without consideration for how it is to be manufactured. The mentality of "we design it - you build it" often prevails. Producibility is a characteristic inherent in a product's design denoting ease and economy of manufacture. Many aspects of producibility are judgmental in character. However, to design products that are properly balanced with regard to all of the ULCE design factors, these qualitative aspects of a design must be handled, and methods of trading off such factors against quantitative factors such as performance and cost measures must be developed [Refs. 3-5].

The most comprehensive definition of producibility is from the US Army Materials and Mechanics Research Center (now the Army Materials Laboratory):

The combined effect of those elements or characteristics of a design and the production planning for it that enables the item, described by the design, to be produced and inspected in the quantity required and that permits a series of trade-offs to achieve the optimum of the least possible cosi and the minimum time, while still meeting the necessary quality and performance requirements [Ref. 6].

\section{B . PRODUCIBII.ITY OBJECTIVES}

Although no commonly agreed-upon definition or metric to assess producibility was found to exist, the available literature provided information that can be used to develop a knowledge base with which to assess the many elements of producibility. In general, producibility efforts should be directed toward

- facilitating the readiness of the system to enter the production process,

- ensuring that the system can be acquired on schedule at minimum cost,

- ensuring that a qualified source of production is available, and

- ensuring that manufacturing cost estimates are realistic.

To accomplish these goals, integration of producibility into the design process should seek to lessen

- use of critical processes

- design changes in production

- use of unnecessarily tight tolerances 
- use of unnecessarily fine surface finishes

- need for special purpose machine tools

- procurement lead times

- use of critical (strategic) materials

- dependence on foreign sources

- use of limited availability items and processes

- use of proprietary items

- generation of off-fall rework and scrap

- needed skill levels and manpower of production personnel

- need for special production testing and equipment

- use of special test systems

- energy consumption

- pollution

- use of hazardous materials

- unit costs

- production risk.

Integrating producibility into the design process should increase

- simplicity of the design

- confirmation of design adequacy prior to production

- use of economical materials

- standardization of materials and components

- process repeatability

- product inspectability

- interchangeability of parts

- use of existing labor

- use of automation. 


\section{DEPARTMENT OF DEFENSE GUIDELINES}

Products manufactured for the military aerospace market are highly complex, specification driven, and are produced in relatively low volumes. The difficulties encountered in weapons production have commanded increasing attention in the Department of Defense (DoD). For many sophisticated weapon systems, the production period has proven to be as difficult as the development period. Cost growth and late deliveries stemming from production floor problems have consistently impeded attempts to field new equipment. The additional time and money needed to produce the desired quantities of weapons routinely frustrates the budgeting and planning process. The DoD has taken several actions to direct better preparation for production. The concept of producibility within the defense industry is addressed specifically by many defense and other government sponsored publications. [See Refs. 6, 7, 8, 43, 44, 45, 46, 47, 48.] The government's policies for production and acquisition of weapon systems can be summarized as follows:

- Develop a manufacturing strategy as a part of the acquisition strategy and address manufacturing voids and producibility of concepts during concept demonstration and validation

- Make a comprehensive producibility engineering and planning program a requisite for full-scale development, with specific tasks, measurable goals, and a system of contractor accountability

- Assess production management and production status at each major milestone decision

- Adequately fund producibility engineering and planning, manufacturing technology, and facilities

- Employ pilot production lines, when necessary, to validate production readiness, manufacturing operations, and cost

- Conduct production readiness reviews in support of limited production and full production decisions

- Integrate factors affecting producibility and supportability during full-scale development and structure the design and test cycle to provide a continuum in development, production, and operational support

- Ensure that an adequate number of technically qualified and competent people are committed to the program, and take specific measures to train production personnel, including a defined career progression and extended assignments. 
A report issued by the US General Accounting Office (GAO) cited six case studies of weapons systems production problems [Ref. 45]. The GAO concluded that the production problems are caused, in nearly all cases, by inadequate preparation for production during the developmental stage. When problems occurred, production preparations were, in varying degrees, sporadic, underfunded, and largely compressed into the late stages of development and early production. This poor production planning resulted in increased costs, delayed deliveries, and slower attainment of higher, more efficient production rates. The development conditions that most directly affected the manner and thoroughness of the production preparations were

- Whether pressures to achieve technical performance requirements dominated the development phase

- Whether sufficient program management attention and staff resources were devoted to production concerns

- Whether funding and quantity stability permitted early and serious consideration of production matters during the development phases.

The GAO's major recommendation was that the DoD should place an emphasis on balancing concerns for technical performance with those for production. This balance can be better accomplished when program instabilities, such as changing design requirements, fluctuating funding, and changing deliverable quantities are limited. The use of regular production readiness reviews [Ref. 65] during development should also be employed as a tool for managing production preparations. DoD should, however, recognize that designing for producibility should be a continuing process, and success cannot be achieved through the sole use of production readiness reviews.

Two significant DoD publications that address producibility are the Navy's Manual, Best Practices [Ref. 43], and DoDD 4245.7M, Transition from Development to Production [Ref. 44]. In each of these publications, the design, development, and production stages of a weapon system are separated into templates. DoDD $4245.7 \mathrm{M}$ identifies the risks associated with each template and includes an outline for reducing these risks. Best Practices lists with each template four significant "traps" that managers should avoid during each program phase.

Another important DoD publication relating to producibility is Military Handbook Design Guidance for Producibility [Ref. 6], developed by the Army Materials and 
Mechanics Research Center. This most comprehensive document addresses all aspects of producibility, from nearly every angle of manufacturing.

DoD has also established two programs to enhance producibility and lower the cost of weapon systems--the Manufacturing Technology (MT or Man Tech) Program [Ref. 63] and the Industrial Modernization Incentives Program (IMIP) [Ref. 66].

The MT program objective is to fund development of concepts, processes, and equipment that will reduce cost and lead time, improve quality and reliability, and eliminate the use of hazardous materials in weapon system production [Ref. 63]. Because of the risks involved in such development, industry will not sponsor such efforts.

IMIP provides incentives to contractors willing to undertake major plant modernization. The program guarantees the contractor a negotiated return on investment should its return drop below a certain amount within a specified time period.

\section{PRODUCIBILITY METHODOLOGIES AND TOOLS}

During the past decade, many corporations and researchers have begun to recognize the importance and necessity of designing for producibility. After much study and research, many have developed or have begun to develop producibility software or producibility tools to help designers and manufacturers obtain optimum designs. Chapter IV includes descriptions of the following producibility software and tools:

- DFA/DFM, Boothroyd and Dewhurst

- Hitachi Assemblability Evaluation Method (AEM)

- Texas Instruments Component Analysis System (CAS) and the Printed Wiring Board (PWB) Expert System for Producibility (PESP)

- Casper: A Designing with Features Software Aid

- Process Planning Software.

Many techniques currently used in industry for product/process quality control are closely related to the producibility concept. In addition, many new techniques have become available for integrating manufacturing and assembly considerations into the early design stages. Among these techniques are

- Concurrent Design and Simultaneous/Integrated Engineering

- Design for Assembly and Manufacture (DFA/DFM) 
- Taguchi Measurement Theory

- Group Technology

- Quality Function Deployment (QFD)

- Environmental Stress Screening (ESS)

- Statistical Process Control (SPC)

- Pareto Analysis

- Pugh Concept Selection

- Knowledge Representation of Parts and Assemblies

- Design with Features.

Each of these techniques is discussed in moderate detail in Chapter III of this report.

\section{E. PRODUCIBILITY SYNTHESIS MODEL DEVELOPMENT PLAN}

The first sections of Chapter $\mathrm{V}$ present information from existing studies and research as an example or paradigm of how producibility concepts may be integrated into aircraft conceptual and preliminary design. The architectural foundation for this paradigm is the synthesis model concept described in Appendix A. The information presented is then structured into a concept for a modified synthesis model that combines procedural and heuristic aspects in the proposed design environment. The following paragraphs present an overview of the model, and details are provided in Chapter V.

\section{Life Cycle Cost Model}

Since weapon system cost is an indicator of producibility, the use of a cost model as a procedural module in a synthesis model is one approach to assessing producibility in design. An LCC methodology for use in the conceptual design process of subsonic commercial aircraft has been developed by Johnson [Ref. 42]. Johnson's model addresses the conceptual aircraft design level, which is described as the phase where the general size and configuration (geometry) and the estimated performance of the aircraft are determined. It includes research, development, test, and evaluation (RDT\&E), production, direct operating costs (DOC), and indirect operating costs (IOC) elements (Figure V-1). The LCC model was developed by assembling previously existing programs for each of the individual modules. 
The Science Application Incorporated (SAI) [Ref. 54] airframe model was used in Johnson's model for airframe acquisition cost. The SAI model comprises system-level weight and cost estimating relationships for transport aircraft. The model estimates weights and production costs based on performance parameters at the individual system level, exclusive of the engines. The Rand Corporation model [Ref. 15] was used for estimating the development and production costs of engines. The American Airlines model [Ref. 16] was used for the DOC, as it is based on past experience data. The Lockheed-Georgia Company model [Ref. 55] was used for the IOC.

Johnson integrates the system LCC model with a synthesis model, called Flight Optimization System (FLOPS), used for conceptual and preliminary design. FLOPS consists of four primary modules--Weights, Aerodynamics, Mission Performance, and Takeoff and Landing.

Integrating the LCC module with the synthesis model, FLOPS, is an example of the use of procedural knowledge to assess the producibility of an aircraft concept at the Conceptual design level. A knowledge of the primary level of geometry, i.e., the aircraft configuration, was required.

\section{Proposed Synthesis Model}

The study team proposes to the ULCE community, for the future development of the concept of introducing producibility into the Conceptual and Preliminary design stages of aircraft design, that an example synthesis model, perhaps FLOPS with the LCC developed by Johnson [Ref. 42], be combined with heuristic components of producibility. The LCC module would address the aircraft concept development at the Conceptual design level, while the heuristic module would address the Preliminary design level.

A homogeneous micro-scale model of the proposed design environment should be developed. The proposed design environment is based on the Apple Macintosh II configured as a workstation. A synthesis model, such as FLOPS with the LCC module, should be ported to the Macintosh II environment. In final form, the model would feature the full Macintosh user interface including pull-down menus and embedded graphics. 


\section{a. Procedural Issues}

The procedural issues include consideration of design factors such as manufacturing process, geometry, structural design concept, process control, and cost. These factors may be structured as a cost model, which reflects the effect of the aircraft weight. Aircraft weight, of course, depends on the remaining design factors. An optimization module included in the synthesis model may be used to optimize objective functions such as LCC or weight or a combination such as LCC/weight.

\section{b. Heuristic Issues}

Heuristic producibility issues are those that require the knowledge and experience of experts to resolve. Heuristic issues can often be evaluated using checklists, lists of guidelines, or design rules. Some of these lists, rules, and guidelines are described in Section IV.A. The knowledge base of the heuristic issues may also be developed into expert systems that may be used to advise the designer.

\section{Hardware Requirements}

\section{a. Macintosh II}

The Apple Macintosh II, configured as a workstation, is the proposed hardware for the design environment. The Macintosh II, an alternative to expensive engineering workstations such as the Sun-3/60 and the Apollo DN/3000, offers an enhanced work area. By connecting dual monitors and using Apple's multi-tasking program, MultiFinder, several different applications may be run at the same time.

The Macintosh II, a cost-effective alternative to the expensive engineering workstations such as the Sun-3/60 [Ref. 60] and the Apollo DN/3000 [Ref. 61], offers an enhanced work area. The Macintosh II's greatest advantage is its user interface, which is easy $t>$ use and offers best response to user input.

\section{b. Translink}

The Translink is designed for applications that are computationally intensive or naturally parallel. Naturally parallel means that problems can be reduced to smaller problems and worked on at the same time. Applications that can take advantage of parallel 
processing include differential equation solving, rule-based expert systems, and objectoriented search and parallel search of multiple files in distributed data bases.

\section{Software Requirements}

Commercially available software provides the basis for developing the design environment around the hardware kernel. Included should be:

Brogram

Micro-Dot

GUIDE

HyperCard

NEXPERT OBJECT

SMALLCRAFT

\section{Eunction}

Automated optimization

Hypertexthypermedia

Hypertext

Expert system shell/Object-oriented programming Synthesis model

\section{System Integration}

The objective of this plan is the integration of the automated optimization program, Micro-Dot, and the three-dimensional design space graphics with the demonstration synthesis model, SMALLCRAFT. Interface techniques to facilitate program communication will be developed, which utilize the multiple windowing and graphic capabilities of the Macintosh II workstation.

The knowledge base or heuristic component of the Design Environment should comprise three levels of knowledge cognition for the designer, including a Design Advisor, a Design Guide, and a Design Encyclopedia. The Design Advisor will be the expert system that makes the design decisions and advises the designer. The Design Advisor will be based on the use of NEXPERT OBJECT.

The Design Guide will provide succinct graphical and textural design information that has been extracted and organized in HyperCard stacks for ease of access. The designer could browse through the stacks for specific design information or peruse the stacks for design ideas.

The Design Encyclopedia would provide the designer with a cross-linked data base of technical reports, notes, articles, and texts on specific subjects. The designers would use this knowledge as background information to aid them in making design decisions. The Design Encyclopedia would be developed using GUIDE. 


\section{F. CONCLUSIONS AND RECOMMENDATIONS}

Producibility is the property of a product that determines if it is easily produced. Producibility can apply to manufacturing of single parts, assemblies of parts, and the manufacturing and assembly of products as complicated as jet aircraft. While producibility is not a specific science with governing laws, attaining producibility does require knowledge of both the design and manufacturing processes. It requires that the individuals involved in design, procurement, and production all work together to produce the highest quality final deliverable at the lowest possible cost.

Achieving producibility requires that the manufacturing and design engineers work together as a team. While manufacturing engineers view productivity goals as an ideal way to measure the effectiveness of product design, design engineers may resent having a score applied to their design. Team members should recognize that producibility is simply good design practice that results in better designs, shorter development cycles, and lower costs.

The major conclusions are that producibility results in

- Simpler designs

- An improved engineering/manufacturing interface

- Product designs leading to earlier design maturity in production

- Product designs of higher quality and reliability

- Lower production cost

- Shorter lead times

- A more inspectable and testable product.

Simpler designs mean fewer parts, less complex assembly operations, and lower fixturing costs. Improved interfaces mean better teamwork; early resolution of design, tooling, and process problems; and an improved design release package. Combined, these factors result in better quality and reliability.

In summary, the recommendations of the IDA study team are

- The concept of ease of manufacture or producibility must be integrated into the acquisition process starting with Concept Exploration and Demonstration/ Validation phases and must be continued through Final Design or Full Scale Development. This integration is commonly known as Simultaneous Engineering or Concurrent Design. 
- Best Practices/Transition From Development to Production concepts are most appropriate during Full Scale Development.

- Producibility should be introduced into the aerospace vehicle design process at the Preliminary design level. The Conceptual design level module should be based on historical data for a specific design class.

- An ULCE Application Testbed should be based on the Synthesis Model architecture. A demonstration synthesis model/producibility module should be developed based on the design environment discussed in Section $F$ of Appendix A. 


\section{INTRODUCTION}

The United States faces military threats from potential adversaries and economic threats from many foreign countries. The Soviet Union has historically outproduced the United States in nearly all major weapon categories, in many areas a margin of two to one. Foreign trade deficits and US federal budget deficits continue to grow year after year. Engineering and manufacturing technology in the United States plays a large role in combating the problems that bring about these statistics. Yet it is estimated that in the United States each year only 69,000 students graduate with degrees in engineering, while the Soviet Union graduates 300,000; China, 200,000; and Japan, 73,000.

It is also estimated that 40 percent of the present work force of aerospace engineers in the United States will retire within the next 10 years. The aerospace industry will not only experience a sharp reduction in its work force but also lose its most experienced members [Ref. 1]. For the United States to maintain its position as a world leader, the engineers and manufacturers of the next generation will have to be more cost conscious, more competitive, and more productive.

Traditional weapon system design has always focused on function and performance. During the past few decades, defense systems have become exceedingly sophisticated, causing a high degree of specialization in engineering. Consequently, design groups have evolved apart from manufacturing groups, thus resulting in equipment not designed for economical production.

Too often designers formulate new and elegant solutions that cannot be produced and deployed economically [Ref. 2]. As a result, deliveries are often late and costs exceed expectations. For these reasons, the United States must refine its engineering and management techniques and focus attention on new design and manufacturing methodologies that will increase production efficiency and product quality.

The goal of the Unified Life Cycle Engineering (ULCE) program is to develop enhanced design environments that will encourage producibility and supportability to be 
considered early in the product design cycle along with the usual factors of cost, performance, and schedule. This research will involve developing methods of measuring and quantifying factors related to producibility. Producibility affects product design, process selection, and factory configuration.

The objective of this report is to discuss all aspects of producibility including

- How to increase the producibility of a product;

- What kind of tools have been and can be established to ensure strong producibility characteristics in a product; and

- How to measure or evaluate the producibility of a product.

In addition, an extensive bibliography is provided in Appendix B. The remaining sections of this introductory chapter provide an overview of the product life cycle, life cycle cost (LCC), and producibility.

\section{A. BACKGROUND}

In the spring of 1987 , the Institute for Defense Analyses (IDA) held two workshops to investigate the decision support requirements in a ULCE design environment. Workshop participants from industry, academia, and government constituted the IDA ULCE Decision Support System (DSS) Working Group. The group focused its efforts on determining the tools, techniques, and procedures that are needed to allow considerations of producibility and supportability to be quantified and traded off with cost, performance, and schedule factors throughout the design process.

One research priority identified by the Working Group for ULCE DSS focus was "a search for methods to incorporate the qualitative factors of the design process into the formal and informal optimization procedures contemplated for ULCE." [Ref. 55] Because many components of the concepts of producibility and supportability are qualitative attributes, their potential for formal inclusion in a ULCE DSS depends on whether they can be quantified and meaningfully traded off with other design attributes to achieve a design that balances performance, cost, schedule, producibility, and supportability.

Research into this issue was funded by the Logistics and Human Factors Division of the Air Force Human Resources Laboratory as the FY 1988 IDA task, "Measurement Issues in Unified Life Cycle Engineering." To investigate the producibility measurement issues, DA funded research into this topic at the University of Washington directed by 
Dr. Dale E. Calkins. Dr. Calkins, an Associate Professor of Mechanical Engineering, teaches a senior Mechanical Design project course and has 27 years of design experience in aeronautical engineering, naval architecture, and marine engineering. Dr. Calkins contributed a designer's views on integrating producibility in the early stages of the design process, which were essential to the success of the effort. Working with Dr. Calkins was Mr. Richard S. Gaevert, who has experience in the aerospace industry as a logistics engineering analyst and is now completing graduate studies under Dr. Calkins. The majority of the information in this report is the result of their research.

\section{B . PRODUCT LIFE CYCLE}

The life cycle of a product consists of many stages--need evaluation, conceptual design, demonstration/validation, full scale development, low rate initial production, full scale production, deployment (for military products), maintenance and repair, and disposal or recycle. Each of these steps were traditionally considered separate stages; when one stage was finished, the next was started. Future issues or problems were rarely considered, and congressional budget constraints and funding methods supported this approach.

This serial product development process was often used because the job of considering all elements of a product's life cycle at once was organizationally and computationally overwhelming. This was especially true for complicated products such as military and civilian aircraft, which often involve millions of parts and thousands of design engineers and subcontractors. With the increased use of Computer-Aided Design and Computer-Aided Engineering (CAD/CAE) techniques, some of these tasks can be simplified by combining CAD/CAE with the concepts of ULCE and LCC or cost of ownership.

ULCE integrates the ilities $^{1}$ with performance and cost as design drivers from the start of the development of an aerospace system. ULCE implementation in actual design practice requires new or improved decision support techniques and systems to measure design attributes and to arbitrate among these attributes so that well-defined, cost-effective designs are developed. The following three key decision support capabilities, which

1 Ilities - those aspects of a product that in totality are measures of effectiveness or of fitness of use for accomplishing desired objectives. 
generally have not been achieved in industry, are needed to successfully implement ULCE in the design stages:

- Rapidly and rationally measure the effect of design alternatives on diverse ULCE attributes such as performance, producibility, and supportability

- Logically and compatibly arbitrate design issues among the many attributes to obtain a best or optimum design as dictated by the performance requirements and lowest life cycle cost (LLC)

- Implement decision support techniques for measurement and arbitration in a computer system for a largely inexperienced engineering work force with scarce expert resources.

Techniques and computer systems that achieve these requirements must be developed and applied. Emerging methods in CAD, CAE, and computer-aided manufacturing (CAM), along with advances in applied measurement/decision theory offer the potential to build DSS for effective ULCE practice. As an initial step toward this end, research on a DSS for unified performance and producibility design engineering is required.

The LCC is the total cost of a system. It includes the cost to develop, acquire, operate, and support an item, subsystem, or system over its useful life-span, less any revenue derived from disposal of the system. ULCE is the design process by which all aspects of a product's life cycle are considered and optimized during the design stage for the given performance, reliability, and support costs. The most influential stage in determining a product's LCC and ULCE characteristics is the design phase. During this stage almost all product characteristics, especially producibility, reliability, and maintainability are determined. The design process, and in particular design synthesis, is discussed in detail in Appendix A.

\section{PRODUCIBILITY DEFINITION}

A major portion of the LCC and ULCE evaluation is the determination of a product's producibility characteristics while it is being designed. All too often, a product is designed without consideration for the production methods. The mentality of "we design it - you build it" often prevails. Producibility is a characteristic inherent in a product's design denoting ease and economy of manufacture. Many aspects of producibility are judgmental in character. However, the design of products that are properly balanced with regard to the 
ULCE design factors requires the development of methods for conducting trade offs between the qualitative factors and such quantitative factors as performance and cost measures [Refs. 3-5]. Chapters II, III, and IV present the issues of producibility and its measurement in detail. Chapter $\mathrm{V}$ gives plans for development of a producibility synthesis model, and Chapter VI lists the conclusions and recommendations. 


\section{PRODUCIBILITY CONCEPT}

What is producibility? The literature surveyed for this report (listed in Appendix B) contained a number of similar definitions. The most comprehensive definition is from the US Army Materials and Mechanics Research Center (now the Army Materials Laboratory):

The combined effect of those elements or characteristics of a design and the production planning for it that enables the item, described by the design, to be produced and inspected in the quantity required and that permits a series of trade-offs to achieve the optimum of the least possible cost and the minimum time, while still meeting the necessary quality and performance requirements. [Ref. 6]

\section{A. PRODUCIBILITY ELEMENTS}

Although no commonly agreed-upon definition or metric to assess producibility was found to exist, the available literature provided information that can be used to develop a knowledge base with which to assess the many elements of producibility. In general, producibility efforts should be directed toward

- facilitating the maturity of system design before entering production

- ensuring that the system can be acquired on schedule at minimum cost

- ensuring that manufacturing cost estimates are realistic.

To accomplish these goals, integration of producibility considerations into the design process should seek to lessen

- use of critical processes

- design changes in production

- use of unnecessarily tight tolerances

- use of unnecessarily fine surface finishes

- use need for special purpose machine tools

- procurement lead times

- use of critical (strategic) materials 
- dependence on foreign sources

- use of limited availability items and processes

- use of proprietary items

- generation of off-fall rework and scrap

- needed skill levels and manpower of production personnel

- need for special production testing and equipment

- use of special test systems

- energy consumption

- pollution

- use of hazardous materials

- unit costs

- production risk.

Integrating producibility into the design process should increase

- simplicity of the design

- confirmation of design adequacy prior to production processes

- use of economical materials

- standardization of materials and components

- use of economical manufacturing processes

- process repeatability

- product inspectability

- interchangeability

- use of existing labor

- use of automation.

The key elements of producibility are summarized in Table II-1. 
Table II-1. Key Producibility Elements

- Performance Requirements

- Reliability

- Tolerance Budgeting

- Interchangeability

- Maintenance Concept

- Design Maturity

- Materials Selection

- Materials Availability

- Lead Time

- Capability of Supplier Base

- Mauinine Availability

- Manufacturing Automation
- Manufacturing Flexibility

- Manufacturing Simplicity

- Material Handling

- Production Rate and Quantity

- Special Tooling

- Inspection

- Testing

- Special Inspection and Test Equipment

- Manpower Availability

- Production Risk

- Least Cost

\section{Manufacturing Processes}

Manufacturing of components requires transforming raw materials into finished products. The four types of primary manufacturing processes, shown in Table II-2, are forming, reduction, joining, and finishing. Forming transforms raw material through deposition or deformation into a desired shape or configuration. Reduction processes transform raw material or formed shapes by removing material. Joining is a process to create new components by fastening together similar or dissimilar materials or parts. Finishing processes prepare the surface of a product for subsequent final surface treatment or provide final surface treatment. Table II-2 lists conventional and nonconventional manufacturing processes for metal and plastic.

To determine the approach to production, the designer and manufacturer must know the production rate and total quantity to be produced. There are three production options-the item can be produced manually, with a flexible manufacturing system (FMS), or with fixed automation. Each of these methods can be used on individual workstations or applied throughout an entire factory. The method of manufacture is determined economically; the approach that yields the highest return on investment (ROI) and the lowest unit production cost (UPC) is used [Ref. 64]. 
Table II-2. Conventional and Nonconventional Manufacturing Processes for Metal and Plastic

\begin{tabular}{|c|c|c|c|}
\hline \multicolumn{4}{|c|}{ Primary Manufacturing Processes } \\
\hline Forming & Reduction & Joining & Finishing \\
\hline \multicolumn{4}{|c|}{ Traditional Secondary Manufacturing Processes for Metals } \\
\hline $\begin{array}{l}\text { Ausforming } \\
\text { Casting } \\
\text { Cold-Heading } \\
\text { Hot-Heading } \\
\text { Cold-Roll Forming } \\
\text { High Energy Forming } \\
\text { Rubber Pad Forming } \\
\text { Hydroforming } \\
\text { Martorm Forming } \\
\text { Stretch Forming } \\
\text { Stretch Draw } \\
\text { Deed Draw } \\
\text { Electroform } \\
\text { Explosive Form } \\
\text { Extruding } \\
\text { Forging } \\
\text { Spinning } \\
\text { Metalizing } \\
\text { Roll Forming } \\
\text { Seaming } \\
\text { Swaging } \\
\text { Thread Rolling } \\
\text { Thermoforming } \\
\text { Tube Bending } \\
\text { Tube Forming } \\
\text { Drawing }\end{array}$ & $\begin{array}{l}\text { Boring } \\
\text { Broaching } \\
\text { Chemical Milling } \\
\text { Chemical Blanking } \\
\text { Drilling } \\
\text { Electrochemical } \\
\text { Electrical Discharge } \\
\text { Electron Beam } \\
\text { Flame Cutting } \\
\text { Grinding } \\
\text { Hobbing } \\
\text { Milling } \\
\text { Reaming } \\
\text { Shaping } \\
\text { Nibbling } \\
\text { Plercing } \\
\text { Notching } \\
\text { Slitting } \\
\text { Shearing } \\
\text { Punching } \\
\text { Tapping } \\
\text { Trepanning } \\
\text { Tuming }\end{array}$ & $\begin{array}{l}\text { Bonding } \\
\text { Brazing } \\
\text { Soldering } \\
\text { Cold Wolding } \\
\text { Welding } \\
\text { Mechanical Fastening }\end{array}$ & $\begin{array}{l}\text { Silk Screening } \\
\text { Cleaning } \\
\text { Surface Blasting } \\
\text { Shot Peening } \\
\text { Deburring } \\
\text { Knurling } \\
\text { Painting } \\
\text { Parkerizing } \\
\text { Electroplating } \\
\text { Tumbling } \\
\text { Brushing } \\
\text { Lapping } \\
\text { Buffing } \\
\text { Hydrohoning } \\
\text { Iriditing } \\
\text { Anodizing }\end{array}$ \\
\hline \multicolumn{4}{|c|}{ Secondary Manufacturing Processes for Plastics } \\
\hline $\begin{array}{l}\text { Injection } \\
\text { Extrusion } \\
\text { Compression Molding } \\
\text { Transfer Molding } \\
\text { Thermoforming } \\
\text { Blow Molding } \\
\text { Rotational Molding } \\
\text { Mechanical Molding } \\
\text { Casting }\end{array}$ & $\begin{array}{l}\text { Drilling } \\
\text { Milling } \\
\text { Tuming } \\
\text { Tapping } \\
\text { Punching } \\
\text { Grinding }\end{array}$ & $\begin{array}{l}\text { Adhesive Bonding } \\
\text { Mochanical Fastening } \\
\text { Heat Sealing } \\
\text { Ultrasonic Bonding } \\
\text { Ultrasonic Staking } \\
\text { Spin Welding } \\
\text { Vibrating Welding } \\
\text { Hot Gas Welding } \\
\text { Electromagnetic Bonding }\end{array}$ & $\begin{array}{l}\text { Electroplating } \\
\text { Vacuum Metalizing } \\
\text { Painting }\end{array}$ \\
\hline \multicolumn{4}{|c|}{ Nontraditional Secondary Manufacturing Processes for Metals (emerged since 1960) } \\
\hline \multicolumn{2}{|c|}{$\begin{array}{l}\text { Electrical Discharge Machining } \\
\text { Hydrodynamics Machining } \\
\text { Electrochemical Deburning } \\
\text { Electrochemical Discharge Grinding } \\
\text { Electrochemical Grinding } \\
\text { Electrical Discharge Sawing } \\
\text { Traveling Wire Electrical Discharge Machining } \\
\text { Laser Beam Machining } \\
\text { Laser Beam Torch } \\
\text { Laser Beam Drilling }\end{array}$} & \multicolumn{2}{|c|}{$\begin{array}{l}\text { Chemical Machining } \\
\text { Electrochemical Machining } \\
\text { Numerical Control Machining } \\
\text { Computer Numerical Controv Direct Numerical Control } \\
\text { Computer Aided Manufacturing } \\
\text { Computer Integrated Manufacturing } \\
\text { Plasma Beam Cutting } \\
\text { Rotary Forging } \\
\text { Ultrasonic Machining } \\
\text { Flexible Manufacturing } \\
\text { Electron Beam Welding } \\
\text { Electron Beam Cutting }\end{array}$} \\
\hline
\end{tabular}


Manual methods of fabrication and assembly require simple and relatively inexpensive tooling, but highly skilled machinists and assemblers. This method, which allows for great flexibility and adaptability, is usually used when the total quantity produced is small and the production rate is very low.

Flexible fabrication and assembly are usually most cost effective for intermediate production volumes because this method results in flexibility with relatively high production rates, along with more predictably higher quality. Because product life is becoming shorter and domestic labor costs are high, many corporations must rely on FMS to remain competitive.

FMS are computer-integrated systems of numerically controlled and manual workstations or cells, which frequently are automatically loaded and unloaded by robots and are interconnected by automated material handling systems. These systems have become so efficient and cost effective that they can now produce an item on demand, i.e., in quantities of one, competitively with the manual method, especially in the case of repeat orders.

High-speed fixed automation involves hard tooling and transfer lines built to assemble a specific product. These special purpose systems are expensive and require considerable engineering development before they can be put into service. High-speed production using fixed automation is most efficient when a high volume of products are manufactured and production periods are very long. Most weapon systems do not fall into this category.

Figure II-1 compares costs for manual and automated fabrication and assembly methods.

\section{Geometry}

The geometry of the parts or assemblies affects their producibility. Geometry considerations influence all four primary manufacturing processes discussed in the preceding section.

The geometrical complexity of a formed part is limited by the selected material and the forming processes compatible with this material. The forming process, in combination with the specified raw material, predetermines the producibility options. Sand cast parts, for example, must be designed so that molds are easily generated, parting line requirements 


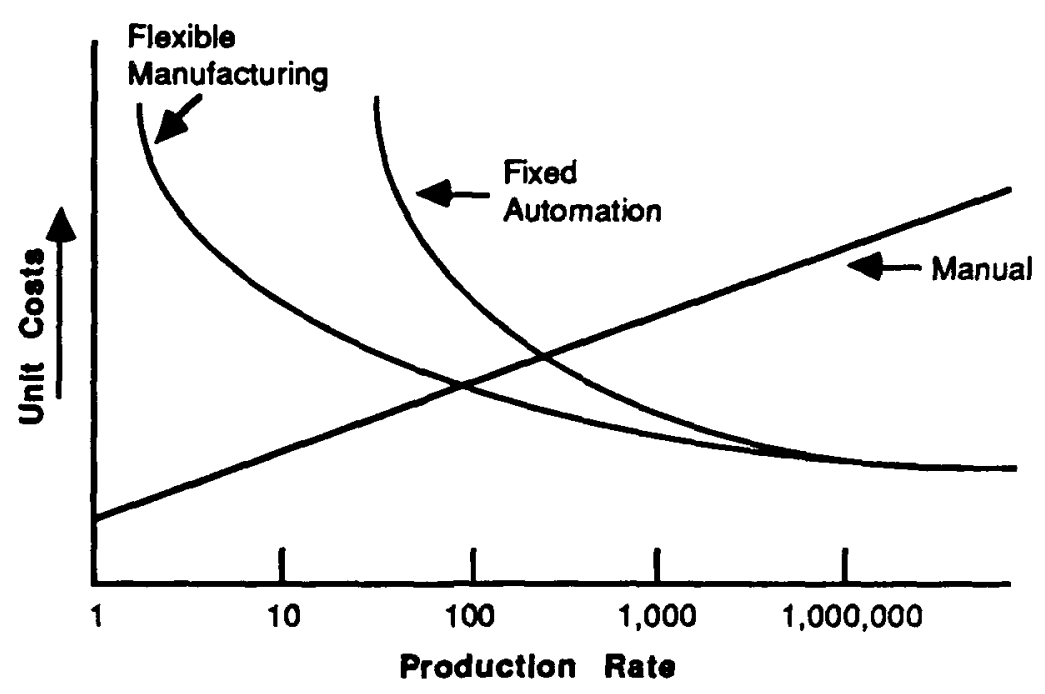

Figure II-1. Costs for Manual and Automatic Assembly Methods

are met, and requirements for coring are kept to a minimum. The part thickness must always be considered. Extreme changes in cross section and very thin sections are difficult to cast consistently. Fillets and rounds should be used freely to accommodate the metal flow and minimize cooling problems. Other types of forming for both metal and plastic have design rules and rules of thumb (heuristic rules) that must be followed when a new configuration is created.

When designing new parts, the designer should consider using the concept of near net shape [Ref. 6]. Near net shape describes forming processes that produce components with a formed shape that is extremely close to the design requirements, hence require a minimum of secondary processing. The philosophy of the concept is to put the material where needed in the first place and minimize the effort required to remove any excess. A near net shape forming process may be more expensive than machining a rough shape to its final configuration, and the designer should consider both options when trying to determine the optimal method. Figure II-2 illustrates the differences between several near net shape techniques.

Part geometry also affects the material removal of reduction and finishing processes. The more complex the final shape, such as curved surfaces, the more difficult and more expensive the part will be to produce. Hence, the designer should strive to create simple and symmetrical part designs and must consider both conventional and 


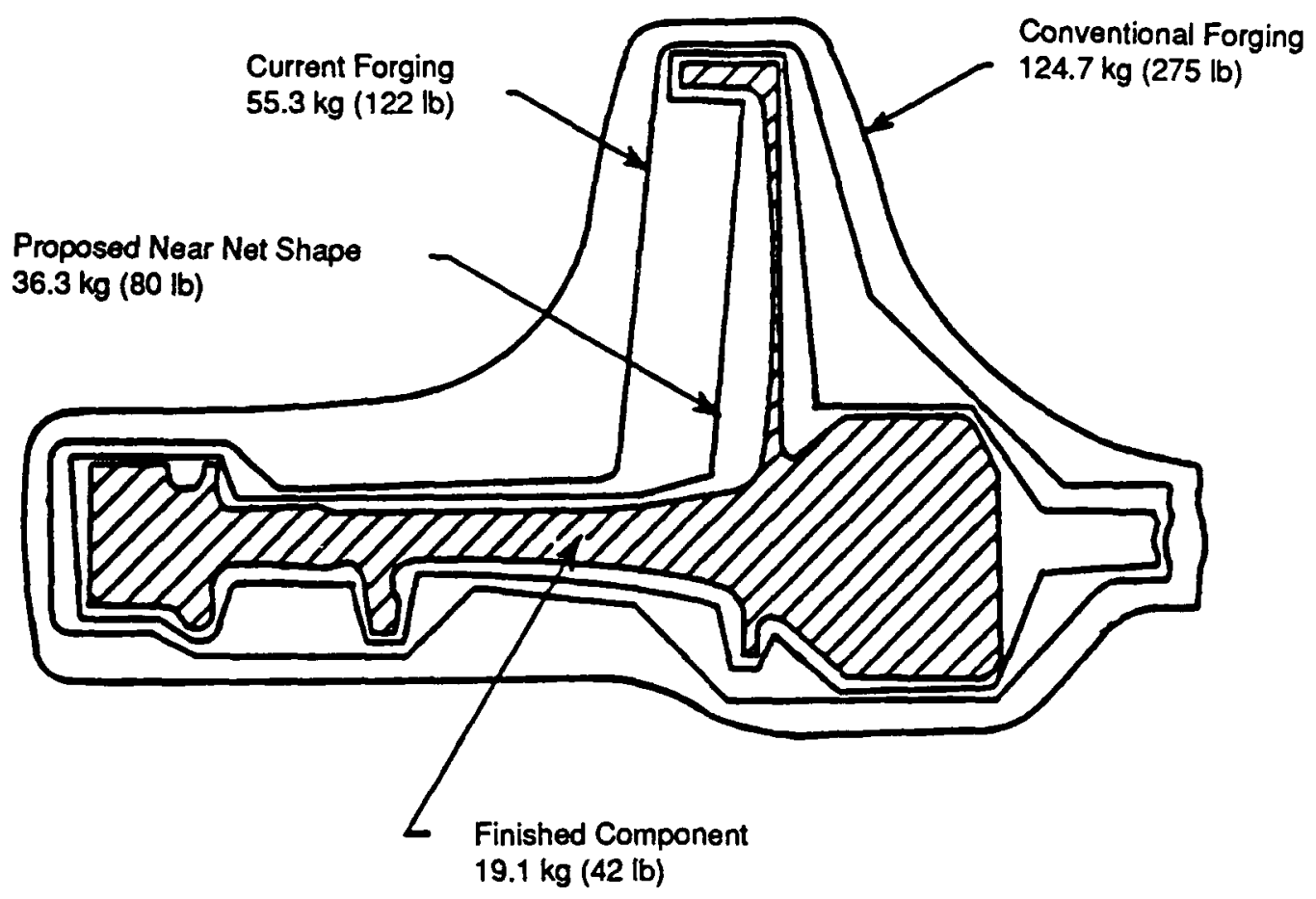

Figure II-2. Near Net Shape Forging

nonconventional methods when determining the most cost-effective and efficient reduction process.

Part geometry also affects the joining and assembly process, whether the process is manual, flexible, or automatic. If the manual process is to be used, the designer must consider clearances for human hands and for tools. To assist assembly personnel and ensure correct part alignment, the designer should design parts that are polarized or color coded. When possible, parts should be designed to snap together rather than be joined with mechanical fasteners. If mechanical fasteners are to be used, the designer may choose from a variety, such as screws, rivets, eyelets, snap rings, and pins. Judicious selection is important because fastener types can have a marked effect on the cost of assembly.

The maintenance concept is another factor that should be considered when selecting the assembly method. Tolerances must be selected to ensure proper fit and wear characteristics. Slip fits must be such that parts can be assembled without the use of force. If the parts are to move relative to each other, such as rotate or slide, the clearance must be sufficient for maintaining proper lubrication. Where a press fit is required, such as in the installation of a bearing, the interference must be sufficient to meet the functional 
requirements without causing undue stresses leading to eventual bearing failure. Orientation of the assembly for ease of access may require special assembly fixtures.

In major systems, such as an airlift wing or fuselage, tolerance budgeting and the selection of tolerances is even more critical. The effects of static and dynamic loading on the structure demands consideration to ensure prevention of interference and buckling. The selection of tolerances is even more significant in the design of systems that have moving parts or are an assemblage of electronic devices, such as a navigation or fire control system. In these systems, the budgeting of tolerances--mechanical, electrical, or hydraulic --will determine whether the system can meet the expected performance n'quirements.

In flexible manufacturing systems, each cell can accommodate a variety of geometries as long as the part can be accommodated within the spacial confines of the work area of the cell. The parts may or may not be loaded automatically into and removed from the cell. While robots may be used extensively in this operation, robots cannot see unexpected obstacles, nor do they have the dexterity of humans to ! each around, over, or underneath the objects being assembled. A slight collision involving robotic manipulators could be very expensive. Another drawback is that a robot gripper requires highly organized and aligned parts and tool storage and delivery. Without vision and a knowledge-based capability, a robot cannot pick and choose necessary tools or parts. Parts' geometries must be robot graspable and designed to prevent jamming and tangling in parts bins and on delivery mechanisms.

The advantages of flexible manufacturing systems are that the work cell permits a greater number of operations to be performed in a single set up. Fewer set ups mean lower cost and better tolerance control.

The fabrication and assembly in a fully automated factory with hard tooling requires the same essential considerations for geometry as in flexible automation. The advantage of flexible automation is that switching from the manufacture of one part to another is simple, with minimal set-up time and cost of tooling. This method is particularly suitable in the production of military hardware--with the exception of conventional munitions--because production rates are low and total production runs are comparatively short.

The increased use of CAE has helped to solve many geometry problems. In the traditional development process, few people are skilled in visualizing three-dimensional objects presented in two-dimensional mechanical layouts. Consequently, changes to affect 
the product design are not suggested until mock-ups or prototype models are built--when there is not sufficient time for major design changes. Improved design visualization through the use of computer-aided solid modelers now allows engineering and manufacturing personnel to view a design early in the development process; these computer-aided models offer clarity approaching that of a prototype model. Once a part geometry is represented successfully within the computer, other forms of computer analyses can be used. Some of these tools include finite element analysis, thermal characteristic evaluation, and moldflow/ moldcool and numerically controlled (NC) tool pathing characteristics associated with manufacturing process designs [Ref. 41]. The application of a knowledge-based system can further enhance the process.

\section{Structural Design Concepts}

The structural design of a product can significantly influence the producibility of the product. In aircraft design, strength, weight, and cost are the three main variables, and these design variables are conflicting. A strong airframe with extensive factors of safety may be prohibitively expensive or prohibitively heavy. Strong but light structures can result in exorbitant expenses due to exotic materials and complicated manufacturing techniques. Producibility analysis techniques can help designers perform the trade-off studies necessary to determine the strongest possible structure at the least weight and cost, to meet the load carrying capacity over a specified distance.

\section{Process Control}

When designing a part, the designer determines the shape of the part, selects the material, and determines special treatments required, such as hardening, and the required finish. The manufacturing processes are predetermined from the extraction of the raw material through the steps in the fabrication process to the configuration needed to meet the performance specifications. Each step involves the use of processes, whether they are metallurgical, mechanical, electrical or chemical, well established and proven, or new. In selecting a process, the designer must evaluate the expected yield. If a process is new and unproven, research is necessary to ensure predictability as well as economic acceptability of yield. Process control and yield are especially important in automated production, both flexible and fixed automation. Loss of process causes line stoppage, and line stoppage rapidly adds to production costs. 


\section{Cost}

Producibility relates directly to cost. The cost of a product is greatly determined by its design, which determines the required manufacturing processes. The major factors in manufacturing cost are materials, forming techniques, assembly method, and finish requirements. Considerable increases in productivity and large cost savings can be achieved by designing for ease of fabrication and ease of assembly and considering what effects the design has on the manufacturing processes. The designer should design parts and assemblies so that the simplest, most inexpensive, and most predictable manufacturing technique can be used. The designer should always consider which type of manufacturing process is to be used--manual, flexible, or automated--since special cost considerations are inherent in each.

During the past few decades, the Department of Defense (DoD) has become increasingly concerned with the high costs of its sophisticated weapon systems. For example, during the 1950s and 1960s, the estimated cost of military aircraft was based on gross take-off weights. Costs were determined from historical and statistical information from past designs. With new technology and lighter but more expensive materials such as composites, this costing method no longer applies. Designers need new methods for accurately determining LCC in the conceptual design stages, especially for large and complex projects such as aircraft and other military hardware. Johnson [Ref. 42] and articles in the NATO Advisory Group for Aerospace Research and Development (AGARD) conference proceedings [Ref. 14] present some methods for determining LCC in the early design stages. Recent improvements in computer capabilities and development of codes specifically oriented to conceptual design make it possible to consider cost along with other conceptual variables, rather than as an afterthought. Johnson [Ref. 42] lists three cost modeling techniques:

- Bottom-up approach--determining the price and quantity of each type of material and each type of labor required for fabrication

- Comparison--modifying costs of related items with similar physical performance characteristics

- Parametric or top-down approach--an aggregate of cost estimating relationships that have been statistically derived from historical data containing some noncost parameters, i.e., predict the cost of a new product or service by extrapolating from the historical data base. 


\section{B . PROCEDURAL AND HEURISTIC ISSUES}

The governing issues of designing for producibility can be divided into heuristic issues and procedural issues (Figure II-3). The procedural issues include considering design factors such as manufacturing process, geometry, structural design concept, process control, and cost. Heuristic producibility issues are those that require the knowledge and experience of experts to resolve. Heuristic issues can often be evaluated using checklists, lists of guidelines, or design rules. Some of these lists, rules, and guidelines are described in Section IV.A. The knowledge base of the heuristic issues may be developed into knowledge-based systems that may be used to advise the designer.

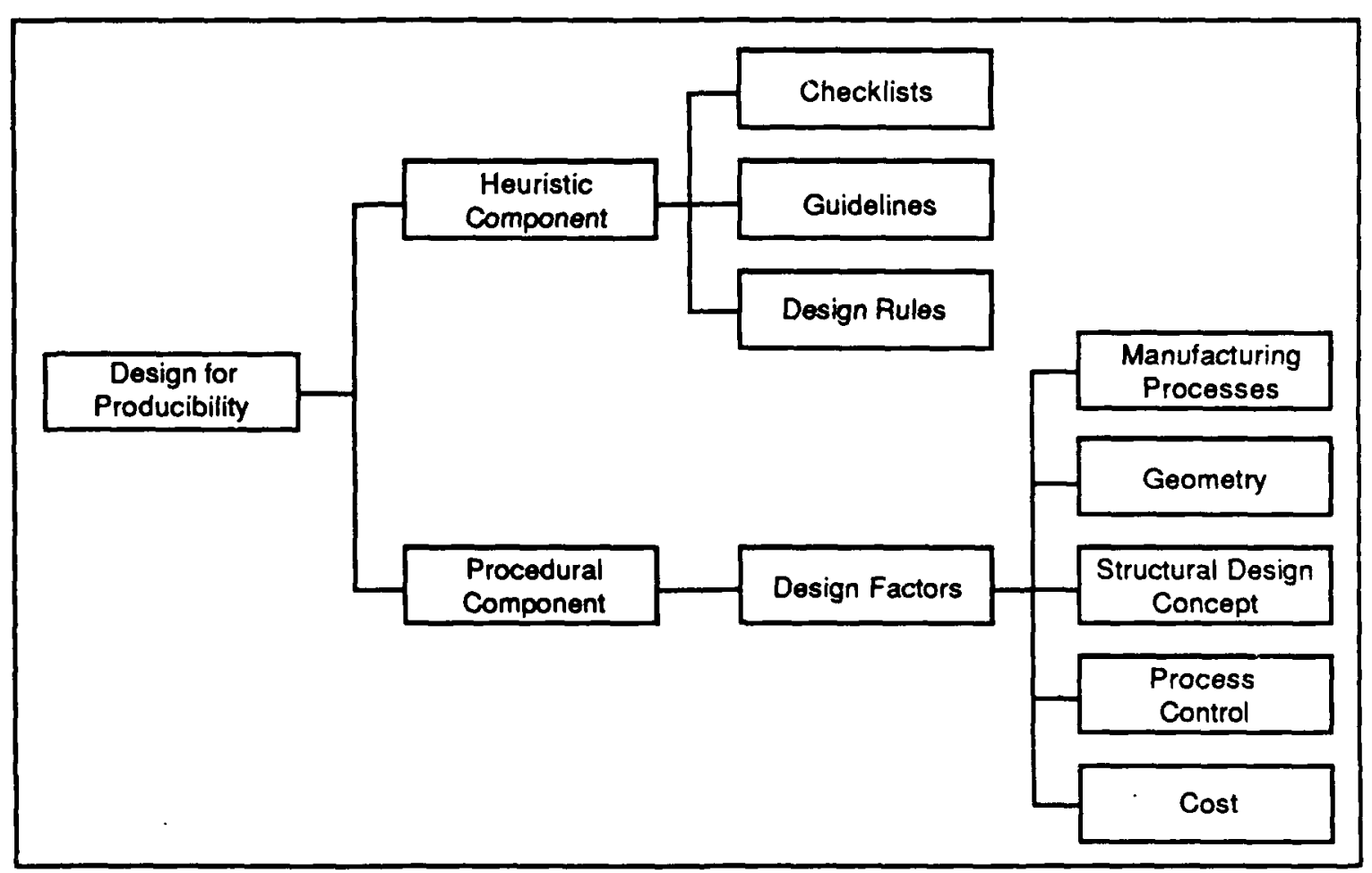

Figure II-3. Design for Producibility Components

\section{DESIGN LEVEL DETAIL}

To fully understand the problem of introducing the concept of producibility into the Conceptual and Preliminary design stages of aircraft design, these stages must be defined. As the aircraft design concept proceeds through the various stages, the level of detail of the geometry increases (Figure II-4). 


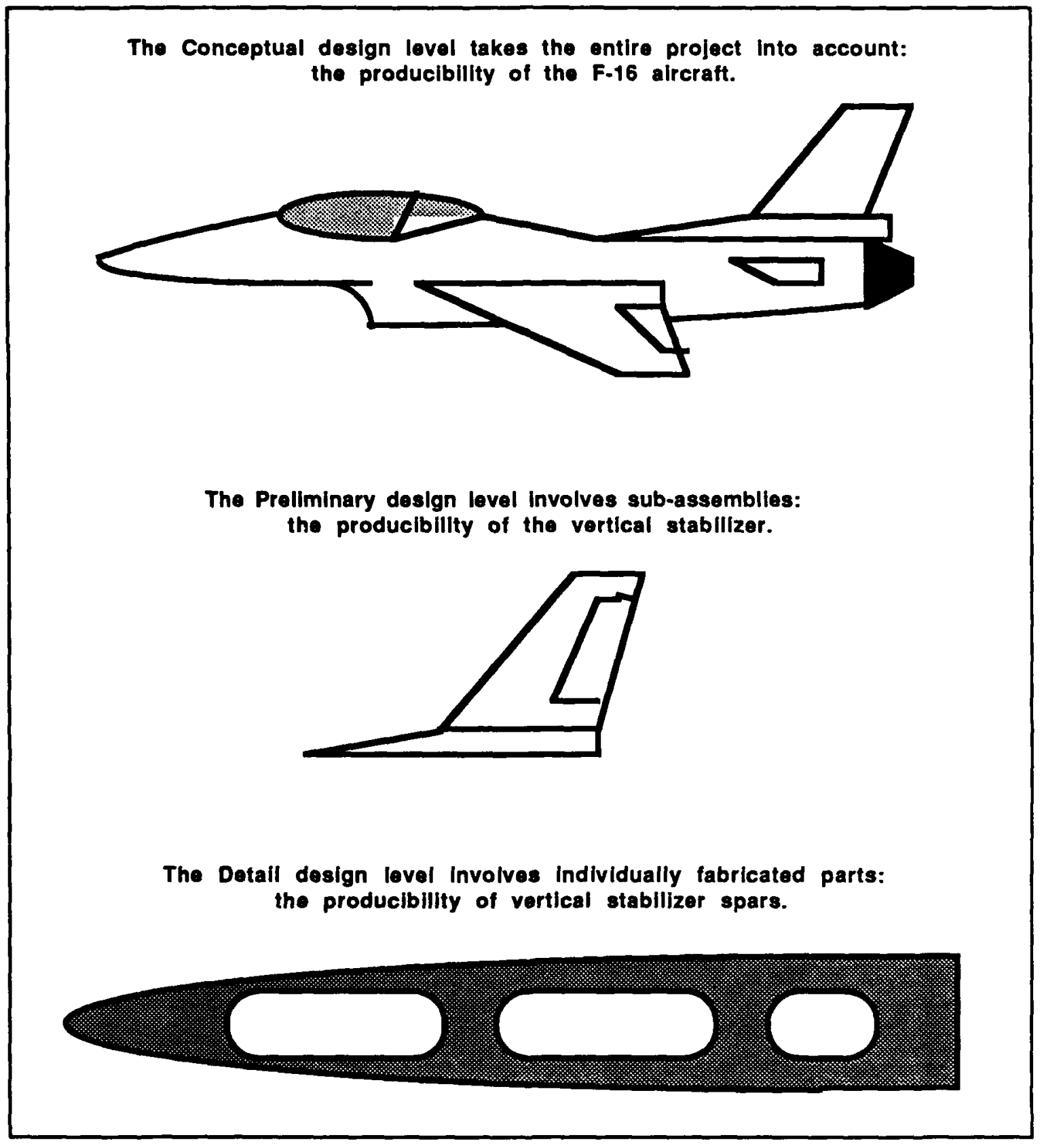

Figure 11-4. Producibility at Various Levels

\section{Conceptual Design Level}

At the Conceptual design level, the exterior geometry configuration of the aircraft is developed. At this stage the aircraft is initially sized, and a weight estimate is made based on the expected performance, mission, and payload requirements. 


\section{Preliminary Design Level}

At the Preliminary design level, the geometry state vector is increased to consider the aircraft concept at the subsystem level. This requires consideration of the interior structural concepts and their geometry.

\section{Detail Design Level}

At the Detail design level, the geometry state vector increases to include the consideration of sub-subsystems. At this level, mechanical or machine design tasks prevail.

\section{DECOMPOSITION}

\section{Aerospace System Decomposition}

The concept of producibility can be addressed at various design levels, whether complete systems, assemblies, subassemblies, or individually formed parts are being designed. The goal of the work reported in this paper is to examine producibility concepts at the Conceptual and Preliminary design levels. A technique for decomposing and tracking the geometry configuration is needed that is appropriate for these two design levels.

For example, an aerospace vehicle can be decomposed into the subassemblies of the fuselage, wings, horizontal stabilizers, vertical stabilizers, engine nacelles, and landing gear. The wings can be decoupled further into the planform and the section (Figure II-5). Decomposition continues until the level of individual parts are reached.

Each level of decomposition corresponds to a specific level of design in the design process. This decomposition technique aids understanding the level of detail of knowledge required of the geometry state. To fully evaluate the producibility of a system, producibility considerations must be assessed at every level. A truly optimum design requires near simultaneous evaluation at each level. The designer must keep in mind that the ultimate goal is an adequate and affordable final product. An expenditure of an extra dollar forming better parts may save hundreds in the later stages of assembly and maintenance. 


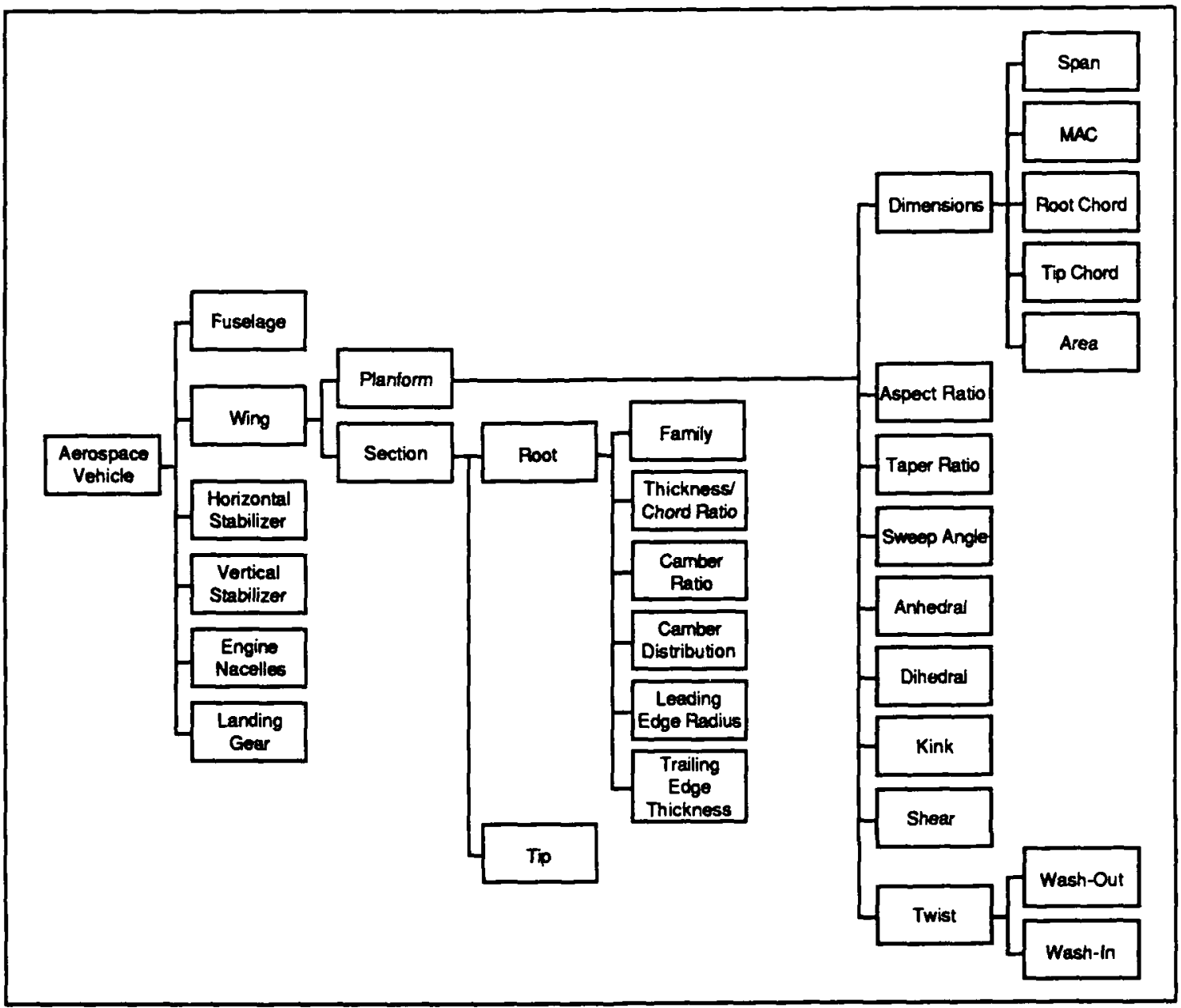

Figure II-5. Aerospace Vehicle Decomposition

\section{Geometry Decomposition}

To achieve producibility, knowledge of the geometry state of the vehicle design is imperative. A second scheme for decomposing and classifying the geometry of an aerospace vehicle is according to the following state vector: Entity, Object, Feature, Detail, and Model (Figure II-6).

Entities are defined as an ensemble of primitive volume instances, while an Object is an individual primitive volume instance. A Feature is a geometrical feature or a surface on an Object, which is then decomposed into Details, which are curves or two-dimensional contours. The Model, which is the database, contains the points that define the Details or surface contours. 


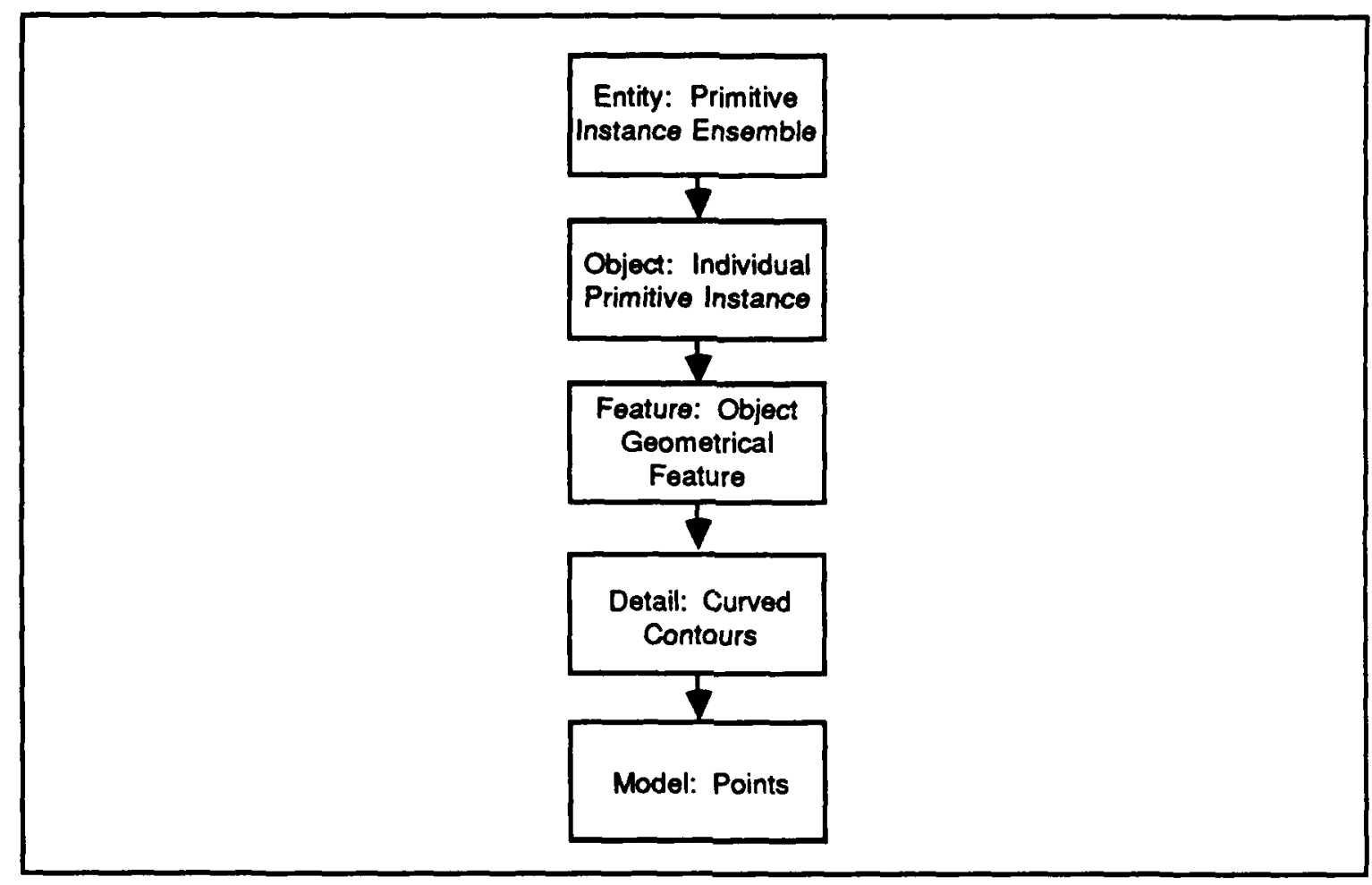

Figure I1-6. Geometry Decomposition

This scheme may be used to decompose and define the geometry state of an aerospace vehicle (Figure II-7). The Entity is the aerospace vehicle, while an individual object might be the wing, for example. The wing may be further decomposed into various features such as its upper and lower surfaces and wing tip. Each of these Features are then decomposed into Details, which may include root and tip airfoil sections as well as the wing planform. This approach to geometry decomposition interfaces well with the historical aeronautical descriptors used to define the wing in the last section (Figure II-5).

\section{E. PRIOR WORK}

\section{Producibility at the Mechanical Design Level}

The first attempts to quantify producibility, in the late 1960s and early 1970s [Ref. 3], focused on the producibility of single parts produced by conventional machining. During the late 1960s, a number of new high technology alloys were coming into common use, especially in the rapidly evolving aerospace field. The newly developed materials were usually more difficult to machine, and machining times increased, resulting in lower 


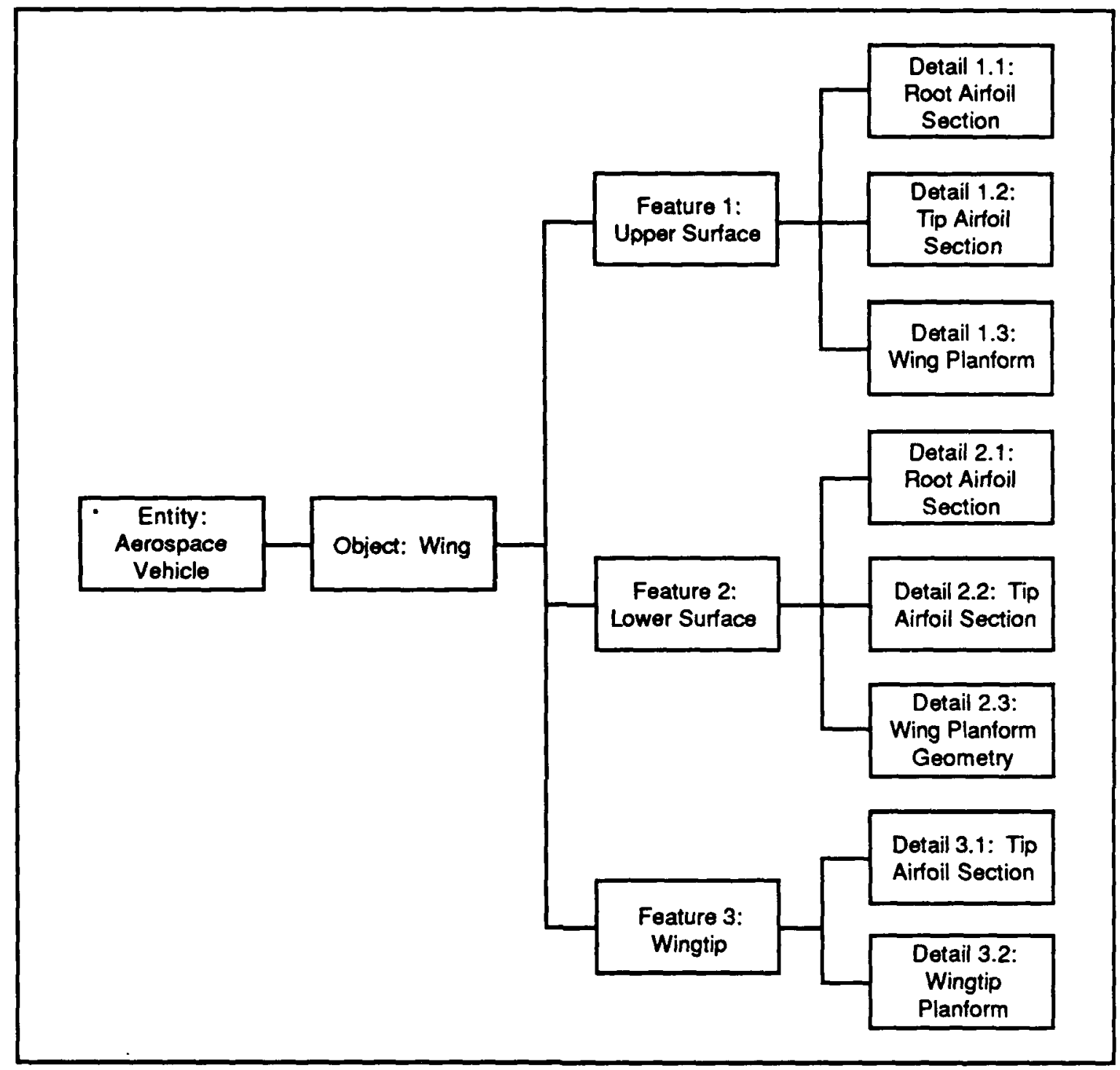

Figure II-7. Geometry Decomposition of Aerospace Vehicle

production rates. Also, new materials often required machining under optimum conditions. (Ref. 12 contains extensive evaluations, comparisons, and producibility ratings for many materials, new in the 1960 s, using conventional machining operations including turning, milling, drilling, tapping, and grinding.) 


\section{a. Producibility Ratings}

Howe defines producibility ratings as composed of two elements, the producibility ratio and the machining-time ratio [Ref. 12]. The producibility ratio is the rate at which a part can be fabricated from a given material compared with the rate at which the same part can be fabricated from a selected baseline material with all other pertinent variable factors held constant. The machining-time ratio is the inverse of the producibility ratio, i.e., the machining-time ratio is the relative number of production hours required to fabricate a part from a given material compared with the time required to fabricate a part from a standard material. Producibility ratings from this publication used two baseline materials, Aluminum Alloy 7075-T6 and AISI 4340 Alloy Steel. The producibility ratings can be used to estimate the total machining time for both small single-operation jobs as well as for larger multi-operation profiling jobs.

\section{b. Nonmachining Work Elements}

Howe also measured producibility of single parts by accounting for the nonmachining work elements. The nonmachining work elements are those associated with part handling, fixturing, inspecting, positioning, clamping, tool changing, and other work items not directly involved with material removal. They are influenced by fixture design and the peculiarities of the particular job. With conventional machining, these elements can contribute from 30 to 80 percent of total cost, averaging 52 percent of total cost. Some of the nonmachining work elements and their cost percentages are

- Maintenance: 10 to 20 percent

- Setup: 8 to 18 percent

- Cutter and clamp changing: 7 to 14 percent

- Operator absent from workstation: 4 to 8 percent

- Operator kept waiting: 2 to 6 percent

- Inspection of part: 1 to 3 percent. 


\section{Producibility at the System Design Level}

\section{a. Aerospace Systems}

The literature surveyed indicates that producibility was first recognized and publicized as a major concern among large aerospace firms in 1971. Three papers published by the Society of Automotive Engineers (SAE) outlined the producibility campaigns at three large aircraft manufacturers: Boeing, Grumman, and LTV. The following paragraphs briefly describe the producibility campaigns at each corporation. The respective producibility definitions used by corporations were presented in the introduction to Chapter II.

The efforts to develop and produce the 747 widebody aircraft at Boeing are described by Torget. Torget defines Boeing's 747 producibility effort as follows:

The marriage of the product design with the manufacturing plan to balance maximum product capability with cost-effective production. This is achieved through a process of design review, production analysis, manufacturing research, and producibility verification. [Ref. 3]

The producibility effort for the $\mathbf{7 4 7}$ commenced at the Preliminary design stage and included all activities necessary to define and verify the hardware and software concepts that would satisfy customer needs. Preliminary design included the efforts of all company functions (Design, Technology, Operations, Finance, Systems Analysis, Facilities, Contracts, etc.). The producibility effort focused on: preliminary product design, facilities planning, logistics planning, subcontractor planning, scheduling, and long-lead and highrisk area identification.

In preliminary product design, a team consisting of representatives from Product Engineering, Finance, Manufacturing Research and Development, Factory Management, Quality Control, and Material was established. The overall objective of the product team was to create a cost-effective design that represented the most efficient structure or system possible, consistent with mission parameters and cost targets and achievable within current or projected manufacturing capability. Figure II-8 [Ref. 3] illustrates how designs can be simplified to ensure easier and more cost-efficient fabrication and assembly. In the diagram, the proposed design of a side canted main shock strut and a double-hinged inward- and aft-folding linkage offered minimum drag, but the quantity of machined parts and complexity of the mechanism were excessive. Changing the direction of the shock 


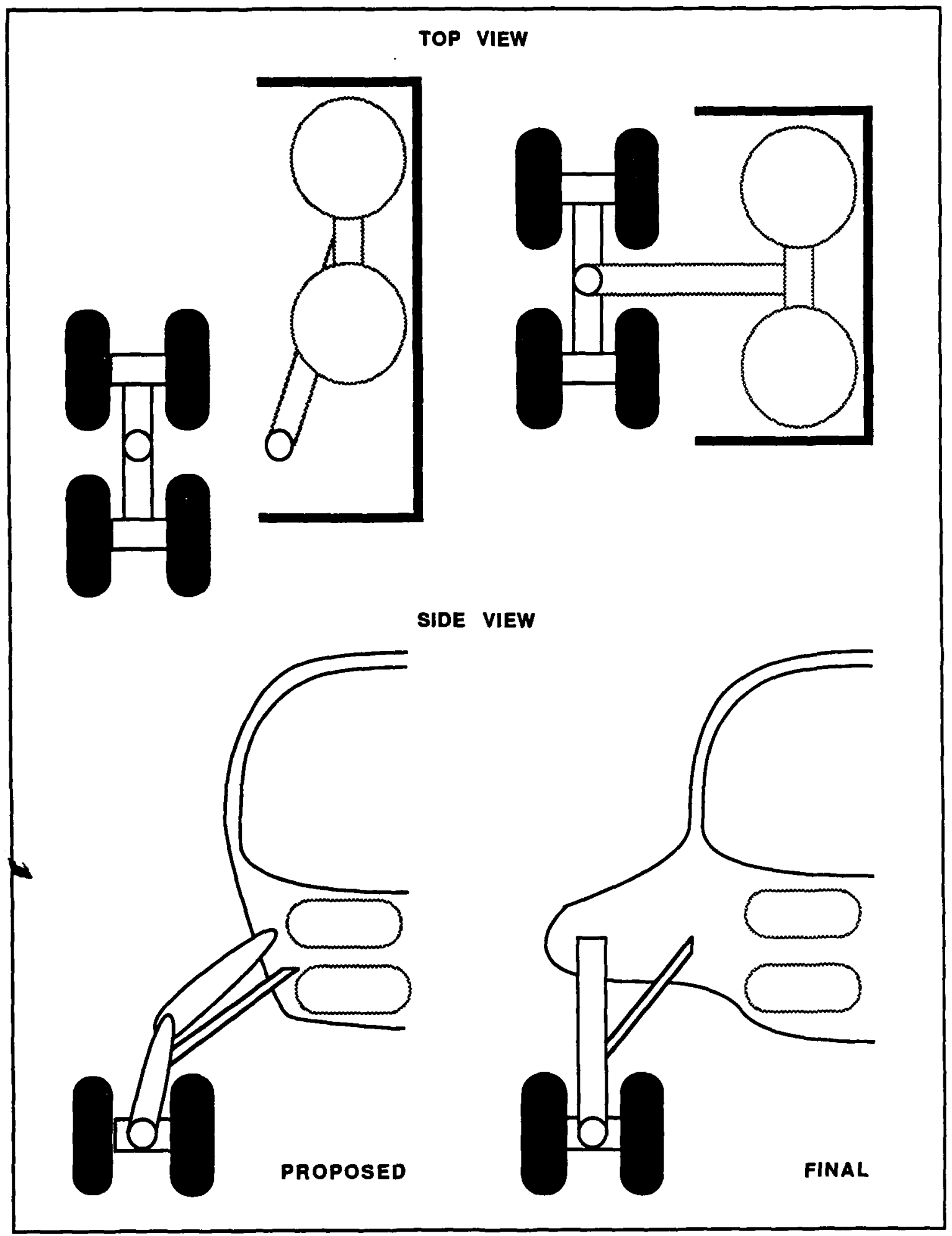

Figure II-8. Example of Design Simplification 
strut to vertical and changing the direction of retraction to just inward-folding simplified the mechanism and allowed for use of identical parts for both left- and right-hand units.

Preliminary facilities and logistics planning ensured adequate physical facilities. Plant layouts were made on the basis of inputs from all operations groups. These layouts were optimized for work and materials flow, and the required equipment was procured or fabricated.

Preliminary subcontractor planning ensured balance between optimum use of inhouse resources and the speciality capability of specific subcontractors. Because the subcontractor was an integral team member, all available resources were efficiently used. Communication between subcontractors and Boeing was paramount in the process.

Scheduling included consideration of long-lead and high-risk items. A tracking system was set up to call attention to long-lead items, special problem items, or other items identified as high-cost or high-risk. All schedules were worked back from the final delivery date.

Torget stresses that positive attitudes and strong motivation on the part of the team members were fundamental requirements for optimum producibility. The producibility efforts were beneficial to Boeing--the 747 production line has been one of the most successful in commercial aircraft history. It has evolved through many versions, and yearly sales remain brisk. This success can be attributed to the quality of design, manufacturing, and customer support.

The producibility effort at Grumman, described by Petrino [Ref. 5], was similar to Boeing's but centered on the development and production of the F-14, the Navy's air superiority fighter. Petrino defines producibility as "a team effort to assure that engineering design is compatible with fabrication cost and production rates of follow-on production phases." Because of the interdisciplinary nature of producibility, Grumman stressed interdepartmental communication in its producibility efforts. Four management tools emphasized by Grumman were

- Establishing cost targets

- Developing a manufacturing plan

- Establishing integrated interdepartmentai communications

- Developing alternate design and manufacturing techniques. 
These tools were employed to establish

- Trade-off studies of alternate designs

- Continuous design reviews

- Assembly and subassembly sequence

- Tooling philosophy and plan

- Manufacturing flow and crew-load plan

- Long-lead manufacturing

- High-cost areas.

The producibility effort at LTV Aerospace Corporation, described by Brooks [Ref. 4], centered on cost and paralleled the design of the Air Force and Navy's A-7 attack bomber. LTV's plan was to use cost as a major parameter, along with weight, maintainability, reliability, performance, etc., in all design decisions. The basic program plan was to establish, at the beginning of product design, end-product target costs for the various components and systems of an airplane. The key was to establish the targets quickly at the beginning of the design phase. Target costs were established for the product by dividing the airplane into small packages and setting targets for each package.

A result of this program was the assembly and maintenance of a complete engineering cost-data library in which the cost information was organized in a manner most usable by engineering designers. The major cost elements of the target costs were only those cost elements that were most directly affected by design decisions--engineering design, major tests, tooling, materials, and manufacturing. However, each cost-target did not carry its share of overhead of material burden that was necessary to bring all costs to a common level. Target costs usually represented about 60 percent of the total airplane costs.

\section{b. Engines}

Modern aircraft engines have become nearly as complicated as the aircraft they propel. Although no producibility efforts focused on turbine engines prior to the $1980 \mathrm{~s}$, military and commercial operators began to emphasize LCC (closely related to producibility) during the 1970 s. From the mid-1960s to the mid-1970s, dramatic advances in gas turbine engine performance combined with sopl.ssticated lighter-weight mechanical design practices, gave rise to higher thrust-to-weight ratios and higher temperature and pressure ratio machines. As a consequence, expensive and complex materials and exotic 
manufacturing techniques such as directionally solidified castings, laser drilling, and inertia welding were used. The new high technology engines had structural durability and support problems, resulting in significantly higher ownership costs. Consequently, both commercial and military turbine engine buyers began to emphasize the cost trades between performance, producibility, and operability/supportability during the conceptual and validation phases of the development process; i.e., they began to emphasize LCC. Some of the early efforts in LCC for engines are presented by Cowie, et al. [Ref. 13], NATO AGARD [Ref. 14], Nelson, and Timson [Ref. 15], and American Airlines [Ref. 16]. 


\section{RELEVANT DESIGN AND MANUFACTURING METHODOLOGIES}

Many techniques currently used in industry for product and process quality control are closely related to the producibility concept. Additionally, many new techniques have become available for integrating manufacturing and assembly considerations into the early design stages. Among these techniques are

- Concurrent Design and Simultaneous/Integrated Engineering

- Design for Manufacture and Assembly (DFM/DFA)

- Taguchi Measurement Theory

- Group Technology (GT)

- Quality Function Deployment (QFD)

- Environmental Stress Screening (ESS)

- Statistical Process Control (SPC)

- Pareto Analysis

- Pugh Concept Selection

- Knowledge Representation of Parts and Assemblies

- Design with Features.

Each of these techniques is discussed in moderate detail in the following sections.

\section{A. CONCURRENT DESIGN AND SIMULTANEOUS/INTEGRATED ENGINEERING}

Much of the cost of producing a product is determined in the early design stages. Once the design is frozen, manufacturing people must often accept the design, regardless of flaws, because the degree of difficulty caused by design changes increases exponentially as a product evolves through its life cycle. The graphs in Figures III-1 and III-2 illustrate these points. 


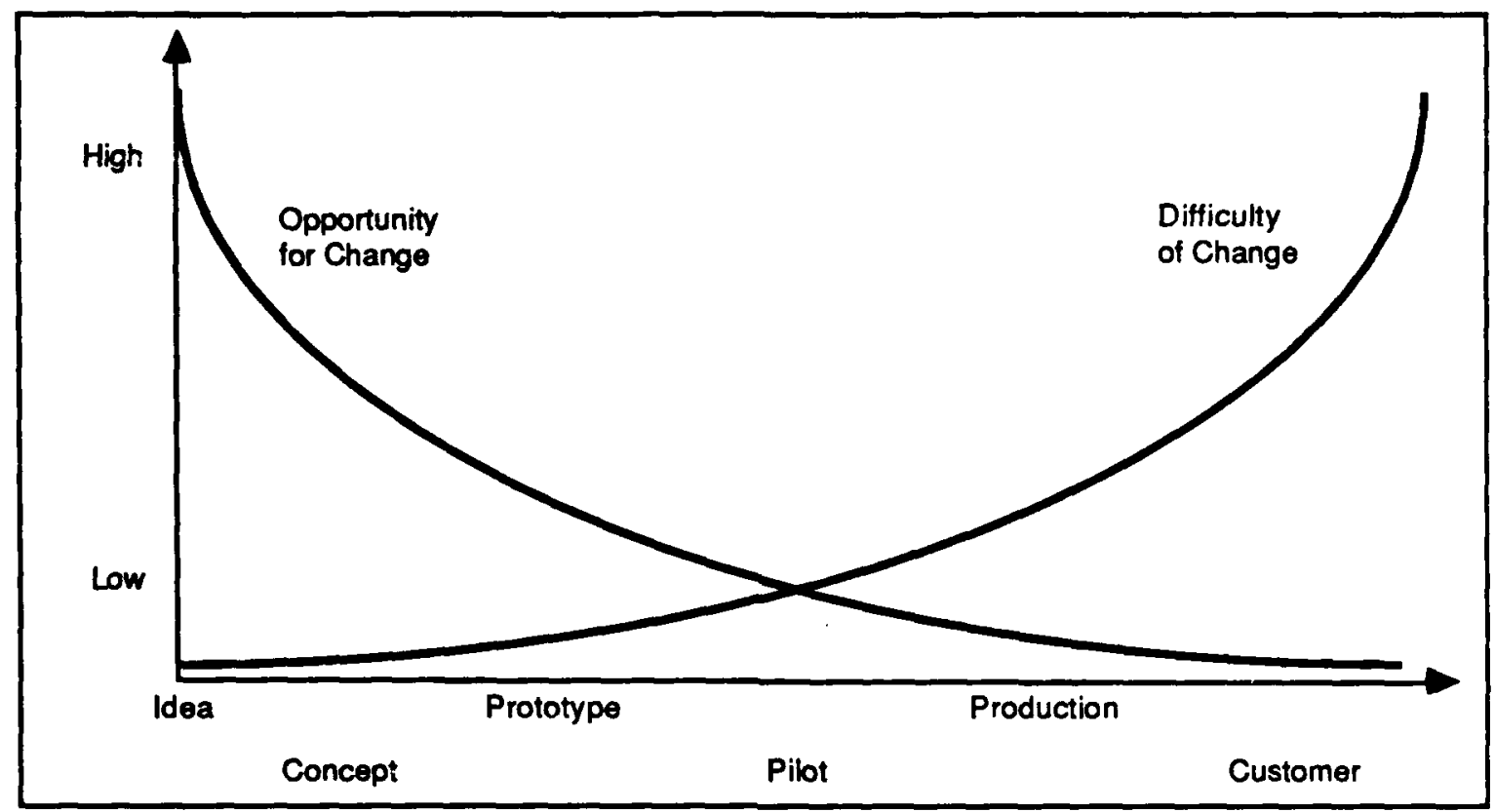

Figure III-1. Degree of Difficulty of Design Change Vs. Time

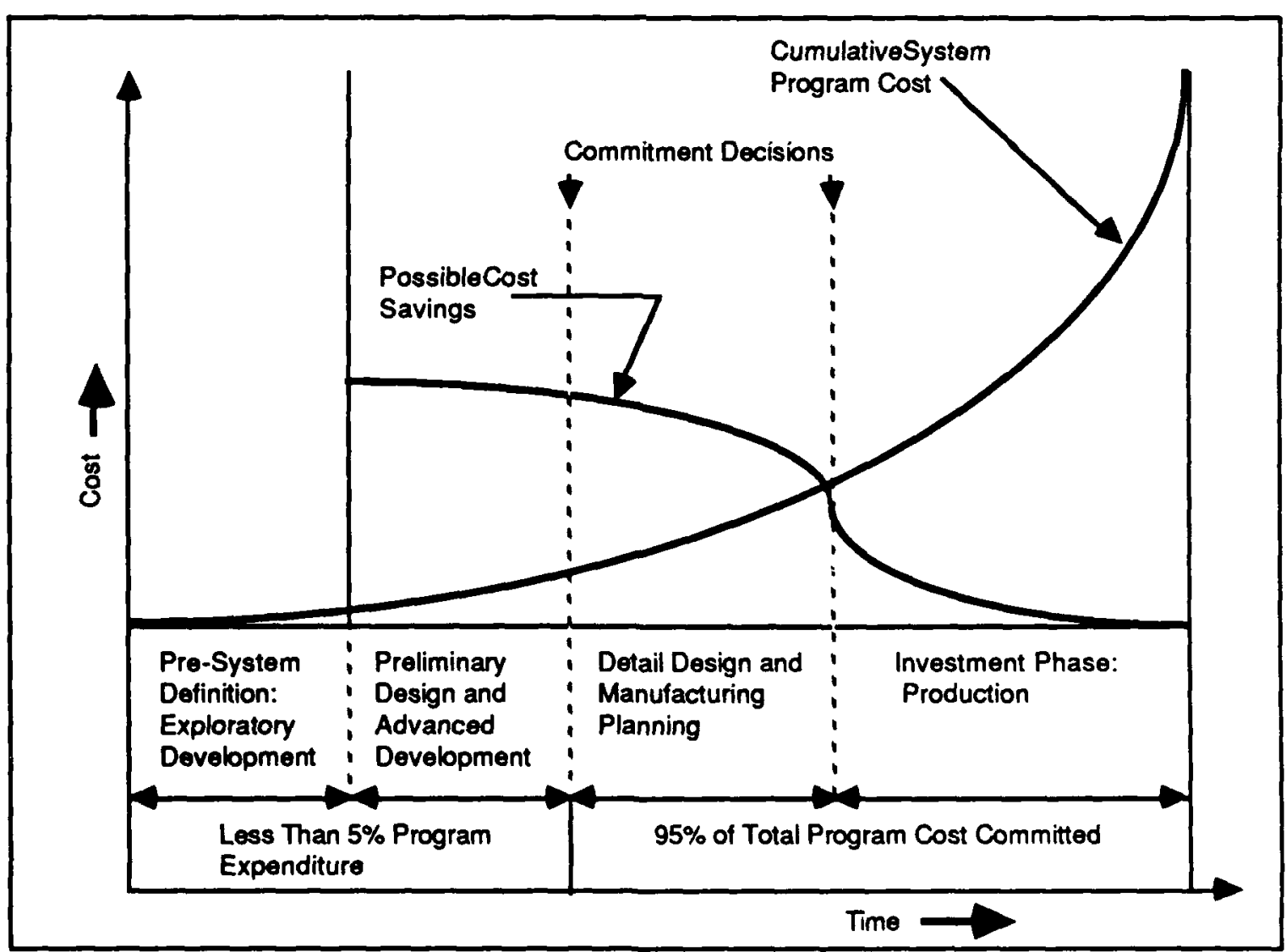

Figure III-2. Decreasing Cost Savings Leverage as Program Progresses 
Engineers are taught that design is an iterative process, but they are rarely taught about the iterations between design and production or bet:veen production and marketing. Concurrent design and integrated engineering imply that all aspects of a product's life cycle are considered during the design phase, i.e., process planning occurs simultaneously with product design. The product is designed to fit the realistic manufacturing capabilities of the manufacturer.

Design for producibility relies on concurrent design and integrated engineering methods. One of the principal advantages of concurrent or integrated engineering is that it encourages designers and manufacturing engineers to work together. Concurrent design can be accomplished by forming concurrent engineering design teams consisting of product designers, manufacturing engineers, quality engineers, and logistics experts, with active participation by marketing, purchasing, and personnel representatives, who can make valuable contributions to the design efforts. The following goals are targeted by the concurrency team:

- Convert the product concept into a manufacturable, sellable, useable product design

- Anticipate fabrication and assembly methods and problems

- Simplify the design, fabrication, use, and repair by reducing the number of parts and identifying and increasing the number of parts common to different models

- Improve robustness of product and process by separating the process into selfcontained modules, adjusting tolerances to eliminate chance failures, and identifying places where tests can be made [Ref. 19].

\section{B . DESIGN FOR MANUFACTURE AND ASSEMBLY}

DFA derives its name from recognition of the need to consider assembly problems at the early design stages. It therefore entails the analysis of both part design and product for ease of manufacture and assembly. DFM/DFA is a method for simplifying a design to ensure the part can be manufactured in the most efficient manner. The idea centers on choosing the best assembly method (manual, flexible, or automatic), reducing the total number of parts by eliminating nonfunctional parts, and combining other parts that need not be separate. The DFA characteristics of a product have a strong positive correlation with the product's producibility. 
DFM/DFA is also concerned with determining the most efficient part design for grasping, manipulating, inserting, and joining each part during assembly. DFM/DFA is especially critical for automated assembly processes because automated machines and robots cannot correct human errors or adapt to changing conditions as humans can.

For these reasons, it is important that a factory and its products are designed correctly from the start. Figure III-3 shows how simple changes in a part's shape can prevent alignment problems during assembly. Figure III-4 compares the traditional design flow with that of a desired design flow that incorporates the DFM/DFA evaluation steps.

The pioneers in DFM/DFA, Boothroyd and Dewhurst of the University of Rhode Island, have developed a method that has become widely used in industry and has increased awareness of the importance of design as the first step in manufacturing. Another DFA system is the Hitachi Assemblability Evaluation Method. Each of these are described in greater detail in Sections IV.C. 1 and 2.

\section{TAGUCHI MEASUREMENT THEORY}

A quiet revolution in the field of quality control and enhancement has been in progress in Japan for some 25 years and has recently received attention in the United States. It has been identified with the name of Genichi Taguchi, an engineer and statistician, who advocated a radical departure from the prevailing Quality Control (QC) theories. The Taguchi method has been documented and analyzed in many publications. [See Refs. 24, 25, 26, 27, and 28.] A discussion of some of Taguchi's ideas follows.

The American Society for Quality Control defines quality as the totality of features and characteristics of a product or service that bear on its ability to satisfy a user's given needs. To identify quality in a product, a set of product characteristics and their target values are identified. The variation of the product characteristic from the target value determines the quality of the product as perceived by the user. The objective of QC is to maintain the product characteristics at their targeted values with minimum deviation, while the objective of quality enhancement is to upgrade the target values to increase the usefulness of the product. 

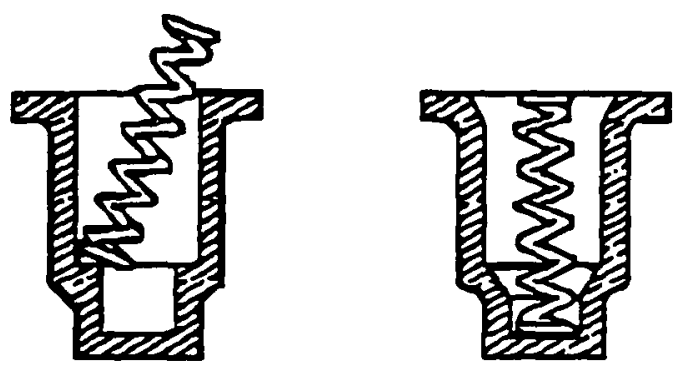

Figure III-3. Design for Simple Alignment

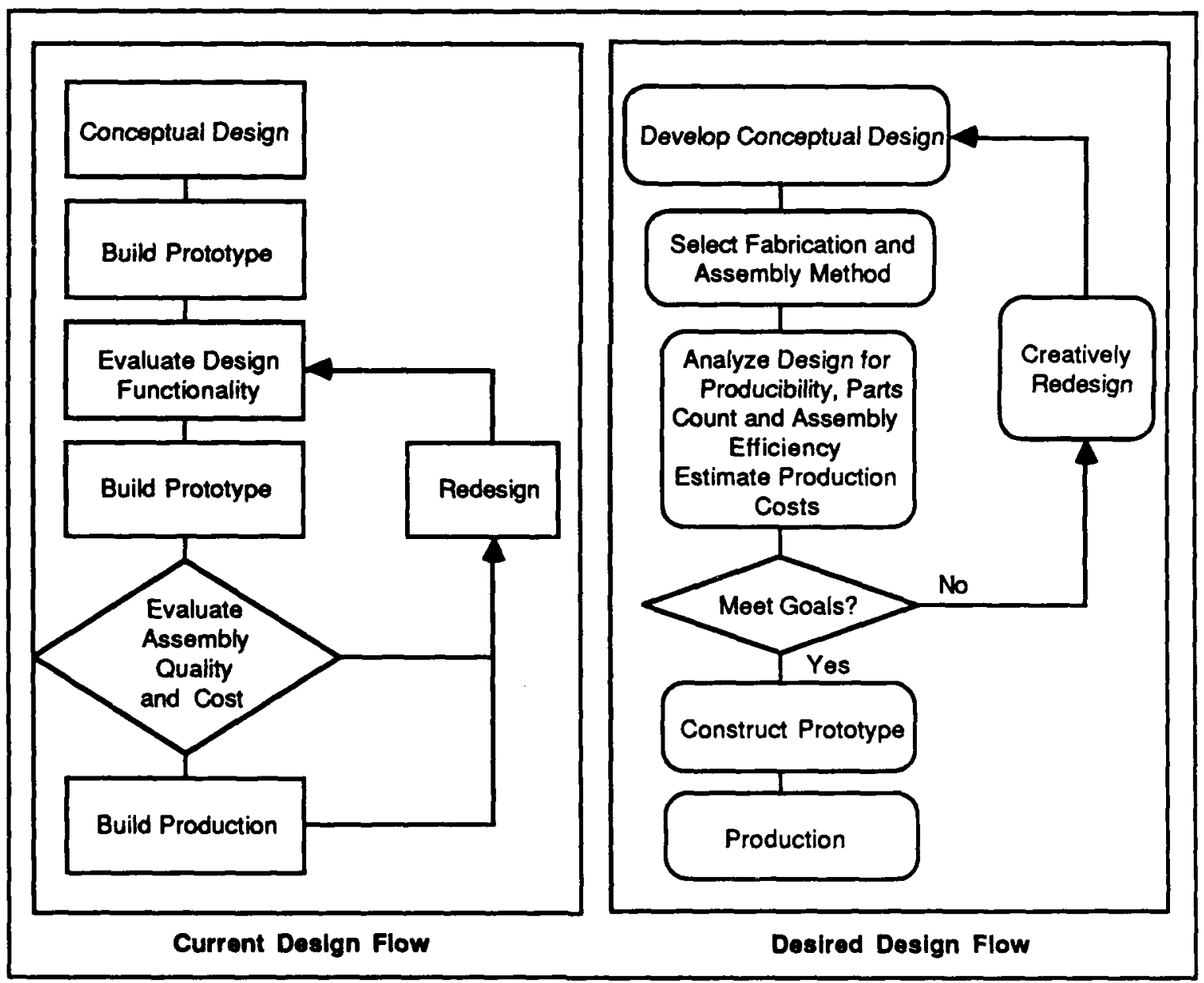

Figure III-4. Current and Desired Design Flow for DFA 
In the United States, $Q C$ has traditionally focused on three concepts:

- $Q C$ in manufacturing centers on the process and the part, which is referred to as "on-line" QC.

- Cause and effect relationships in the manufacturing process are studied so that the causes of variation can be eliminated, without analysis of the engineering design to determine the true root cause.

- The goodness of quality is defined in terms of a specified tolerance band about the target values. A product with measured characteristics beyond the band is judged defective and unacceptable.

In contrast, the Taguchi view is based on the following three premises:

- Emphasis in QC is on the product rather than the manufacturing process, shifting the focus to off-line $Q C$, which may minimize on-line variation and could affect interchangeability.

- Cause and effect relations are studied to create a design that is not susceptible to causes of variation and that eliminates such causes if it is more economical to do so.

- The goodness of quality is defined in terms of a user-loss function that attains its minimum at the target value and increases as the measured parameter deviates from the target value, i.e., a loss in quality even at very small deviations.

The loss function is described as follows. If $t$ represents the target value for a particular product characteristic, $y$, the Taguchi Method defines the loss to the user, $L$, to be proportional to $(y-t)$ squared or:

$$
L(y)=k(y-t)^{2}
$$

where $L(y)$ is the loss function and $k$ is a proportionality constant. The loss function is a measure of dissatisfaction with deviations from the target values of the product characteristics (Figure III-5). As the figure indicates, loss increases quadratically with deviation from target values. Taguchi distinguishes among three cases for the target value $t$, which he labels small is best, large is best, and target value is best. The assumption of a quadratic loss function implies an important philosophical departure from traditional thinking, since it presumes continuity of loss over the full range of variation, i.e., there is a loss at any deviation from the target value. This sharply contrasts with the traditional, go/no-go, acceptable/not-acceptable philosophy (Figure III-6). 


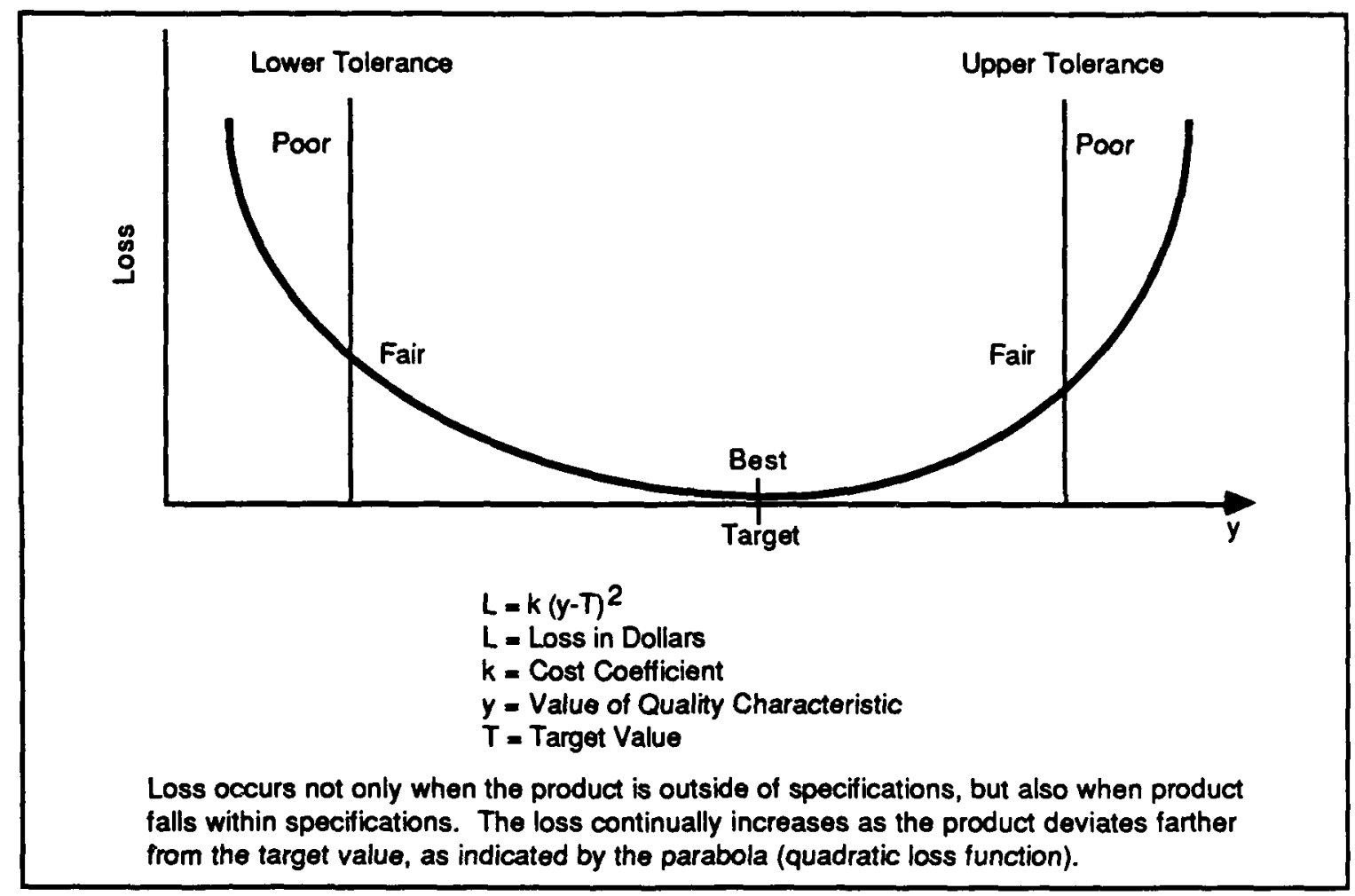

Figure III-5. Taguchi Theory and the Quadratic Loss Function

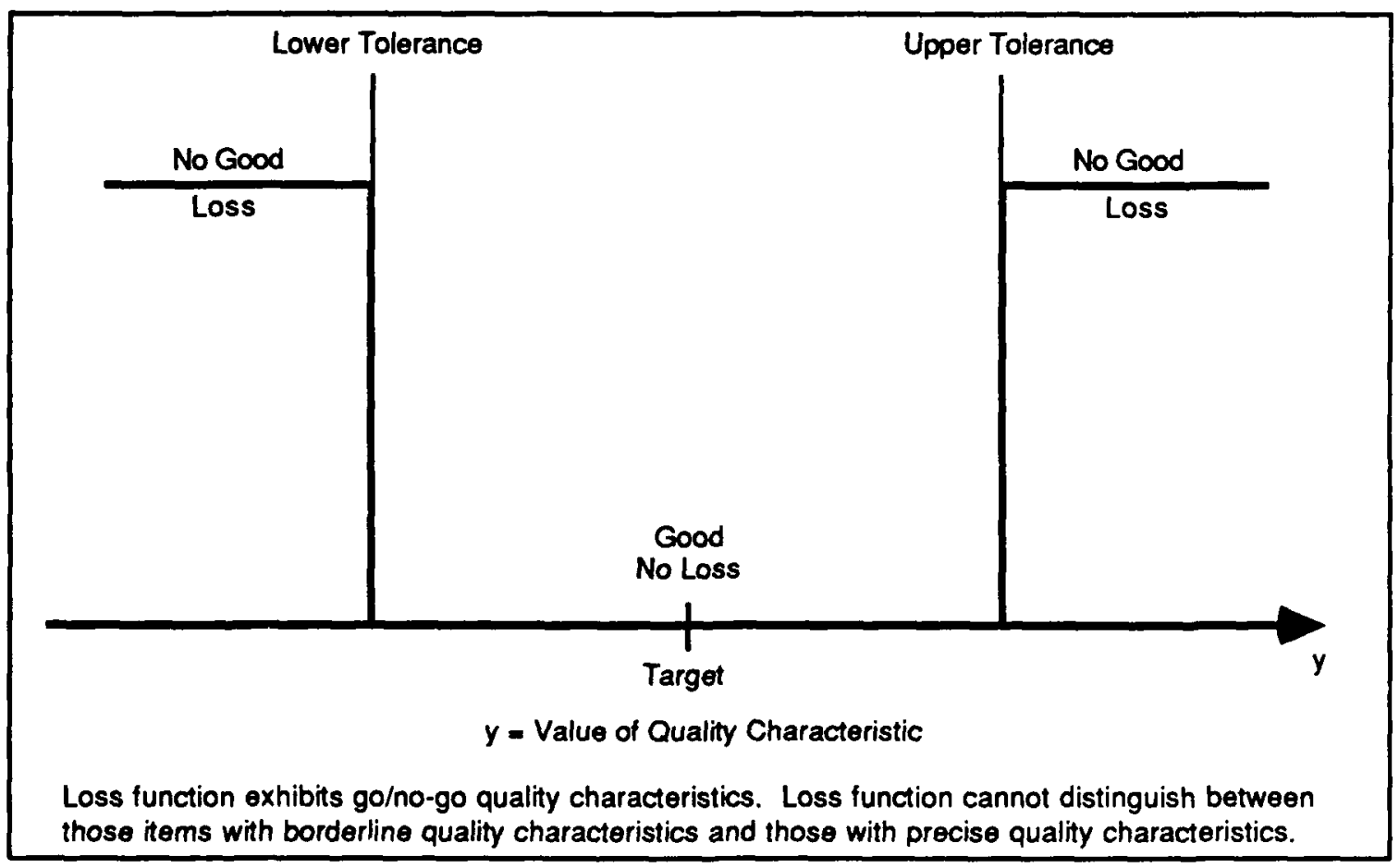

Figure III-6. Traditional Step-Type Loss Function 
The Taguchi approach emphasizes using the design phase to influence the final quality of a product instead of waiting until the production phase to determine how to control quality. The reason for this approach is that traditional QC is restricted in its domain of influence to only the manufacturing sources of variation. The main thrust of the Taguchi method is to design the product to be relatively insensitive to the sources of performance variations.

Taguchi divides product design into three phases. The first, system design, involves the conception of the type of product to render the required service. The second, parameter design, involves the determination of the design levels of the product and process parameters such that the product's functional characteristics are optimized and the effect of the noise factors is limited. The third, tolerance design, involves determining the sensitivity of the variability to different design factors and tightening tolerances in order of their significance on the variability. Many designers in the United States jump from system design to tolerance design, omitting parameter design--the step where they can reduce costs and improve quality most efficiently.

There are four sources of variation in product performance and quality:

- The environment in which the product is used

- Product deterioration with age and/or use

- Manufacturing process variations

- The skill of the user.

All of these factors can be counteracted by a wise product design. Product variations can be further classified as controllable factors and uncontrollable (noise) factors. There are three types of noise factors--outer noise, inner noise, and between product noise (Figure III-7). Outer noise includes things such as variation in operating environment and human errors. Inner noise includes things such as the aging of the machinery and tolerances on the process factors. Manufacturing imperfections are generally responsible for between product noise. Because controlling noise factors can be very costly, and sometimes impossible, Taguchi suggests selecting values for the controllable factors to make the product or process least sensitive to changes in the noise factors. The determination of the controllable factors and their optimum values should be part of the design phase. 


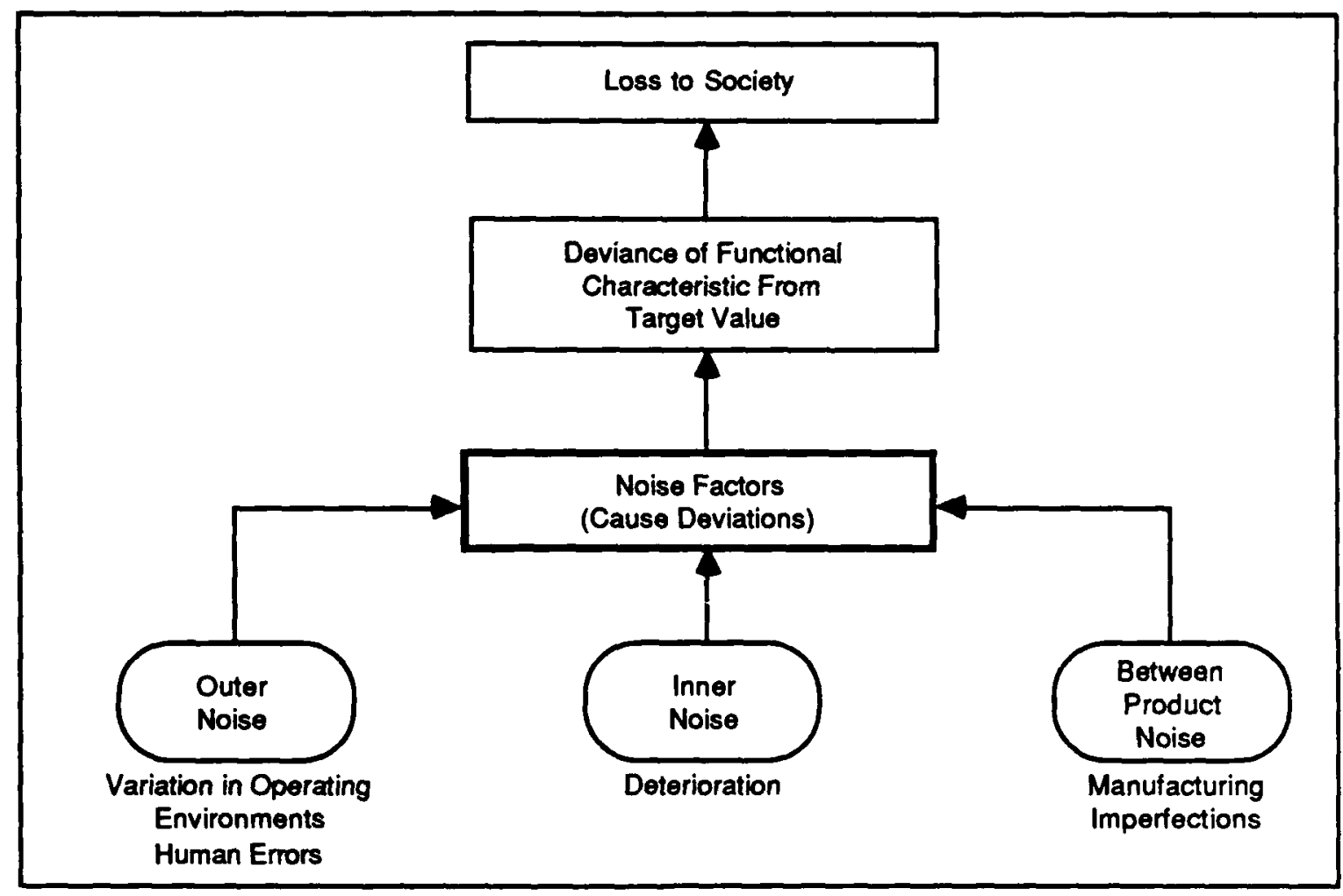

Figure III-7. Noise Factors and Loss

Careful and thorough experimentation is required to determine the optimum values for the controllable factors given the randomness of the noise factors. By using the methods of statistical experimental design, it is possible to include the effects of many parameters within relatively few appropriately selected trials. To design these trials, Taguchi recommends using orthogonal arrays. These arrays allow the design factors to have different numbers of test settings (levels) and also have the pairwise balancing property--every level of a factor occurs with every level of any of the other factors the same number of times. Fractional orthogonal arrays minimize the number of trial runs while keeping the pairwise balancing property.

Taguchi stresses that once data from experimentation are collected, studying the variation of the response using signal-to-noise $(\mathrm{S} / \mathrm{N})$ ratios (sometimes referred to as performance measures) is important. In its simplest form, the $S / N$ ratio is the ratio of the mean (signal) to the standard deviation (noise). The formula used to compute the $\mathrm{S} / \mathrm{N}$ ratio depends on whether the desired target values are small is best, large is best, or target value is best. Regardless of the type of target value, $\mathrm{S} / \mathrm{N}$ ratios are always interpreted the same 
way--the larger the $\mathrm{S} / \mathrm{N}$ ratio, the better. A complete discussion on formulating orthogonal arrays and computing $\mathrm{S} / \mathrm{N}$ ratios, along with some example cases, are listed in References 24 and 25.

\section{GROUP TECHNOLOGY}

The concept of Group Technology (GT), as described by Case and Company [Ref. 20] and Baer [Ref. 21], involves recognizing that many problems are similar and that by grouping similar problems in a systematic manner, a single solution can be found to a set of problems, thus saving time and effort. The most common applications are in the design and manufacture of discrete products.

GT focuses on the family of parts concept. Families are based on similarities in the characteristics of the parts, not necessarily the end products in which the parts are to be used. The family of parts concept is typically applied to four major functional areas: parts design, process planning, plant layout, and purchasing.

Parts design in GT recognizes that while new parts requirements are constantly being introduced into the factory, the different characteristics required of these parts do not increase at the same rate and tend to reach a finite level. In design, part families may be formed based on characteristics such as shape, material, and function. Retrievable past designs, modifications, and efforts toward standardization can aid significantly in reducing the variables, limiting the introduction of entirely new designs and simplifying the manufacturing process.

Manufacturing tends to foster a proliferation of process planning. Too often, many different process plans are used to produce parts that are very similar in terms of their processing. In process planning, families are determined by the processes and the equipment used to produce the part. Standardized process plans for part families can usually be substantially improved when existing part routings are critically examined. In addition, when process plans for new parts must be determined, using an existing documented process plan, directly or with small alterations, reduces expenditures for developing new process plans.

GT and the families of parts concept can greatly affect plant layout. Most current manufacturing involves the production of parts in small lots, in batch or job shop environments. Because of the production methods and plant layout in a typical job shop, a 
part spends about 95 percent of its time being transported or stored/held until work will be done on it. Most batch manufacturing facilities are laid out according to function, i.e., the plant is divided into work centers of similar equipment. Such a layout causes many hidden and indirect inefficiencies, such as long travel distances, large amounts of time devoted to equipment setups, excessive parts handling, and parts waiting in queues between individual operations. If the family of parts concept is applied to manufacturing, families of parts will be produced using similar processes, and the equipment required for the entire process should be organized into a group of physically adjacent tools that form a cell. GT encourages plant layout in the form of manufacturing cells. Traditional functional departments are replaced by cells, each with a balanced complement of tools for producing parts requiring similar processes.

GT and the families of parts concept can also improve the purchasing function. By bringing together parts displaying similar characteristics (families of parts), the procurement personnel are well prepared to reduce cost. Standardization typically results in lower prices, since quantity discounts often result. Parts that are categorically too expensive stand out.

The basis for GT is often a coding system for classifying parts. In a GT system, the worker should be able to recognize both the part and its process plan by the code number alone. Coding should reflect the patterns that have emerged in analysis and be compatible with the manufacturer's other systems, such as NC machinery, computerized inventories, or manufacturing resource planning. Coding schemes should be expandable, to accommodate a company's needs for 10 to 20 years. The classification and coding of parts involve basic information on part geometry, dimensions, mechanical characteristics, and manufacturing features. Specific variables may include shape, finish, and size. More sophisticated coding schemes also describe subelements such as holes, cones, or slots, and material type, chemistry, finish, and special processes. Software is available for classification and coding.

With the use of such software inventories, families of parts can be stored in large databases, which allows a designer to determine whether a particular part exists. If a part does not exist, the computer systems can show the item or items that most closely resemble the required part. The designer can then use the similar part or alter the design to create a new part. 
GT is a philosophy of flexible approach and not a specific tool or rigid science. GT requires team user involvement in planning, development, and implementation and often requires the development of a design database. Along with reduced process planning time, reduced materials handling expense, and improved quality, additional quantifiable benefits of GT can be expected. The additional benefits include increases in engineering productivity and reductions in new part designs, NC programming, set up time, tooling expense, and lead time.

\section{E. QUALITY FUNCTION DEPLOYMENT}

QFD is a product development philosophy that emphasizes customer-driven engineering systems. It is a system for translating customer requirements into appropriate company requirements at each stage from research and product development to engineering and manufacturing to marketing/sales and distribution. QFD focuses efforts on features and characteristics that have the most effect on customer satisfaction. Figure III-8 compares QFD with traditional product development.

\begin{tabular}{|c|c|}
\hline QFD & TRADITIONAL \\
\hline $\begin{array}{l}\text { - Use structured, systematic disciplined } \\
\text { methods, document logic/decisions } \\
\text { - Optimize design of product and process } \\
\text { concurrently } \\
\text { - Increase up-front effort with simultaneous } \\
\text { involvement of key functions (e.g., } \\
\text { marketing, engineering, manufacturing) } \\
\text { - Design and build to target values } \\
\text { - Deploy "voice of the customer" }\end{array}$ & $\begin{array}{l}\text { Let technology drive the process } \\
\text { Solve problems in production; fix customer } \\
\text { dislikes } \\
\text { Perform major steps sequentially } \\
\text { Design and build to engineering tolerances } \\
\text { Stipulate "voice of the executivelengineer" }\end{array}$ \\
\hline
\end{tabular}

Figure III-8. QFD and Traditional Product Development

QFD stresses the use of three tools to help improve the producibility of a product. These tools are failure mode and effects analysis (FMEA), fault tree analysis (FTA), and Taguchi methods (Taguchi methods were described in the preceding section). FMEA is a systematic, analytical technique performed by a design, manufacturing, or QC engineer to ensure that the product characteristics will meet customer needs. FMEA allows the 
engineer to assess the probability of failure occurrence, assess the effect of a failure, and identify process variables to be controlled. The objectives of FMEA are

- Identification of potential and known failure modes

- Identification of the causes and effects of each failure mode

- Priority ranking of the identified modes according to frequency of occurrence, severity, and detection

- Specific directions of problem follow-up and corrective action.

FTA is a method of system reliability or safety analysis that provides an objective basis for analyzing system design, justifying system changes, performing trade-off studies, analyzing common failure modes, and demonstrating compliance with safety requirements. The fault tree graphically represents the Boolean logic associated with the development of a particular system failure. Steps that should occur during an FTA analysis are

- Define the top event

- Establish boundaries

- Understand the system

- Construct the fault tree

- Analyze the fault tree

- Recommend and take corrective actions.

An example of a system along with its fault tree is shown in Figure III-9.

In summary, QFD is a system to help ensure that the key product objectives of quality, cost, and timeliness are retained throughout the product development. $\mathrm{QFD}$ enhances producibility by

- Use of structured, disciplined methods

- Concurrent optimization of product design and process design

- Front-loading effort, involvement of key functions

- Building to target values.

According to Ernst and Whinney Ref. 29], the use of QFD techniques can reduce engineering changes and shorten design cycles by up to 50 percent while reducing start-up costs by up to 60 percent. The QFD concept is becoming widely used in the United States 


\section{Example System}

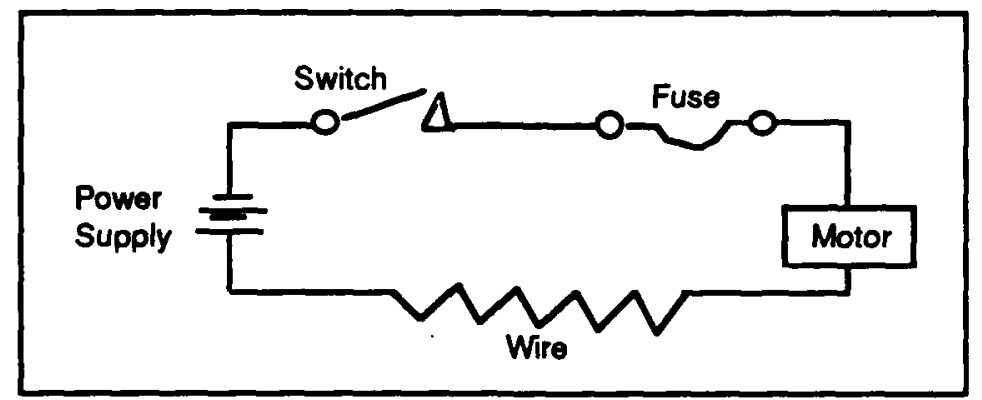

First Fault Tree for the Example System

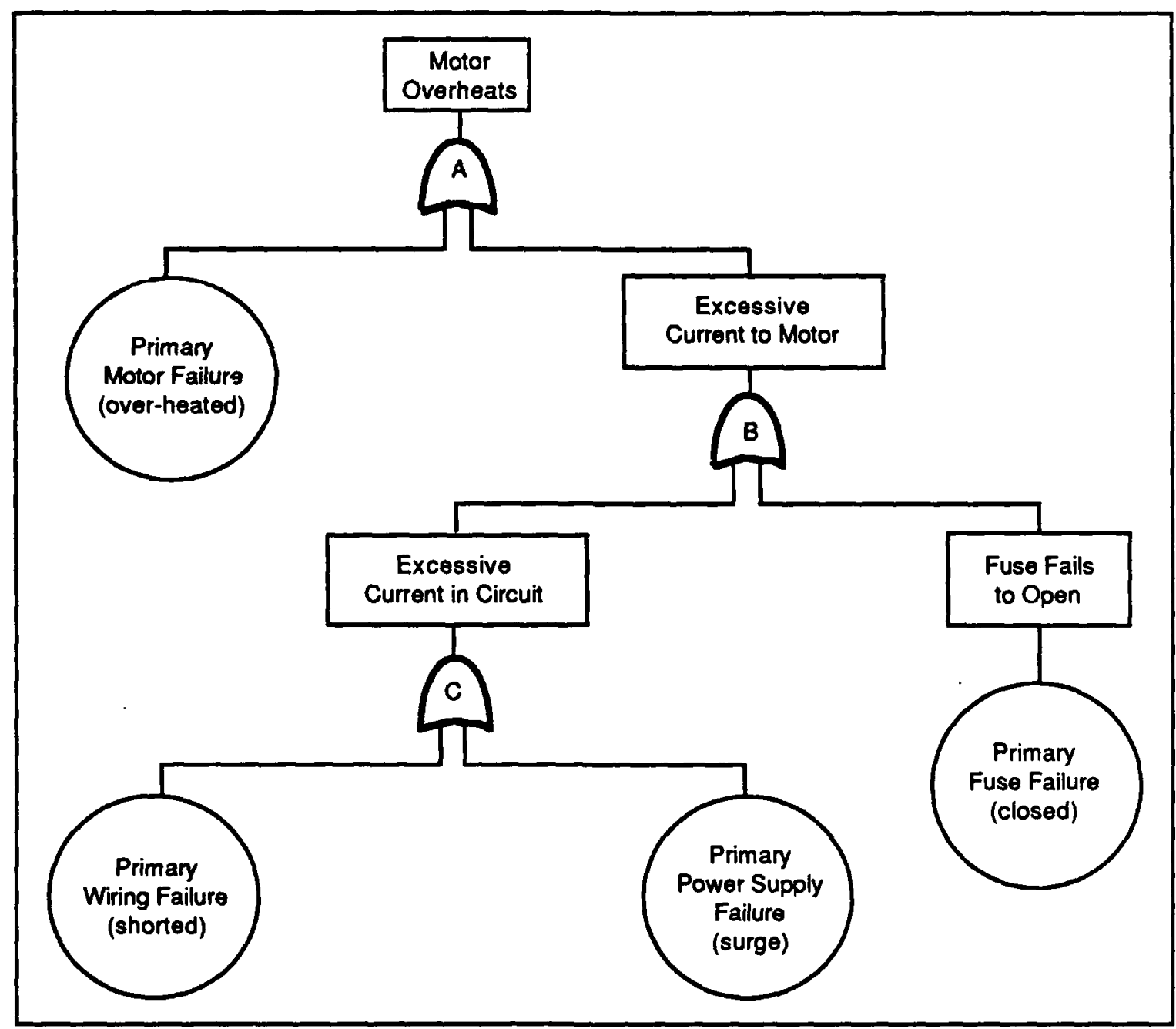

Figure III-9. Fault Tree 
and Japan by companies such as 3M, DEC, Hewlett-Packard, Toyota, Mitsubishi, Honda, and many others.

\section{F. ENVIRONMENTAL STRESS SCREENING}

Mean-time-between-failures determines the availability of a system to perform its intended function. Because mean-time-between failures is a function of the reliability of the parts used in the system, the selection and specification of a part by the designer is an essential factor in system reliability. In many cases the designer does not know the reliability of a part for the intended environment in which the system will operate, or the designer may not pay attention to the reliability when selecting a part. Environmental stress screening (ESS) is the method used to ascertain that a system is capable of meeting the customer's expectation. It also provides an accurate assessment of potential warranty liability. The system is tested in an agreed-upon hostile environment to demonstrate that it will meet a specified level of reliability. If parts fail prematurely, corrective action is taken by making an appropriate design change, and testing is continued until satisfactory results are obtained.

\section{G. STATISTICAL PROCESS CONTROL}

SPC is used to maximize product quality through control of the work process rather than through postproduction inspection. SPC involves the analysis of critical control components, such as materials, equipment, processes, and procedures used to create products or services. The seven basic analysis techniques associated with SPC quality efforts are flowcharts, cause-and-effect diagrams, Pareto diagrams (described later), histograms, scatter diagrams, run charts, and control charts. These graphic charts are used in combination with problem-solving methods such as as brainstorming and nominal group techniques to control manufacturing processes. One such problem-solving method is the installation of sensors and creation of feedback loops for continuous control of the process. SPC focuses on identifying and removing causes of defects and reducing variations in the critical processing romponents. Once a process has attained a state of statistical control, it is expected to consistently produce acceptable products or services. The result is elimination of scrap and rework costs, minimization of inspection costs, and increased productivity. In summary, SPC emphasizes defect prevention rather than defect detection and rework [Ref. 30]. 
Houston [Ref. 30] reports that the principles of W. E. Deming, J. M. Juran, and P. B. Crosby represented the three major approaches to SPC. These quality control consultants advocate the same basic philosophy. Elements of this philosophy include management's responsibility for most quality problems ( 80 to 90 percent), the need to provide workers the means to perform assigned tasks correctly, and the need to minimize the use of postproduction inspection and possible scrapping or rework.

Deming's approach centers on the following 14 points for management:

- Create constancy of purpose towards improving products and services, allocating resources to provide for long-range needs rather than short-term profitability.

- Adopt a new philosophy for economic stability by refusing to allow commonly accepted levels of delays, mistakes, defective materials, and defective workmanship.

- Cease dependence on mass inspection by requiring statistical evidence of builtin quality in both manufacturing and purchasing.

- Reduce the number of suppliers for the same item by eliminating those that do not qualify with statistical evidence of quality; end the practice of awarding business solely on the basis of price.

- Search for problems in the system to constantly improve processes.

- Institute modern methods of training to make better use of all employees.

- Focus on helping people do a better job; ensure that immediate action is taken on reports of defects, maintenance requirements, poor tools, inadequate operating definitions, or other conditions detrimental to quality.

- Encourage effective, two-way communication and other means to eliminate fear from the organization and help people work more productively.

- Break down barriers between departments by encouraging problem solving through teamwork, combining the efforts of people from areas such as research, design, sales, and production.

- Eliminate use of numerical goals, posters, and slogans for the workforce that ask for new levels of productivity without providing methods.

- Use statistical methods for continuing improvement of quality and productivity, and eliminate work standards that prescribe numerical quotas.

- Remove all barriers that inhibit the worker's right to pride of workmanship. 
- Institute a vigorous program of education and retraining to keep up with changes in materials, methods, product design, and machinery.

- Clearly define top management's permanent commitment to quality and productivity and its obligation to implement all of these principles.

Juran's operational approach is represented by his breakthrough sequence--the structure through which annual improvements in quality are achieved. Juran defines a breakthrough as the organized creation of beneficial change and suggests that all breakthroughs follow the same sequence. The breakthrough sequence is as follows.

1. Proof of the need

2. Project identification

3. Organization to guide each project

4. Organization for diagnosis and for analysis of projects

5. Diagnosis--breakthrough in knowledge

6. Remedial action on the findings

7. Breakthrough in cultural resistance to change

8. Control at the new level.

Crosby has developed a list of four absolutes and a 14-step program on how to achieve the four absolutes. The four absolutes are

- Definition: Quality is defined as conformance to requirements.

- Performance standard: The performance standard is zero defects or "do it right the first time."

- System: To obtain quality, a system of prevention rather than appraisal is required.

- Measurement: The cost of quality (COQ) is measured. COQ is the cost of nonconformance or the expense of doing things wrong and includes the costs of scrap, rework, inspection, etc.

Crosby's 14 steps to achieve these absolutes are

1. Establish management commitment to quaiity: Quality is defined as conformance to requirements and company quality policy is prepared.

2. Establish a quality improvement team: The team guides the quality improvement program and comprises representatives from departments, preferably department heads. 
3. Determine measures of quality: The measures are indicative of the status of quality and are determined for all departments.

4. Evaluate COQ: The $\mathrm{COQ}$ indicates where corrective action is profitable and includes all prevention, appraisal, and failure costs.

5. Create awareness of quality: Inform everyone of the need for improvement and the cost of nonconformance, discuss and display quality measurements, and identify nonconformance problems.

6. Take corrective action: Identify and resolve problems.

7. Establish zerc defects program committee: The committee plans the zero defects program and informs everyone of the zero defects concept and program.

8. Train supervisors for their role in the quality management program: Supervisors are trained and they in tum train their employees.

9. Establish a zero defects day: All employees are given an orientation to the new philosophy, and zero defects is established as the performance standard of the company.

10. Establish measurable quality improvement goals: Individual goals are determined by employees in meetings with supervisors.

11. Implement procedures for removing causes of errors: Employees describe barriers that prevent them from attaining zero defects. There is immediate follow-up by the appropriate functional areas.

12. Give employees recognition for achievement: Recognize (not financially) those employees who meet goals or perform outstanding acts.

13. Establish a quality council: The council is composed of quality professionals and team chairpersons and meets regularly to discuss quality-related matters.

14. Do it over again: A typical program takes 12 to 18 months.

SPC techniques are being implemented by US corporations and branches of the US military to improve quality and productivity. Deming, Juran, Crosby, and other institutions and corporations offer SPC commercial training programs for managers and engineers. (Reference 28 lists and briefly reviews the prominent SPC training courses available. This reference also includes a listing and short description of some of the available SPC software packages.) 


\section{H. PARETO ANALYSIS}

Pareto's law, developed by a 19th century Italian engineer, states that the significant items in any given group represent a relatively small percentage of the total group. For example, when a problem is examined, a large percentage of the problem usually results from a small percentage of the possible causes. Pareto's law is sometimes referred to as the 80-20 Rule: 80 percent of the problem results from 20 percent of the parts. Pareto's analysis relies on the establishment of key objectives, such as high cost components or long lead time components. Once the key objectives have been established, intense efforts, e.g., producibility engineering efforts, can be focused upon. In summary, more benefit can be achieved for a given amount of engineering effort if the effort is focused on the high cost items [Ref. 31].

\section{PUGH CONCEPT SELECTION}

Professor Stuart Pugh of the University of Strathclyde in Glasgow, UK, is noted for his work in the science and education of the design process [Refs. 32-35]. Much of Pugh's work focuses on the context of the total design, i.e., the understanding of leadership skills in parallel with the emerging understanding of engineering design. Pugh believes design is a team activity requiring the creative integration of specialists from different disciplines. Diversity within a design team is crucial, but this diversity must be carefully handled. The most important element in design is the use of systematic design methods that provide structure, so that disagreements converge productively in solutions all can understand and accept. To assist in providing systematic design methods, Pugh recommends the use of design activity models. Pugh's criteria for any model of the design activity are

- All must be able to relate to it.

- All must be able to understand it.

- All must be able to practice more effectively and efficiently as a result of using it.

- It should be comprehensive.

- It should preferably have universal application, owing allegiance to neither traditional discipline, industry, or product.

Pugh's design activity model consists of a central core of design activity, disciplined or restrained by the nature of the agreed-upon specification. According to 
Pugh, this model, which allows creative work within a framework of disciplines, always seems to fit whatever situation it is related to. The use of such a model greatly enhances the understanding of the comprehensive design, which leads to better teaching and practice, and consequently, to better designs that satisfy the user-need situation. Such a structured model, while conveying a discipline of systematic work and comprehensiveness, should also allow for variations to that systematic work.

Some of Pugh's work also focuses on the static and dynamic concepts of a design [Ref. 33]. A static design is one that has evolved over a long period of time and has reached a conceptual plateau. At this point, changes in design are incremental details about the same generic base. Examples of static designs are bicycles and automobiles. Convergence to the ultimate static concept often takes as long as 100 years. Other products, such as microcomputers and other high technology products, are considered dynamic since they have not reached a generic base. A designer's goal is to seek out the generic base--the ultimate static concept. This generic base usually results in the simplest, most elegant design, making the best use of the fundamental knowledge and information. Pugh cautions against labeling a design as static since this might dull a designer's creativity. Retrofit and derivatives of designs considered to be static may prolong the life of a product, but if the generic base has not been found, this life could well be short lived as the new derivative might be conceptually vulnerable. Designers must initially assume that all products are conceptually dynamic and that the end generic base has not been reached.

\section{J. DESIGN WITH FEATURES}

The Design with Features approach, presented by Luby and Dixon [Ref. 36], is a method for creating a high-level representation of part geometry, allowing manufacturability evaluation and possibly other computer-integrated manufacturing (CIM) tasks. (Other papers that discuss this method are by Dixon, et al. [Refs. 37-38].) The first step in this process is representing objects in a way that the computer can understand, and this is done by describing much of the knowledge of manufacturability and the knowledge required for the process design and planning in terms of geometric features. A feature is a geometric form or entity whose presence or dimensions are required to perform at least one CIM function (such as graphics, analysis, planning, and manufacturability evaluation) and whose availability as a primitive permits the design to occur (Figure III-10). 


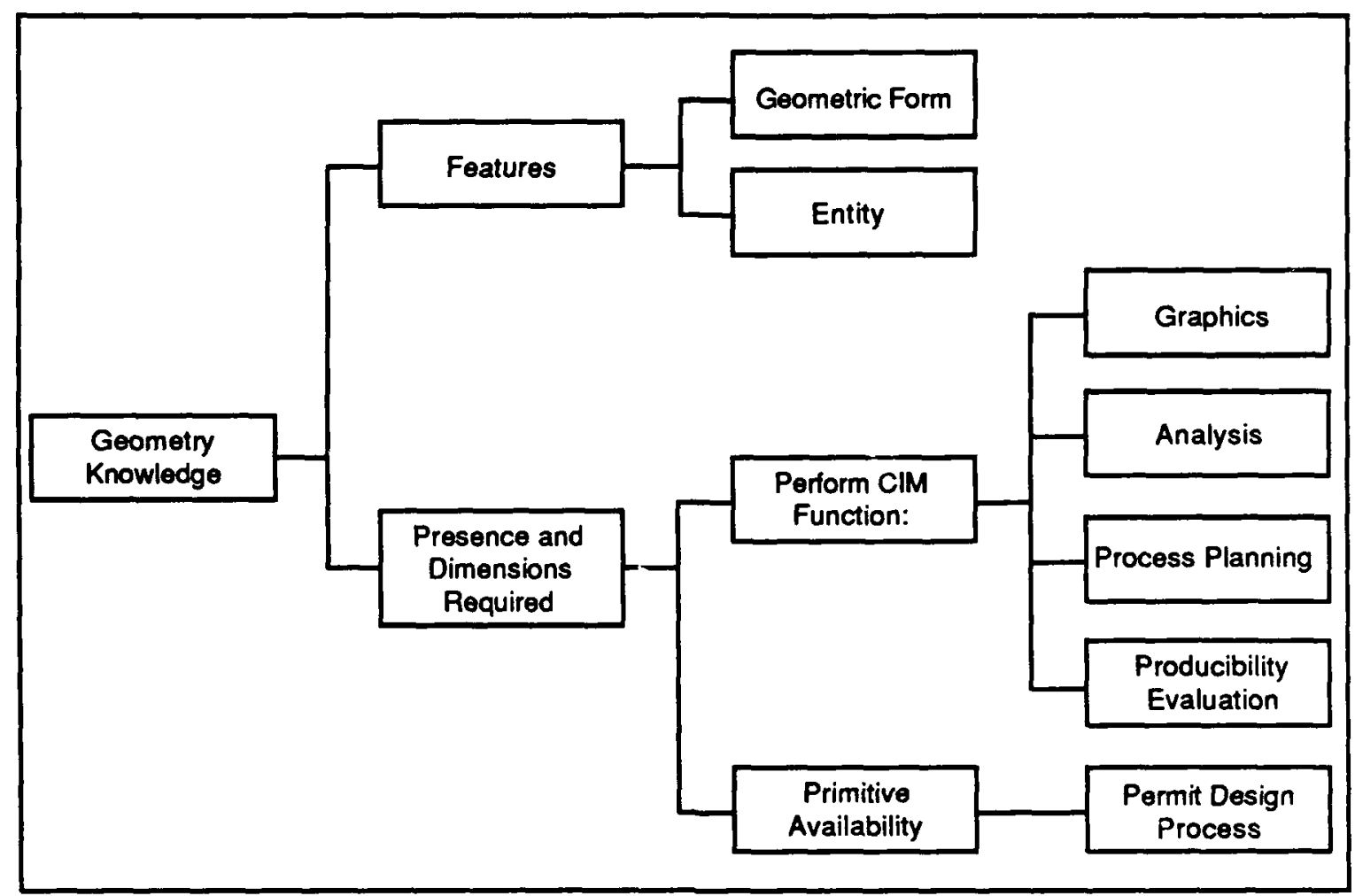

Figure III-10. Geometry Knowledge

The features a designer needs are dictated by the particular domain. For example, production problems in casting are closely related to certain associated geometric features, such as slabs, bosses, and holes. Features must logically symbolize the domain as the designer understands it. A design is represented as a structure of features, usually a hierarchical representation. This is accomplished using data structures such as lists, association lists, and property lists. The relationships between features can be found using the various types of connectivity information contained in the representations. Features can be separated into macro features and co-features. Macro features describe classes of geometric forms, and co-features are attachments or details that can be added to macro features. The Design with Features approach should be iterative. Modules should be available that allow the designer to add, create, modify, and delete features as desired. The designer should be able to run a design through functional analysis modules and manufacturing analysis modules. The most suitable computer language for containing this data base of features is the artificial intelligence language of LISP. A features based design aid for producing aluminum cast parts, called Casper, is described in Section IV.C.4 [Ref. 36]. 


\section{PRODUCIBILITY MEASUREMENT}

\section{A. EVALUATION TECHNIQUES (GUIDELINES AND CHECKLISTS)}

Many methods for evaluating producibility involve using guidelines and checklists that contain the procedural and heuristic information that a designer should constantly consider [Ref. 6]. When performing a complete producibility analysis, the following questions must be asked. The answers to these questions within the checklist may indicate where a design needs to be improved.

\section{General Aspects of Design}

- Does a design for the item already exist?

- Have alternative design concepts been considered, and was the simplest and most producible one selected?

- Is the design conducive to the application of economic processing?

- Does the design specify the use of proprietary items or processes?

- Is the item overdesigned or underdesigned?

- Can redesign eliminate anything?

- Does the design exceed the manufacturing state of the art?

- Has the functionality of the design been verified?

- Have inspection and test concepts been included in the design?

- Has the assembly sequence been adequately considered?

- Have heating and cooling needs been considered?

- Have the software and hardware interfaces been defined?

- Has susceptibility to electrical noise been considered?

- Have calibration requirements been considered?

- Can the design be simplified?

- Can a simpler manufacturing process be used? 
- Can parts with slight differences be made identical?

- Can compromises and trade offs be used to a greater degree?

- Is there a less costly part that will perform the same function?

- Can a part designed for other equipment be used?

- Can weight be reduced?

- Is there something similar to this design that costs less?

- Has interchangeability been considered?

- Has repairability been considered?

- Has reliability been considered?

- Are quality requirements too rigorous for design or functions?

- Can multiple parts be combined into a single shape?

- Have human factors been considered?

Specifications and Standards

- Can the design be made to secure additional functions?

- Can the item be machined with standard cutting tools to a greater degree?

- Is there a standard part that can replace a manufactured item?

- Is there a standard part that can replace a sole source item?

- Can any specifications be relaxed or eliminated?

- Can standard gauges be used to a greater degree?

- Can standard hardware be used to a greater degree?

- Can standard hardware be standardized to a greater degree?

- Can nonstandard threads be replaced with standard threads?

- Can stock items be used to a greater degree?

- Can packaging specifications be relaxed?

- Are specifications and standards consistent with the planned product environment?

- Has the item been designed for available shop equipment?

- Has the item been designed for automated fabrication and/or assembly?

- Have hole sizes been standardized to the greatest extent possible? 


\section{Drawings}

- Are drawings properly and completely dimensioned?

- Are tolerances consistent with manufacturing process capabilities?

- Is required surface roughness realistic, producible, and not better than function requires?

- Are forming, bending fillet and edge radii, fits, hole sizes, reliefs, counterbores, countersinks, O-ring grooves, and cutter radii standard and consistent?

- Are all nuts, bolts, screws, threads, rivets, torque requirements, etc., appropriate and proper?

- Have requirements for wiring clearance, tool clearance, component space, and clearance for joining connectors been met?

- Have all required specifications been properly invoked?

- Are adhesives, sealants, encapsulants, compounds, primers, composites, resins, coatings, plastics, rubber, mouldings, and tubing adequate and acceptable?

- Have galvanic corrosion and corrosive fluid entrapment been prevented?

- Are welds minimal and accessible, and are the symbols correct?

- Have design aspects contributing to hydrogen embrittlement, stress corrosion, or similar conditions been avoided?

- Are lubricants and fluids proper?

- Are contamination controls of functional systems proper?

- Have limited life materials been identified, and can they be replaced without difficulty?

- Have radio frequency interference (RFI) shielding, electrical, and static bond paths been provided?

- Has proper electrical grounding been called out?

- Have spare connector contacts been provided?

- Are identification and marking schemes for maximum loads, pressures, thermal, nonflight items, color codes, power, and other hazards on the drawings properly? 
- Do drawings contain catchall specifications that manufacturing personnel would find difficult to interpret?

- Have all possible alternatives of design configurations been shown?

\section{Materials}

- Have materials been selected that exceed requirements?

- Will all materials be available to meet the required need dates?

- Which are the long-lead items?

- Have special material sizes and alternate materials been identified, sources verified, and coordination effected with necessary organizations?

- Does design specification unduly restrict or prohibit use of new or alternate materials?

- Does the design specify peculiar shapes requiring extensive machining or special production techniques?

- Are specified materials available in the necessary quantities?

- Are specified materials difficult or impossible to fabricate economically?

- Is the design flexible enough so that many processes and materials may be used without functionally degrading the end item?

- Can a less expensive material be used?

- Can the number of different materials be reduced?

- Can a lighter gauge material be used?

- Can a more easily machinable material be used?

- Can use of critical materials be avoided?

- Are alternate materials specified where possible?

- Are materials and alternates consistent with all planned manufacturing processes?

- Is the material or component a proprietary item?

\section{Fabrication Process}

- Does the design involve unnecessary machining requirements?

- Have proper design specifications been used with regard to metal stressing, flatness, comer radii, types of casting, flanges, and other proper design standards? 
- Does the design present unnecessary difficulties in forging, casting, machining, and other fabrication processes?

- Do the design specifications unduly restrict production personnel to one manufacturing process?

- Can parts be economically subassembled?

- Has provision been made for holding or gripping parts during fabrication?

- Are expensive special tooling and equipment required for production?

- Have the most economical production processes been specified?

- Have special handling devices or procedures beer initiated to protect critical or sensitive items during fabrication and handling?

- Have special skills, facilities, and equipment been identified and coordinated with all affected organizations?

- Can parts be removed or disassembled and reinstalled or reassembled easily and without special equipment or tools?

- Is the design consistent with normal shop flow?

- Has consideration been given to measurement difficulties in the production process?

- Is the equipment and tooling list complete?

- Are special facilities complete?

- Can a simpler manufacturing process be used?

- Have odd size holes and radii been used?

- In the case of net shape processes, have alternate processes been specified?

- Can self-threading fasteners be used to eliminate tapping?

- Can weld nuts be used instead of a tapped hole?

- Can any machined surfaces be eliminated?

- Can roll pins be used to eliminate reaming?

- Do finish requirements prohibit use of economical speeds and feeds?

- Are processes consistent with production quantity requirements?

- Are alternate processes possible within design constraints? 


\section{Joining Methods}

- Are all parts easily accessible during joining processes?

- Are assembly and other joining functions difficult or impossible due to lack of space or other reasons?

- Can two or more parts be combined into one?

- Is there a newly developed different fastener to speed assembly?

- Can the variety of hardware be minimized?

- Can the design be changed to improve assembly or disassembly of parts?

- Can the design be ved to minimize installation or maintenance problems?

- Have considerations for heat-affected zones been considered when specifying a thermal joining process?

\section{Coating Materials and Methods}

- Are protective finishes properly specified?

- Has corrosion protection been adequately considered from the standpoint of materials, protective measures, and fabrication and assembly methods?

- Have special protective finish requirements been identified and solutions defined?

- Can any special coating or treating be eliminated?

- Can precoated materials be used?

\section{Heat Treating and Cleaning Processes}

- Is the specified material readily machined?

- Are machining operations specified after heat treatment, and can this be avoided?

- Have all aspects of production involving heat treating and cleaning processes and their interactions with other production areas been reviewed?

- Are heat treatments properly specified?

- Are process routings consistent with manuiacturing requirements (straightness, flatness, etc.)?

\section{Safety}

- Have static ground requirements been implemented?

- Have necessary safety precautions been initiated for pyrotechnic items? 
- Have RFI requirements been implemented in the design?

- Have necessary safety requirements for processing materials, such as magnesium and beryllium copper, been considered?

\section{Environmental Requirements}

- Have adequate provisions been included to meet the thermal, humidity, or other special environmental requirements?

- Has adequate heating and/or cooling been identified and implemented?

- Is the item inspected by the most practical method?

- Have conditions or aspects anticipated to contribute to high rejection rates been identified and remedial action initiated?

- Have required mock-ups and models been provided?

- Are special and standard test and inspection equipment on hand, calibrated, proofed, and compatible with drawing requirements?

- Are master and special gauges complete?

- Have nondestructive testing techniques been implemented?

- Have adequate provisions been made for the checkout, inspection, testing, or proofing of functional items per operational procedures?

\section{B . DEPARTMENT OF DEFENSE GUIDELINES}

Products manufactured for the military aerospace market are highly complex, specification driven, and are produced in relatively low volumes. The difficulties encountered in weapons production have commanded increasing attention in the Department of Defense (DoD). For many sophisticated weapon systems, the start of production has proven to be as difficult as the weapon development period. Cost growth and late deliveries stemming from production floor problems have consistently impeded attempts to field new equipment. The additional time and money needed to produce the desired quantities of weapons routinely frustrates the budgeting and planning process. The DoD has taken several actions to direct better preparation for production. The concept of producibility within the defense industry is addressed specifically by many defense and other government sponsored publicatior.s. [See Refs. 6, 7, 8, 43, 44, 45, 46, 46, 48.] The government's policy for production and acquisition of weapon systems can be summarized as follows: 
- Develop a manufacturing strategy as a part of the acquisition strategy and addressing manufacturing voids and producibility of concepts during concept demonstration and validation

- Make a comprehensive producibility engineering and planning program a requisite for full-scale development, with specific tasks, measurable goals, and a system of contractor accountability

- Assess production management and production status at each major milestone decision

- Adequately fund producibility engineering and planning, manufacturing technology, and facilities

- Employ pilot production lines, when necessary, to validate production readiness, manufacturing operations, and cost

- Conduct production readiness reviews in support of limited production and full production decisions

- Integrate factors affecting producibility and supportability during full-scale development and structure the design and test cycle to provide a continuum in development, production, and operational support

- Ensure that an adequate number of technically qualified and competent people are committed to the program, and take specific measures to train production personnel, including a defined career progression and extended assignments.

A report issued by the US General Accounting Office (GAO) cited six case studies of weapon system production problems [Ref. 45]. The GAO concluded that the production problems are caused, in nearly all cases, by inadequate preparation for production during the developmental phase. When problems occurred, production preparations were, in varying degrees, sporadic, underfunded, and largely compressed into the late stages of development and early production. This poor production planning resulted in increased costs, delayed deliveries, and slower attainment of higher, more efficient production rates. The development conditions that most directly affected the manner and thoroughness of the production preparations were

- Pressures to achieve technical performance requirements dominated the development phase

- Sufficient program management attention and staff resources were devoted to production concerns

- Funding and quantity stability permitted early and serious consideration of production matters during the development phases. 
The GAO's major recommendation was that the DoD should place an emphasis on balancing concerns for technical performance with those for production. This balance can be better accomplished when program instabilities, such as changing design requirements, fluctuating funding, and changing deliverable quantities, are limited. The use of regular production readiness reviews during development should also be employed as a tool for managing production preparations. DoD should, however, recognize that designing for producibility should be a continuing process, and success cannot be achieved through the sole use of production readiness reviews.

Two significant DoD publications are the Navy's Manual, Best Practices, [Ref. 43] and DoD Directive 4245.7M, Transition from Development to Production [Ref. 44]. In each of these publications, the design, deveiopment, and production stages of a weapon system are separated into templates (Figure IV-1). Reference 43 identifies with each template four significant "traps" for managers to avoid during the program phase. (Reference 47 identifies the risks associated with each template along with an outline for reducing these risks.)

Another important DoD publication relating to producibility is [Ref. 6], Military Handbook - Design Guidance for Producibility, developed by the Army Materials and Mechanics Research Center under the Manufacturing Technology (MT) program [Ref. 63]. This is the most comprehensive and dedicated document found on the topic of producibility. All aspects of producibility from almost all angles of manufacturing are addressed. Figure IV-2 illustrates the extensiveness of the material covered in this reference.

DoD has also established two programs to enhance producibility and lower the cost of weapon systems--the Manufacturing Technology (MT or Man Tech) Program [Ref. 63] and the Industrial Modernization Incentives Program (IMIP) [Ref. 66].

The MT program objective is to fund development of concepts, processes, and equipment that will reduce cost and lead time, improve quality and reliability, and eliminate the use of hazardous materials in weapon system production [Ref. 63]. Because of the risks involved in such development, industry will not sponsor such efforts.

IMIP provides incentives to contractors willing to undertake major plant modernization. The program guarantees the contractor a negotiated return on investment should its return drop below a certain amount within a specified time period. 


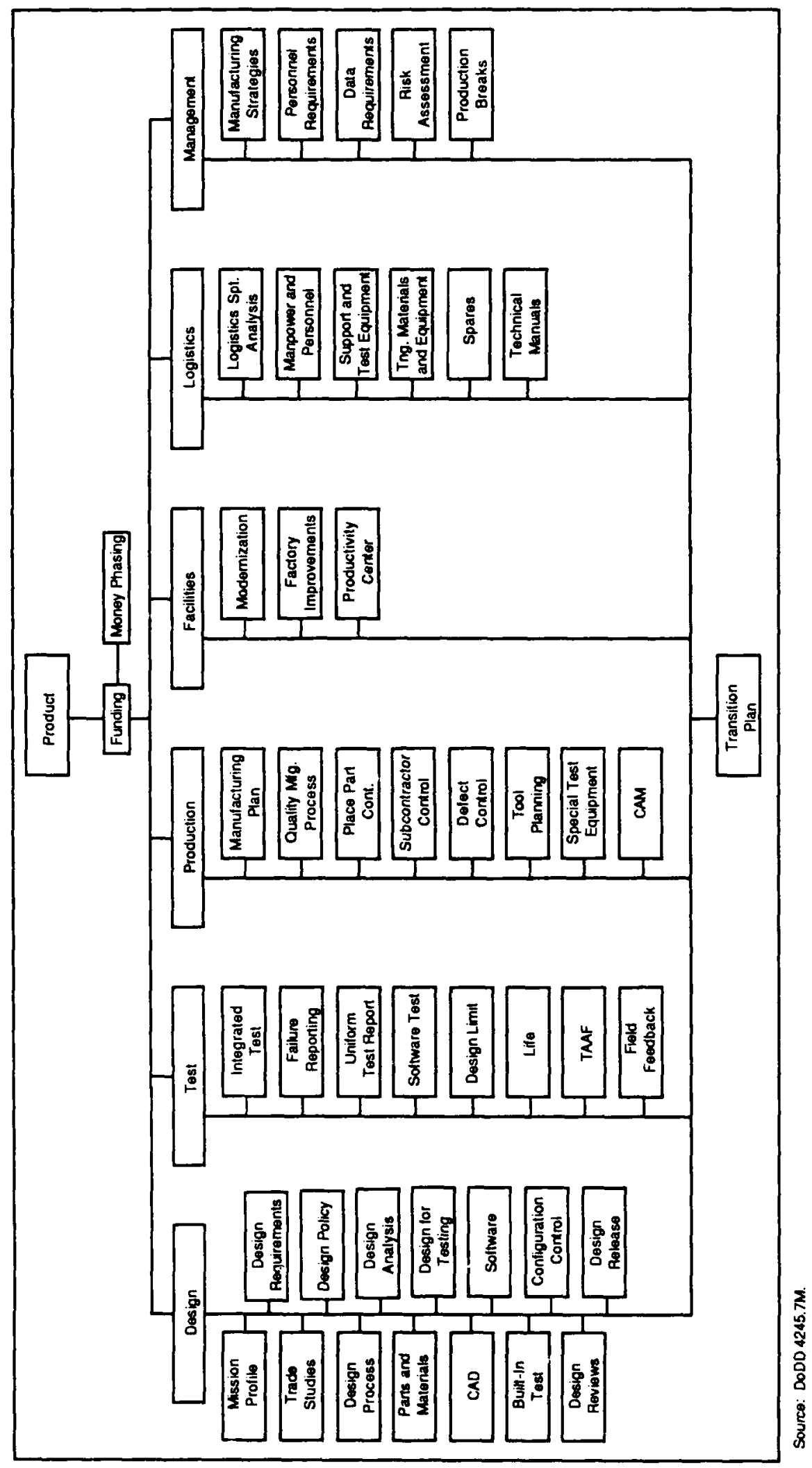

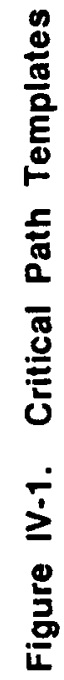




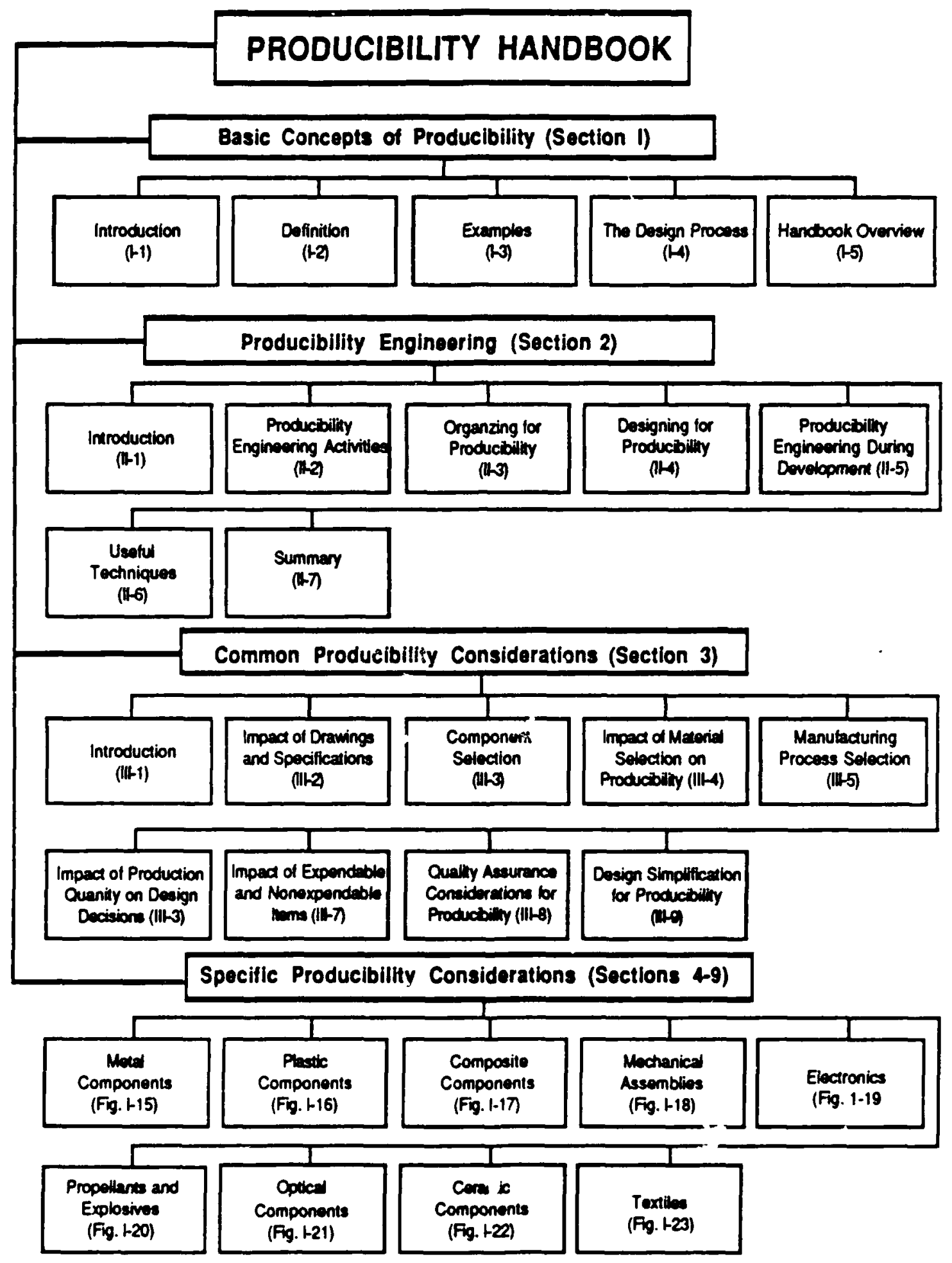

Figure IV-2. Referenced Material 


\section{PRODUCIBILITY MEASUREMENT TOOLS}

During the past decade, many corporations and researchers have begun to recognize the importance and necessity of designing for producibility. After much study and research, many have developed or have begun to develop producibility software or producibility tools to help designers and manufacturers obtain optimum designs. This section describes the following producibility software and tools:

- Design for Manufacture and Assembly (DFM/DFA) (Boothroyd and Dewhurst)

- Hitachi Assemblability Evaluation Method (AEM)

- Texas Instruments Component Analysis System (CAS) and the Printed Wiring Board (PWB) Expert System for Producibility (PESP)

- Casper: A Designing with Features Software Aid

- Process Planning Software.

\section{Boothroyd and Dewhurst Design for Assembly}

Boothroyd and Dewhurst, pioneers in the DFM/DFA, have been working in the area for more than 10 years. They have developed a DFA method that has become widely used in industry and has helped to increase awareness of the importance of design as the first step in manufacturing. The results derived from using the method have also hirhlighted the fact that manufacturing costs are mainly determined during the initial design stages.

The boothroyd and Dewhurst procedure involves two principal steps. The first and most important is determining whether each part can be eliminated or combined with other parts in the assembly. Such simplification substantially reduces product costs. When considering a redesign and determining the theoretical minimum number of parts, the designer must address the following issues:

- During the operation of the product, does the part move relative to all other parts already assembled? Only gross motion should be considered--minor motions that can be accommodated by elastic hinges, for example, do not sufficiently justify use of the part.

- Must the part be of different material or be isolated from all other parts already assembled? Only fundamental reasons concerned with material properties are acceptable. 
- Must the part be separate from all other parts already assembled? The answer is yes only if the necessary assembly or disassembly of other separate parts would be impossible if the part under consideration were not separate.

The second principal step is estimating the cost and time associated with grasping, manipulating, and inserting each part using the appropriate assembly process, either manual, flexible, or high speed automatic assembly. This estimation allows the designer to evaluate design changes in terms of assembly savings or complications and to evaluate different manufacturing methods for the same product to determine the most efficient method. After completing these steps, it is then possible to obtain the total assembly time and to compare this figure with the assembly time for an ideal design.

A list of rules or guidelines are provided for the designer to keep in mind at all times while designing or redesigning a product for ease of assembly:

- Minimize the number of parts.

- Ensure that the product has a suitable base part on which to build the assembly.

- Ensure that the base part has features that will enable it to be readily located in a stable position in the horizontal plane.

- If possible, design the product so that it can be built in layers, with each part added from above and positively located so that there is no tendency for it to move under the action of horizontal forces during the machine index period.

- Try to facilitate assembly by providing chamfers or tapers, which will help to guide and position the parts correctly.

- Avoid expensive and time-consuming fastening operations such as screwing and soldering.

The rules for individual parts design for automatic assembly are

- Avoid projections, holes, or slots that will cause tangling with identical parts when placed in bulk feeder. This may be achieved by designing the holes or slots to be smaller than the projections.

- Attempt to make the parts symmetrical to avoid the need for extra orienting devices, which can cause a corresponding loss in feeder efficiency.

- If symmetry cannot be achieved, exaggerate asymmetric features to facilitate orientation or, alternatively, provide corresponding asymmetric features that can be used to orient the parts. 
Boothroyd and Dewhurst provide detailed examples of completing each step in the DFA evaluation [Ref. 49]. The reference contains detailed charts, tables, and worksheets for selecting assembly methods, determining handling times and handling costs, and figuring their design efficiency measure.

\section{Hitachi Assemblability Evaluation Method}

As described by Miyakawa [Ref. 50], AEM is a simple method developed by Hitachi for evaluating assemblability--one of the most important factors of producibility. AEM can improve product design by identifying weak points through the use of two indices. These indices should be used at the earliest possible stage of design:

- The assemblability evaluation score, $\mathrm{E}$, which is used to assess design quality or the difficulty of assembly operations

- The estimated assembly cost ratio, $K$, used to project assembly costs.

Since a cost index alone cannot express whether design quality is acceptable, a quality index is also required for assessment. Evaluation results are used to compare alternatives or compare a model with those of competitors. After the evaluation results are reviewed, the design is improved. The improved design is again subjected to the assemblability evaluation process to evaluate effects of the improvements qualitatively.

Figure IV-3 shows the steps of an assemblability evaluation and the design improvement steps. The first step is to prepare conceptual drawings, completed drawings, or samples of the product to be evaluated. The more precise the drawings, the better the results of the evaluation. Next, the attachment sequence is determined and an assemblability evaluation calculatir . . is completed. The names and numbers of the parts and corresponding AEM symbols are entered in the same order as the planned assemtly sequence. The next step is to calculate the evaluation indices. The part assemblability evaluation scores, $P$, for all the parts are calculated first. The product assemblability evaluation score, E, is then calculated. Evaluation usually takes 2 to 3 minutes per part.

The next step is judging the evaluation index. The assemblability evaluation indices of the product are compared to target values. The higher the $\mathrm{E}$ value, the lower the manual assembly costs and the greater the ease of assembly automation. (According to experience with the AEM method, products with an assemblability evaluation score greater than 80 can be fully assembled automatically, and investment in the automatic assembly setup is 


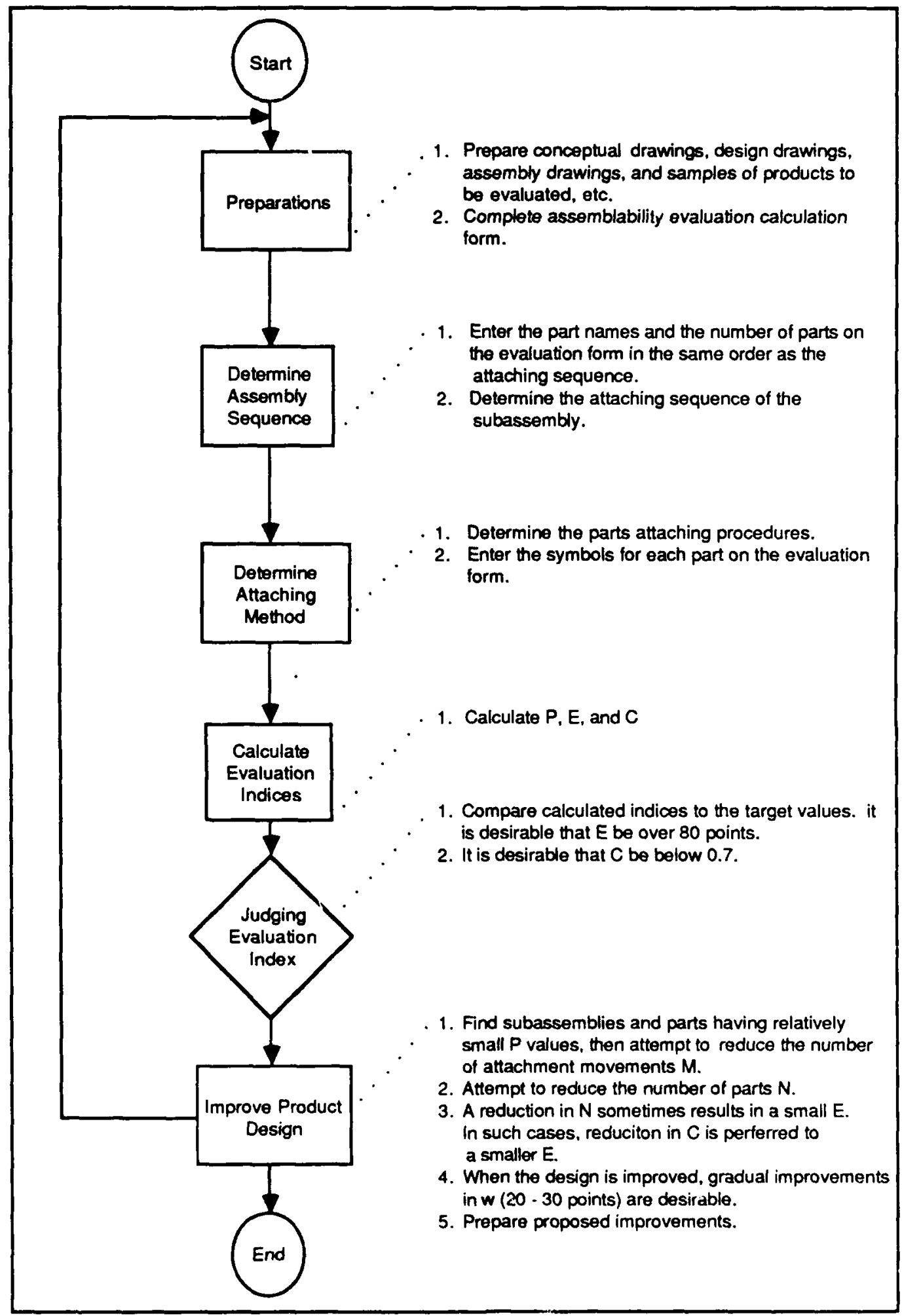

Figure IV-3. Hitachi Assemblability Procedure 
economically justified.) Next the estimated assembly operation cost, C, is calculated from the $E$ value, the number of parts $N$, and the assembly operation cost of the basic product. Following these calculations, design can be improved by:

- Identifying any weak points and causes of a low score by reviewing the evaluation results.

- Making alternative designs to eliminate the low score operations structure and reduce the number of parts.

- Evaluating the effects of the improvement by comparing the assembly costs using the estimated assembly cost ratio, which is easily calculated from the $\mathrm{E}$ and $N$ values.

While AEM calculations are quite simple, an automated AEM computing system that uses handheld or larger computers has been developed. The system requires at least 12 KB of memory and graphic display functions that enable the display of AEM symbols and part names. After assembly is analyzed with AEM symbols, the number of parts and the symbols for parts are entered into the system, according to the assembly sequence. Calculations and printing of results are done automatically. Results include the names of parts, the AEM symbols used, the part assemblability evaluation scores, and product assemblability evaluation score.

The major differences between the Hitachi (AEM) method and the Boothroyd and Dewhurst method, as described by Boothroyd [Ref. 51], are

- The Hitachi method does not conside1 part count reduction, the major avenue to cost reduction.

- The Hitachi method does not consider part handling, either manual or automatic, whereas the Boothroyd and Dewhurst method includes analysis of manual handling costs or, where appropriate, automatic feeding and orienting costs.

- The Hitachi method makes no distinction between manual, flexible, or automatic assembly. Hitachi gives two reasons for this. The first is strong correlation between degrees of assembly difficulty by manual, robot, and automatic assembly. A second reason is the difficulty designers have in considering the production mode early in the design stage. Even production of the same model can be changed from manual to automatic assembly.

The Hitachi method has been introduced and used effectively in many other Japanese companies and American, European, and other Asian firms. 


\section{Texas Instruments Component Analysis System and the PWB Expert System for Producibility}

As described by Hawisczak [Ref. 52], the PWB CAS is a producibility tool used for the selection of PWB components and for allocating PWB real estate for producibility. CAS is composed of a family of tools, all of which interrogate a large component database containing more than one million pieces of information on 24,000 components. Developed in 1984-87 by a team of producibility engineers at Texas Instruments, CAS has proven useful in identifying producible components, pinpointing problems, and defining PWB space and height envelopes. CAS can also identify problems that may surface at PWB layout and documentation.

CAS, however, is a complex tool requiring a trained producibility engineer user to load and analyze the results of a consultation. CAS is integrated with the design process and is part of the design methodology. This design methodology requires a CAS analysis prior to PWB design release. CAS has been applied on more than 1,000 designs since 1985.

The PWB expert system for producibility (PESP) was developed to support a larger portion of the PWB design process and improve user friendliness. PESP is an intelligent tool intended to provide electrical design engineers access to producibility data concerning all phases of PWB design. PESP is a rule driven tool that builds from the CAS data base (Figure IV-4). PESP modules address individual phases of PWB design including parts analysis, raw board, layout, routing, and documentation. The figure depicts the applications of CAS and PESP superimposed on the PWB design process. The system can guide an engineer through a design, posing alternatives to assist in developing a producible design. The first release of this system is targeted for June 1988.

\section{Casper: A Designing with Features Software Aid}

Casper is a software aid for designing and manufacturing of aluminum castings based on the Design with Features method, as described in Section III.J. In contrast to Boothroyd and Dewhurst's DFA and Hitachi's AEM, Casper concentrates on the producibility of single parts. The Casper architecture, as described by Luby and Dixon [Ref. 36], is based on a series of modules that are used to perform functions such as creating, arding, or modifying a part's geometry; evaluating the part's manufacturability; or performing functional analysis. Casper builds with two types of features, macro-features 


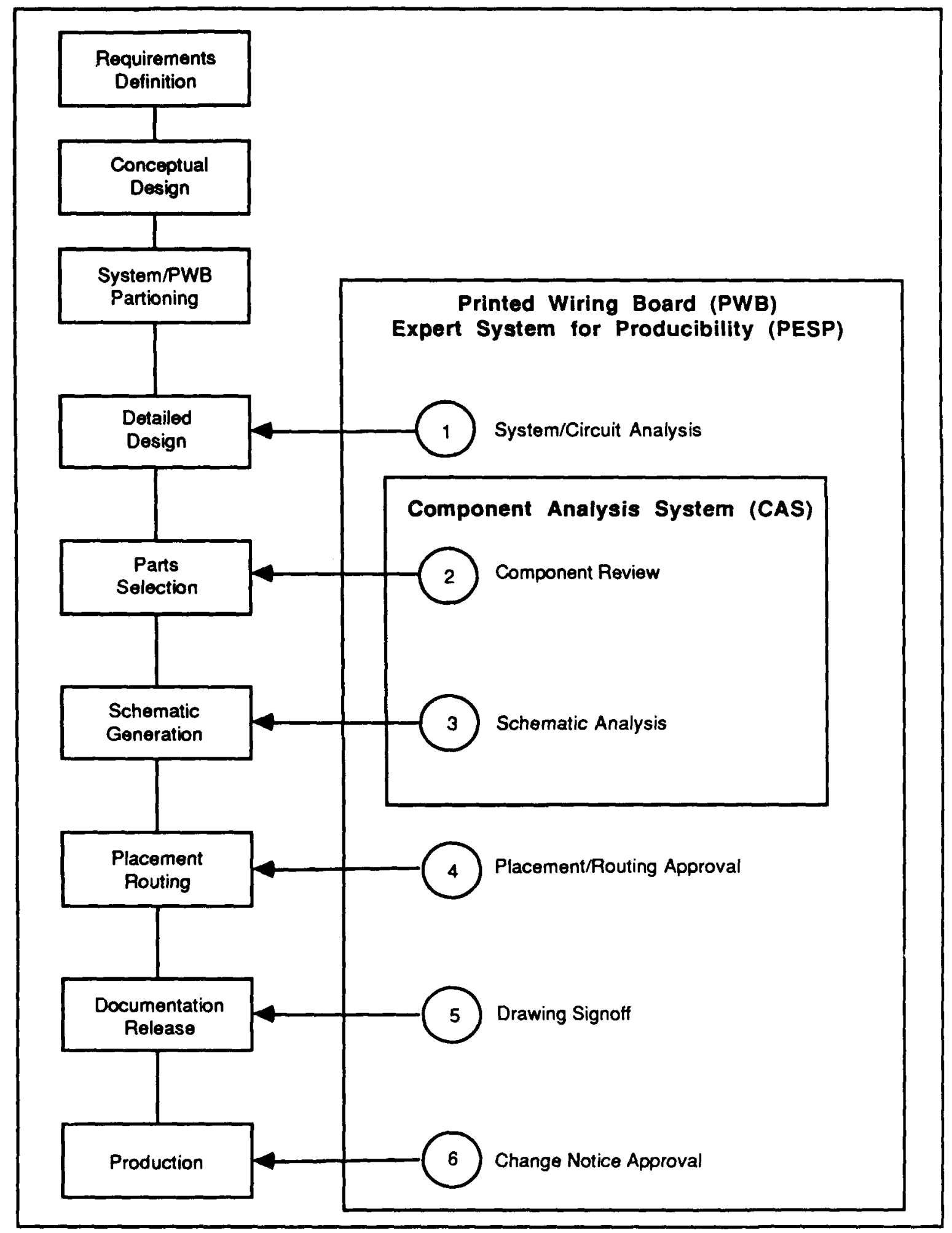

Figure IV-4. Producibility Tools Integration Within a PWB Design Environment [Ref. 52] 
and co-features. Macro-features used include slabs, corners, L-brackets, U-channels, shelves, and boxes. Co-features include bosses, holes, ribs, and some others. A designer creates part geometries by combining macro- and co-features with the appropriate dimensions and positions. Once the part geometry is complete, Casper can perform manufacturability evaluation and functional analysis. Casper performs analysis and has the knowledge to identify certain problems associated with the features used in casting. Manufacturability problems during casting involve metal flow, metal feeding, and residual stresses generated during cooling.

The development goals for Casper were research r riented and while it is ready for commercial use, the ideas and computer techniques are steps toward complete CIM. Although Casper's present domain is limited to aluminum castings, the method of using a features database to synthesize and evaluate parts can easily be extended to other categories of parts. More research is needed to determine the features needed for each domain and whether a features database is even feasible for a particular domain. Other areas of Casper research include developing domain independent systems and trying to incorporate an automatic redesign module that could automatically implement design improvement suggestions. This has been accomplished with some success with an expert system named Domain Independent Redesign Program (DOMINIC) [Refs. 39-40]. In DOMINIC, the domain knowledge and the control are completely separated.

\section{Process Planning Software}

Process planning for a mechanical part involves the preparation of a plan that outlines the routes, machines, tools, etc., required to produce that part. An $\sim$ ptimum process plan can save much time, effort, and money, and therefore can greatly enhance a product's producibility. Process planning traditionally has been done by human experts; however, within the last decade, a trend to automate process planning using knowledgebased techniques has emerged. As a result, a number of automated process planning systems have been developed. Heragu and Kusiak [Ref. 53] survey a number of the intelligent process planning systems such as TOM, GARI, PROPLAN, CUTTECH, and Hi-Mapp. Successful computer-aided process planning is a necessary step toward a true CIM system. These systems are usually referred to as Manufacturing Resource Planning (MRP) systems. 


\section{PRODUCIBILITY SYNTHESIS MODEL DEVELOPMENT PLAN}

The life cycle of defense products includes three design phases before production-the Concept Exploration phase, the Demonstration/Validation phase, and Full Scale Development. In recent years, investigations have been conducted to discover where in the life cycle of a product the greatest opportunities exist to significantly influence cost and to what degree cost can be influenced. Evidence clearly shows that these opportunities diminish with each step in the life cycle. The early design phases are the most sensitive, and producibility concepts should be integrated into these phases. This chapter presents a plan for the development of a design environment that will allow the integration of producibility concepts into the early design phases.

The first section of this chapter uses information from existing studies and research to present an example or paradigm of how producibility concepts may be integrated into aircraft Conceptual and Preliminary design. The architectural foundation for this paradigm is the synthesis model concept described in Appendix A. The information is presented and then structured into a concept for a modified synthesis model that combines procedural and heuristic aspects in the proposed design environment. The concluding section presents the requirements for such a model.

\section{A. LIFE CYCLE COST MODEL}

Since weapon system cost is an indicator of producibility, the use of a cost model as a procedural module of a synthesis model is one approach to assessing producibility in design. One LCC methodology for use in the conceptual design process of subsonic commercial aircraft has been developed by Johnson [42].

Johnson's model addresses the conceptual aircraft design level, which is described as the phase where the general size and configuration (geometry) and the estimated performance of the aircraft are determined. Mission and payload determine the design and the weight of the vehicle. 
The LCC of an aircraft is defined as the total cost of the aircraft, from cradle to grave, including research, development, test, and evaluation (RDT\&E); acquisition (production); operation; ground support equipment; initial spares; training aids; spares; and all other maintenance costs.

The LCC model developed by Johnson includes RDT\&E, production, direct operating costs (DOC), and indirect operating costs (IOC) elements. The LCC model was developed by assembling existing programs for each of the individual modules. The Science Applications Incorporated (SAI) [Ref. 54] airframe model was used for airframe acquisition cost. The SAI model comprises system-level weight and cost estimating relationships for transport aircraft. The model estimates weights and production costs based on performance parameters at the individual system level, exclusive of the engines. The Rand Corporation model [Ref. 15] was used for estimating the development and production costs of engines. The American Airlines model [Ref. 16] was used for the DOC, as it is based on past experience data. The Lockheed-Georgia Company model [Ref. 55] was used for the IOC.

Johnson integrates the system LCC model with a synthesis model called Flight Optimization System (FLOPS) used for conceptual and preliminary design (Figure Y-1). FLOPS consists of four primary modules:

- Weights

- Aerodynamics

- Mission Performance

- Takeoff and Landing.

The LCC module integration into the synthesis model, FLOPS, is an example of the use of procedural knowledge to assess the producibility of an aircraft concept at the conceptual design level. A knowledge of the primary level of geometry, i.e., the aircraft configuration, was required.

\section{B . SUPERSONIC TRANSPORT PRODUCIBILITY STUDIES}

The design problem considered for the development plan is the supersonic transport (SST) cruise aircraft (Figure V-2). Producibility technology studies of the supersonic cruise aircraft were conducted by the Lockheed-California company in the mid-1970s [Refs. 63, 64]. The purpose of the studies, funded by the NASA Langley Research 


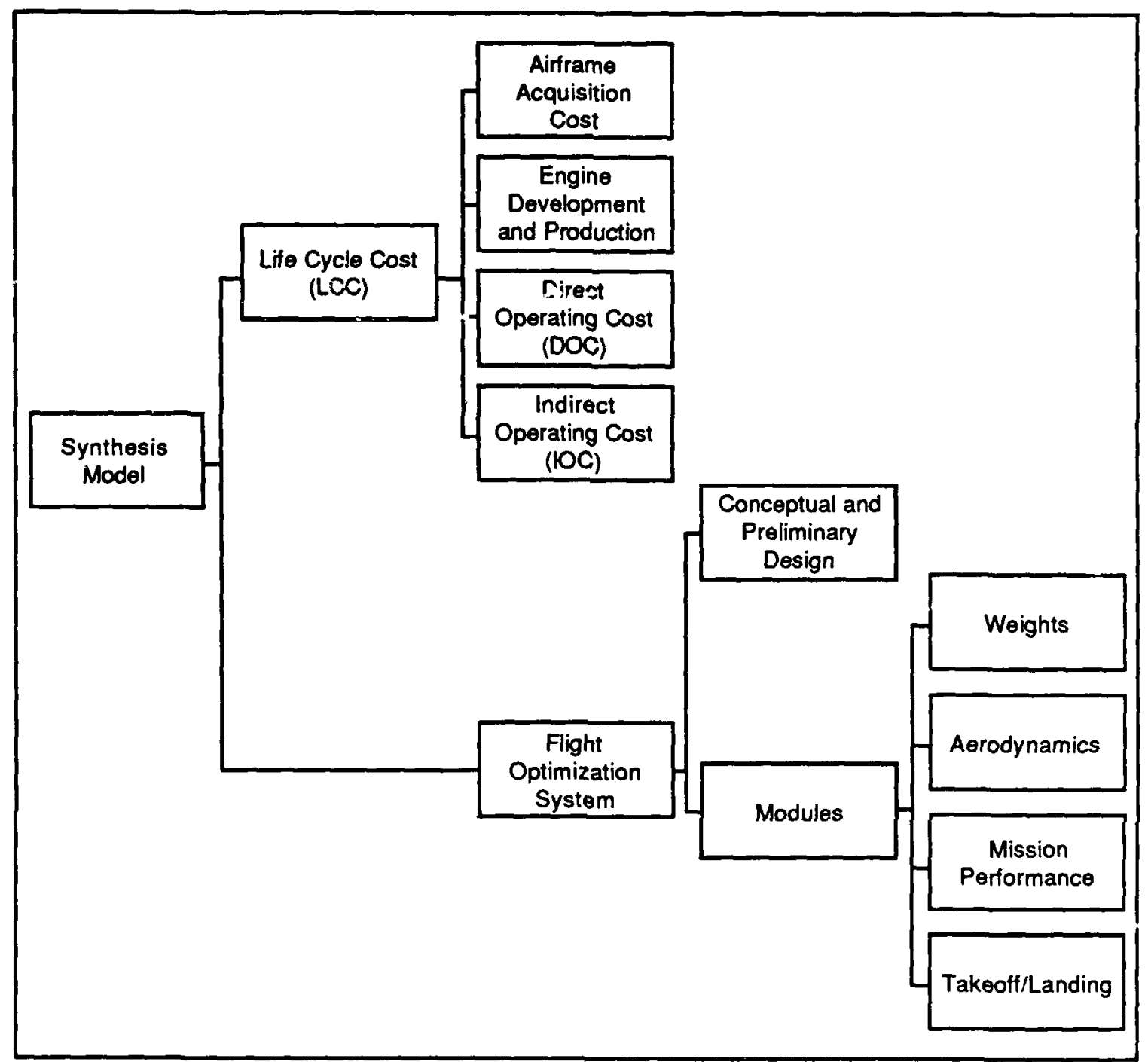

Figure V-1. Johnson's LCC Model

Center, was to assess materials and producibility methods for the design of the primary structure of a supersonic cruise aircraft. NASA Langley was interested in a supersonic cruise aircraft research program for three main reasons:

- To provide an expanded technology base for future supersonic aircraft

- To provide the data needed to assess the environmental and economic impacts on the United States of present and future foreign supersonic cruise aircraft

- To provide a sound technical basis for any future US consideration to the development of an environmentally acceptable and economically viable commercial supersonic cruise aircraft. 

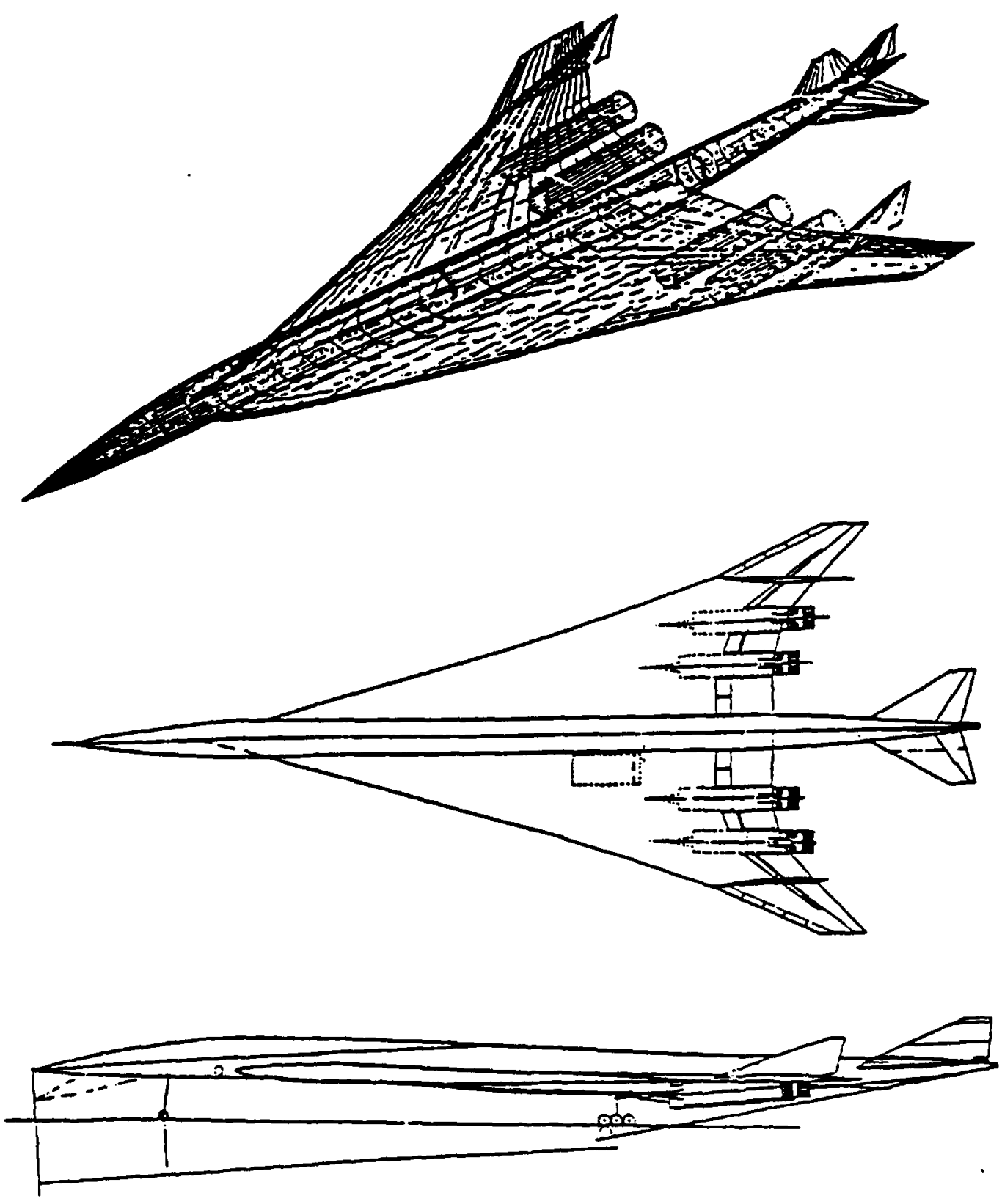

Figure V-2. Supersonic Transport Cruise Aircraft 
The producibility technology studies centered on a Mach 2.7 titanium structure arrow wing design configuration. Vehicle takeoff weight was assumed to be 750,000 lbs. Emphasis was placed on an integrated design/manufacturing approach to develop low-cost producible structural configurations by identifying potential materials and fabrication technologies that would be available in the 1980 s. The wing construction methods under consideration were titanium skin stiffened chordwise and spanwise arrangements and monocoque biaxial stiffened honeycomb sandwich configurations. Each of these structural concepts was analyzed, screened, and the arrangement geometry defined in terms of minimum mass.

Materials and fabrication techniques were the primary focus. Metallic and composite material systems were considered, although only selective reinforcement of the basic metallic structure was considered. The following material properties were assessed:

- Mechanical and physical properties

- Ease of manufacture

- $\quad$ Cost effectiveness

- Minimum mass.

The final material selection thus required knowledge and evaluation of materials, processing, properties, and cost. Specific producibility studies included

- Improved fatigue quality through minimizing fasteners by use of welding, bonding, and brazing

- Large-scale fabrication to minimize the number of joints

- Minimizing or eliminating tank sealing by use of large-scale application of welding, bonding, and brazing.

Research focused on an integrated design and manufacturing approach to develop low cost producible structural design concepts using advanced materials and fabrication processes (Figure V-3). To achieve this goal, manufacturing guidelines were developed to assist in the design concepts studies. Fabrication limits and constraints were developed for forming, joining, metal removal, and assembly technologies. Tentative fabrication and problems were identified for the various structural design concepts for the wing and fuselage primary structures.

Design guidelines were established to assist in the assessment of the relative importance of design parameters, such as fatigue quality, tank sealing, damage tolera. 'se, and structural approach, on the candidate arrangements. The evaluation and selection of 


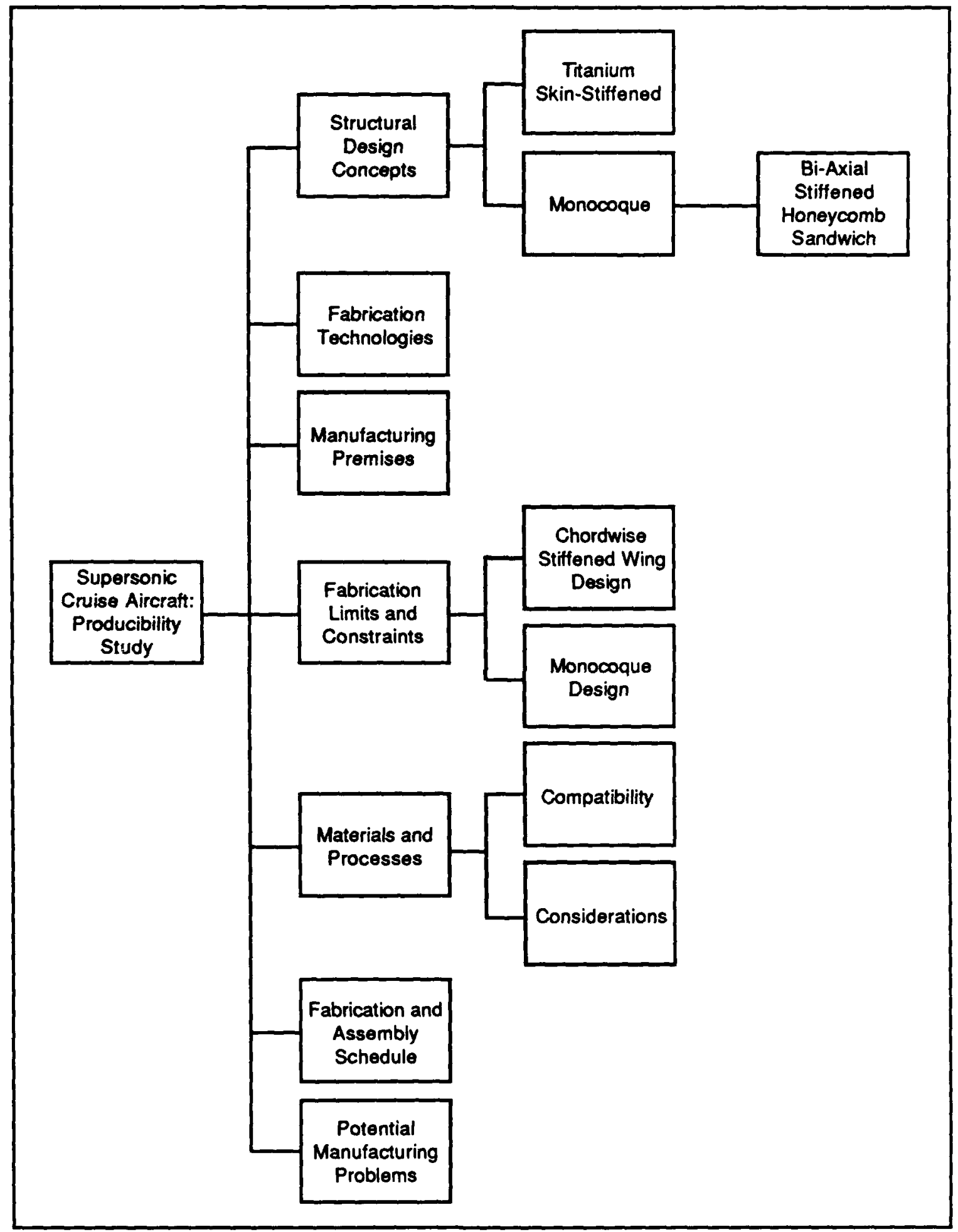

Figure V-3. Supersonic Cruise Aircraft Producibility Study 
candidate structural approaches were performed on the basis of direct operating cost (DOC), which includes such factors as mass, production cost, maintainability, and fuel consumption. Simplified cost-benefit studies were performed to provide an additional basis for decision.

These producibility studies are an example of the use of heuristic knowledge to assess the producibility of an aircraft concept at the preliminary design level. Required was a knowledge of the second level of geometry, i.e., the structural design concept of the wing.

\section{PROPOSED TRANSPORT SYNTHESIS MODEL}

The study team proposes to the ULCE community, for the future development of the concept of introducing producibility into the Conceptual and Preliminary design stages of aircraft design, that an example synthesis model, perhaps FLOPS with the LCC developed by Johnson [Ref. 42], be combined with heuristic components of producibility as shown in Figure V-4. The LCC would address the aircraft concept development at the Conceptual design level, while the heuristic module would address the Preliminary design level.

\section{Knowledge Base}

A homogeneous micro-scale model of the proposed design environment should be developed. The design environment will be based on the Apple Macintosh II configured as a workstation as shown in Figure V-5. A synthesis model, such as FLOPS with the LCC module, should be ported to the Macintosh II environment. In final form, the model would feature the full Macintosh user interface including pull-down menus and embedded graphics.

\section{Hardware Requirements}

\section{a. Macintosh II}

The Macintosh II is a modular system built around the Motorola 68020 chip with the 68881 floating-point co-processor chip running at $16 \mathrm{MHz}$, and the Macintosh toolbox and operating system routines. A 32-bit data path is used for memory and bus access. The Macintosh II has $1 \mathrm{Mb}$ of RAM (expandable to $8 \mathrm{MB}$ ), an internal $800 \mathrm{~K}$ floppy drive, and 


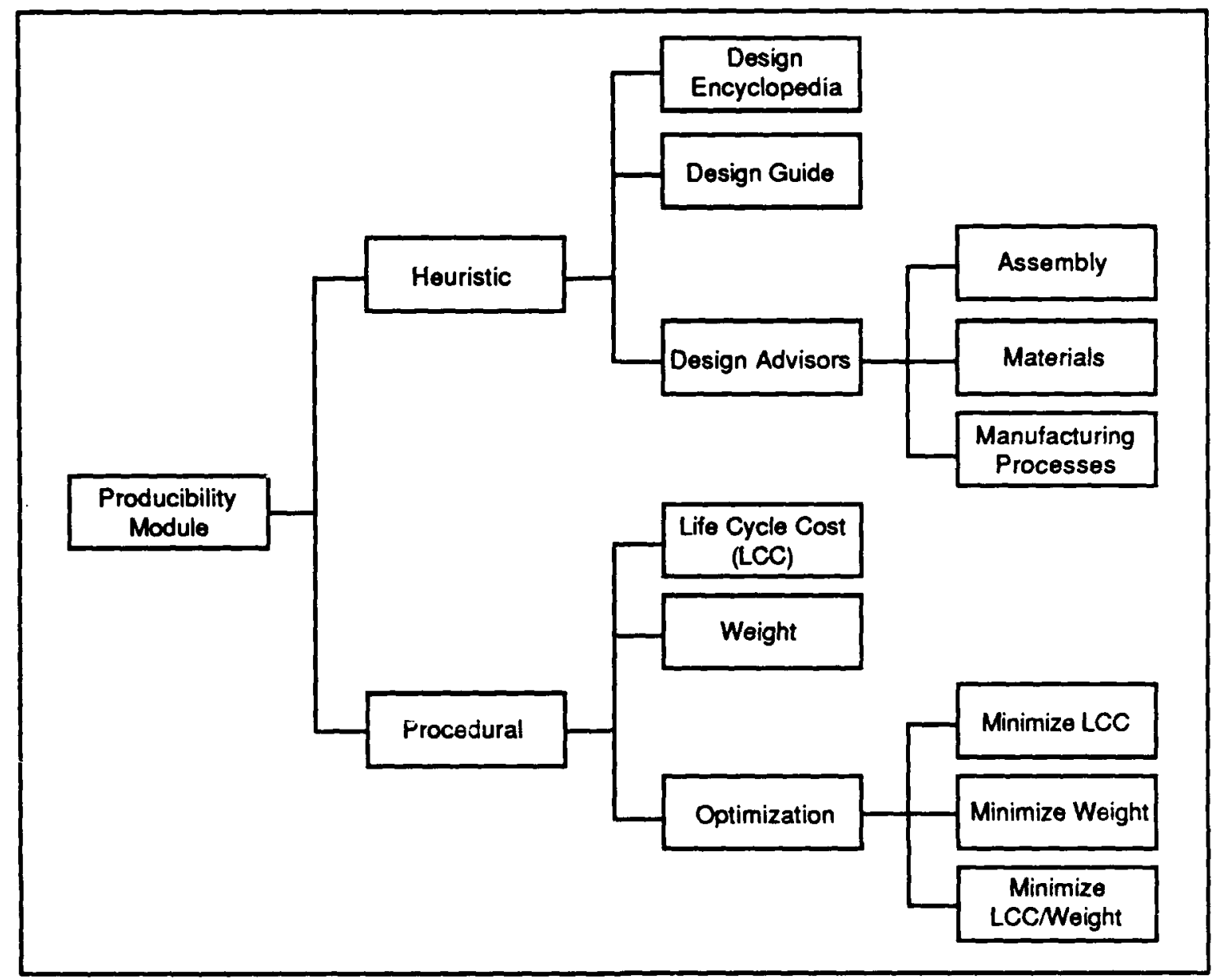

Figure V-4. Producibility Module

six NuBus expansion slots. Internal SCSI hard discs for mass storage are available in 20 , 40 , or $80 \mathrm{MB}$ capacities. By connecting dual monitors and using Apple's multi-tasking program, MultiFinder, several different applications may be run at the same time.

The Macintosh II, a cost-effective alternative to expensive engineering workstations, such as the Sun-3/60 [Ref. 60] and the Apollo DN/3000 [Ref. 61], offers an enhanced work area. The Macintosh II's greatest advantage is its user interface, which is easy to use and offers the best response to user input.

b. Translink

Translink is an expandable Inmos Transputer based accelerator package that provides high-speed parallel processing and Reduced Instruction Set Computer (RISC) technology to the Macintosh II. The 32-bit Transputer contains 4 inter-processing links 


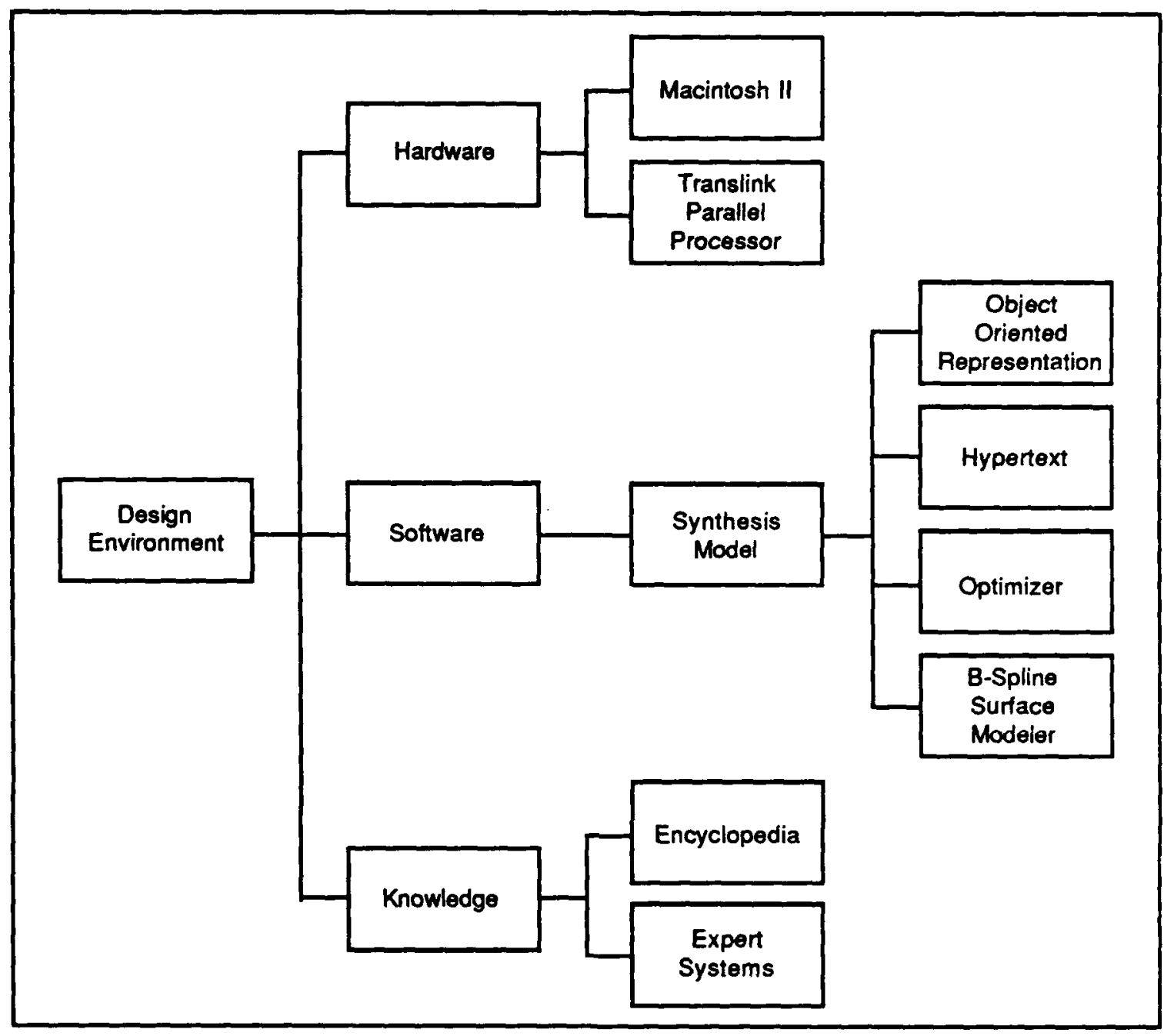

Figure V-5. Design Environment for the Designer

that have a throughput of 10 million instructions per second (MIPS), equivalent to a VAX 8600 mainframe computer. Translink vastly improves the standard 2.5 MIPS performance of the Macintosh II. A RISC processor has short, simple instructions that can be executed very quickly (50 to 100 nanoseconds). A majority of the snmputer instructions are embedded in silicon, thus eliminating the step of translating hose instructions before executing them.

The Transputer (Transistor-computer) is a 32-bit high-speed RISC, based on VLSI technology and designed for parallel processing. The Translink is designed for applications that are computationally intensive or naturally parallel. Naturally parallel problems can be reduced to smaller problems and solved at the same time. Applications 
that can take advantage of parallel processing include differential equation solving, rulebased expert systems, and object oriented search and parallel search of multiple files in distributed databases.

\section{Software Requirements}

Commercially available software provides the basis for developing the design environment around the hardware kernel. Included should be:

Program

Micro-Dot

GUIDE

HyperCard

NEXPERT OBJECT

SMALLCRAFT
Function

Automated optimization

Hypertext/ hypermedia

Hypertext

Expert system shell/Object-oriented programming

Synthesis model

\section{a. Micro-Dot Optimizer}

Micro-Dot (Microcomputer/mainframe Design Optimization Tool), a numerical optimization code, is intended to work directly with user-supplied FORTRAN code. Micro-Dot, which is based on the Modified Feasible Directions method, solves the nonlinear optimization problem iteratively and is designed to run on a personal computer or on a mainframe. Although Micro-Dot was designed to run on the IBM PC and compatibles, porting it to the Macintosh II seems to pose no problems.

\section{b. GUIDE}

GUIDE is a Macintosh implementation of hypertext and a multi-dimensional electronic information processor and management program. The final document is in electronic form. With GUIDE, the users have the ability to create "hot spots" (buttons) within a document, which are dynamically linked to other text or graphics in the same or another document. Buttons can be used to explore the information contained in a document. For example, when a user clicks the mouse over a button on the screen, GUIDE provides a more comprehensive view of the information, revealing additional levels of detail, cross-reference multiple documents, or display notes in a pop-up window.

These buttons allow users to read a document at the level of detail required for understanding. The users simply reviewing the data would be the first level. However, if 
more detail is needed, highlighting a key word in the first level will provide the next level, which includes either more textural or graphical information. GUIDE provides four types of buttons:

- Notes--Note buttons are specific key words in the text that provide arbitrary levels of detail beneath them.

- Replacements--The replacement button is substituted with another piece of text or a graphic to expand on a point or serve as an additional explanation.

- Inquiry--Inquiry buttons allow the user to build a questionnaire that can expand for certain users but is limited to the major topics for others.

- Reference--Reference buttons move the display to another point in the same document or to a related item in a different guide document.

\section{c. HyperCard}

HyperCard can be described as a data base, graphic information manager, presentation program, programming language, information retrieval system, and an educational authoring system. HyperCard is a nontraditional data base management system that supports graphics and sound, as well as text. The programming language on the scripting level is called HyperTalk, which is an English-like language that allows the programmer to invoke the same command in different ways. HyperCard allows information to be organized by association and context as well as by hierarchy. It permits the creation of files of information that can be linked or cross referenced to other information.

The files, called stacks, are composed of screens of information known as cards. A stack is similar to an electronic rolodex full of screen-sized cards containing information. Cards may be connected so that the user can jump from one part of the data base to another by clicking on a button using the mouse. Stacks of interconnected cards created using HyperCard are referred to as stackware.

\section{d. NEXPERT OBJECT}

A hybrid expert system uses descriptions of objects in addition to rules. An object in an expert system is a collection of properties that the computer knows about each time the object is mentioned in the rules. NEXPERT OBJECT is a hybrid system tool that combines the knowledge components and their links and the rules of thumb (heuristics). NEXPERT OBJECT is based on the concept of knowledge design, which allows domain 
experts to be fully involved in the construction of a knowledge base. This is in contrast to the usual procedure of requiring both the knowledge engineer and the domain expert(s).

An object in NEXPERT OBJECT is an instance or a prototype, a structured description of an item corresponding to a precise reality. An object has a name and belongs to one of several classes. It has a set of properties (slots) to describe its qualities in symbolic or numerical terms and may also have sub-objects that constitute its components. For any given object, its class is a set of such objects, or a generalization, while the object to which it belongs (as a sub-object) is closer to a construction with which it shares a few properties.

\section{System Integration}

The objective of this plan is to integrate the automated optimization program, MicroDot, and the three-dimensional design space graphics with the demonstration Synthesis model SMALLCRAFT. Interface techniques to facilitate program communication will be developed that will use the multiple windowing and graphic capabilities of the Macintosh II workstation.

The knowledge base or heuristic component of the Design Environment will comprise three levels of knowledge cognition for the designer. These will include a Design Advisor, a Design Guide, and a Design Encyclopedia. The Design Advisor will be the expert system that makes the design decisions and advises the designer. The Design Advisor will be based on the use of NEXPERT OBJECT.

The Design Guide will provide succinct graphical and textural design information that has been extracted and organized in HyperCard stacks for ease of access. The designer will then browse through the stacks for specific design information, or to peruse for design ideas. As an example, the composite sandwich panel (skin/core) construction discussed by Becker [Ref. 62] in terms of specific design notes for producibility could be used.

The Design Encyclopedia would provide the designer with a cross-linked data base of technical reports, notes, articles, and texts on specific subjects. The designers would use this knowledge as background information to aid them in making design decisions. The Design Encyclopedia would be developed using GUIDE. 


\section{CONCLUSIONS AND RECOMMENDATIONS}

Producibility is the property of a product that determines if it is easily produced. Producibility can be applied to the manufacturing of single parts, assemblies of parts, and the manufacturing and assembly of entire products as complicated as jet aircraft. While producibility is not a specific science with governing laws, attaining producibility does require knowledge of both the design and the manufacturing processes. It requires that the individuals involved in design, procurement, and production all work together to produce the highest quality final deliverable at the lowest possible cost.

Achieving producibility requires that the manufacturing and design engineer work together as a team. While manufacturing engineers view productivity goals as an ideal way to measure the effectiveness of product design, design engineers may resent having a score applied to their design. Team members should recognize that producibility is simply good design practice that results in better designs, shorter development cycles, and lower costs.

The major conclusions are that producibility results in

- Simpler designs

- An improved engineering/manufacturing interface

- Product design leading to earlier design maturity in production

- Product designs of higher quality and reliability

- Lower production costs

- Shorter lead times

- A more inspectable and testable product.

Simpler designs mean fewer parts, less complex assembly operations, and lower fixturing costs. Improved interfaces mean better teamwork; early resolution of design, tooling, and process problems; and an improved design release package. Combined, these result in better quality and reliability. 
In summary, the recommendations of the IDA study team are

- The concepts of ease of manufacture or producibility must be integrated into the acquisition process starting with Concept Exploration or Demonstration/ Validation phases and must be continued through Final Design or Full Scale Development. This integration is commonly known as Simultaneous Engineering or Concurrent Design.

- Best Practices/Transition From Development to Production concepts are most appropriate during Full Scale Development.

- Producibility should be introduced into the aerospace vehicle design process at the Preliminary design level. The Conceptual design level module should be based on historical data for a specific design class.

- An ULCE Application Testbed should be based on the Synthesis Model architecture. A demonstration synthesis model/producibility module should be developed based on the design environment discussed in Section $F$ of Appendix A. 


\section{REFERENCES}

[1] Hagar, R.W., "The Technical Productivity Gap," Aeronautics and Astronautics, Vol. 21, May 1983, pp. 66-70.

[2] Welch, J.F., Jr., "Balancing the Scale Between Innovation and Manufacturability," The Bridge, Winter 1986, pp. 10-12.

[3] Torget, S.J., "Producibility Considerations in Production Planning for New Aircraft," SAE 710746, 1976.

[4] Brooks, D.T., "Designing for Producibility: Design-Influenced Production Cost Program," SAE 710747, 1971.

[5] Petronio, G., "Producibility in Design," SAE 710748, 1971.

[6] Military Handbook Design Guidance for Producibility (MIL-HNDBK-727), Army Materials and Mechanics Research Center, 5 April 1984.

[7] Department of Defense Directive 4245.6: Defense Production Managements Department of Defense, 19 January 1984.

[8] Alder, F.L., D.G. Adlucin, D.V. Glass, and R.A. Gunkel, "Program Management Guidelines for Producibility Engineering and Planning," Logistics Management Institute (Government Accession No. AD-A153730), January 1985.

[9] Gimigliano, R.F., "Producibility-The Road to Increased Productivity," $R C A$ Engineer, January/February 1983, pp. 25-28.

[10] Bogard, T.V., "Integrating Systems Producibility into the Design Process," Proceedings of the Second International Conference on Product Design for Manufacture and Assembly, Newport, RI, 6-8 April 1987.

[11] Tanner, J.P., "Manufacturing Engineering, An Introduction to the Basic Functions," Marcel Dekker, Inc., 1985.

[12] Howe, R., "Producibility/Machinability of Space-Age and Conventional Materials," American Society of Tool and Manufacturing Engineers, 1968.

[13] Cowie, W.D., E.E. Abell, and E.W. Horn, "A New Development Concept for Gas Turbine Engine Optimize Life Cycle Costs," Third International Symposium on Air Breathing Engines, 1976, pp. 27-38. 
[14] Design to Cost and Life Cycle Cost, AGARD Conference Proceedings No. 289, NATO Advisory Group, May 1980.

[15] Nelson, J.R. and F.S. Timson, "Relating Technology to Acquisition Costs: Aircraft Turbine Engines," Rand Corporation (R-1288-R) and NTIS (AD-780636), March 1974.

[16] "A New Method for Estimating Current and Future Transport Aircraft Operating Economics," American Airlines, NASA CR-145190 (No. N78-13027).

[17] Von Hamersveld, John, "Producibility Technology Studies-Supersonic Cruise Aircraft," Bicentennial of Materials Progress, Society of Advanced Materials and Process Engineering, Series Vol. 21, 1976, pp. 138-155.

[18] Sahata, I.F. and G.W. Davis, "Arrow-Wing Supersonic Cruise Aircraft Structural Design Concepts Evaluation," NASA Report No. CR-132575-1, August 1976.

[19] Nevins, J.L., T.L. DeFazio, R.E. Gustavson, R.W. Metzinger, J.M. Rourke, and D.S. Seltzer, "The Strategic Approach to Product Design," Charles Stark Draper Laboratory, Inc., December 1986.

[20] Group Technology Assessment, Case and Company, US Army Materiel Command (Government Accession No. AD-A152045), January 1985.

[21] Baer, T., "With Group Technology, No One Reinvents the Wheel," Mechanical Engineering, November 1985, pp.60-69.

[22] Schongerger, R., "Just-in-Time Production Systems: Replacing Complexity with Simplicity in Manufacturing Management," Industrial Engineering, October 1984, pp. 52-63.

[23] Willis, R.G., J.P. Piatt, and S. Dimitriyev, "An Analysis of Computer Integrated Manufacturing Technology, Benefits, and Strategies for the US Army Materiel Command," US Army Materiel Command (Government Accession No. ADA176754), December 1986.

[24] Elmaghraby, S.E., Y. Fathi, and W.G. Ferrel, "The Taguchi Approach to Quality Control and Enhancement: A Primer," US Army Research Office: Report No. ARO 22835.1-MA, November 1986.

[25] Logothetis, N. and A. Haigh, "Characterizing and Optimizing Multi-Response Processes by the Taguchi Method," Quality and Reliability Engineering International, Vol. 4, February 1988, pp. 159-169.

[26] Shanin, D. and P. Shanin, "Better Than Taguchi Orthogonal Tables," Quality and Reliability Engineering International, Vol. 4, February 1988, pp. 143-149.

[27] Box, G., S. Bisgard, and C. Fung, "An Explanation and Critique of Taguchi's Contributions to Quality Engineering," Quality and Reliability Engineering International, Vol. 4, February 1988, pp. 123-131. 
[28] Logothetis, N., "The Role of Data Transformation in Taguchi Analysis," Quality and Reliability Engineering International, Vol. 4, February 1988, pp. 49-61.

[29] QFD Results, Ernst and Whinney Company, Chicago, IL.

[30] Houston, A., J. Shettel-Neuber, and J.P. Sheposh, "Management Methods for Quality Improvement Based on Statistical Process Control: A Literature and Field Survey," Navy Personnel Research and Development Center (NTIS No. ADA169), June 1986.

[31] Manufacturing Management Handbook for Program Managers, Second Edition, Chapter 8, Defense Systems Management College, Fort Belvoir, VA, July 1984.

[32] Morley, I.E. and S. Pugh, "The Organization of Design: An Interdisciplinary Approach to the Study of People, Process and Contexts," International Conference on Engineering Design, Boston, MA, 17-20 August 1987.

[33] Pugh, S., "Further Development of the Hypothesis of Static Dynamic Concepts in Product Design," International Symposium on Design and Synthesis, Tokyo, 11 13 July 1984.

[34] Pugh, S., "Total Design, Partial Design: A Partial Reconciliation," International Conference on Engineering Design, Boston, MA, 17-20 August 1987.

[35] Pugh, S., "Design Activity Models: Worldwide Emergence and Convergence," Design Studies, Vol. 7, No. 3, July 1986.

[36] Luby, S.C., J.R. Dixon, and M.K. Simmons, "Creating and Using a Features Data Base," Computers in Mechanical Engineering, November 1986, pp. 25-33.

[37] Dixon, J.R. and M.K. Simmons, "Expert Systems for Mechanical Design: A Program of Research," American Society of Mechanical Engineers, Paper No. 85DET-78, 1985.

[38] Dixon, J.R., C.D. Jones, E.C. Libardi, S.C. Luby, and E.H. Nielson, "Knowledge Representation in Mechanical Design Systems: Issues and Examples," Society of Automotive Engineers, No. 860335, 1986.

[39] Dixon, John R., Adele Howe, Paul R. Cohen, and Melvin K. Simmons, "DOMINIC I: Progress Toward Domain Independence in Design by Iterative Redesign," Engineering with Computers, Vol. 2, 1987, pp. 137-145.

[40] Ovelup, Mark F., John R. Dixon, and Melvin K. Simmons, "DOMINIC II: More Progress Towards Domain Independent Design by Iterative Redesign," Proceedings of the ASME Winter Annual Meeting, Boston, MA, 13 December 1987.

[41] Devoi, F.E., "Design for Manufacturability," Proceedings of the Second International Conference on Product Design for Manufacture and Assembly, Newport, RI, 6-8 April 1987. 
[42] Johnson, V.S., "Life Cycle Cost in the Conceptual Design Process," AIAA, Paper No. 87-2889, September 1987.

[43] Best Practices-How to Avoid Surprises in the World's Most Complicated Technical Process-The Transition from Development to Production, Reliability, Maintainability, and Quality Assurance Directorate, Department of the Navy, NAVSO P-6071, March 1986.

[44] Transition from Development to Production (DoD Directive 4245.7M), US Department of Defense, Research and Engineering, September 1985.

[45] Why Some Weapon Systems Encounter Production Problems While Others Do Not: Six Case Studies, Comptroller of the United States, General Accounting Office (GAO-NSLAD-85-34), May 1985.

[46] Cabuk, J.G., T.J. Duncan, I.L. Hoffman, and D.V. Nowlin, "Identification of Bottlenecks and Capacity Constraints," Defense Logistics Agency, No. AD-A134629, Alexandria, VA, April 1983.

[47] Producibility Engineering and Planning, US Army Materiel Command Regulation DARCOM-R-70-6, 21 June 1983 (now undergoing revision).

[48] Defense Production Management, Department of Defense Directive 4245.6, Department of Defense, 19 January 1984.

[49] Boothroyd, G. and P. Dewhurst, "Product Design for Assembly," Boothroyd Dewhurst, Inc., 1987.

[50] Miyakawa, S. and T. Ohashi, "The Hitachi Assemblability Evaluation Method (AEM)," Proceedings of the International Conference of Product Design for Assembly, Newport, RI, 15-17 April 1986.

[51] Boothroyd, G. and P. Dewhurst, "Product Design for Manufacture and Assembly," Proceedings of the Third International Conference of Product Design for Manufacture and Assembly, Newport, RI, 6-8 June 1988.

[52] Hawisczak, R., "Integrating Producibility Tools into a CAE Design Environment," Proceedings of the Third International Conference of Product Design for Manufacture and Assembly, Newport, RI, 6-8 June 1988.

[53] Heragu, S. and A. Kusiak, "Analysis of Expert Systems in Manufacturing Design," IEEE Transactions on Systems, Man, and Cybernetics, Vol. SMC-17, No. 6, November/December 1987, pp. 898-912.

[54] Noton, B.R. and R.R. Preston, "ICAM Manufacturing Cost/Design Guide (MC/DG) Background, Metallic and Nonmetallic Demonstration Sections," 26th National - -LMPE (Society of Advanced Materials and Process Engineering) Sympe iu , 28-30 April 1981, pp. 593-600. 
[55] Decision Support Requirements in a Unified Life Cycle Engineering (ULCE) Environment, Volume I: An Evaluation of Potential Research Directions, ULCE DSS Working Group, IDA Paper P-2064, May 1988.

[56] Beltraamo, M.N. and M.A. Morris, "Application of Parametric Weight and Cost Estimating Relationships to Future Transport Aircraft," SAE Paper 1292, 1979.

[57] Stoessel, R.R., "A Proposed Standard Method for Estimating Airline Indirect Operating Expense," Lockheed-Georgia Company, LW70-500R, May 1970.

[58] VanHamersveld, J., "Producibility Technology Studies-Supersonic Cruise Aircraft," Bicentennial of Materials Progress, SAMPE, V-21, 1976, pp. 138-155.

[59] Sakata, I.F. and G.W. Davis, "Arrow-Wing Supersonic Cruise Aircraft Structural Design Concepts Evaluation," NASA, Report No. CR-132575-1, August 1976.

[60] Shebanow, A.G., "Mac II vs. SUN-3/60," MacWorld, February 1988, pp. 164 169.

[61] Borkin, H., "Mac II vs. Apollo DN/3000," MacWorld, February 1988, pp. 170174.

[62] Becker, W., "Designing Composites for Producibility," SAE, No. 850903, 1985.

[63] Manufacturing Technology Program, DoD Instruction 4200.15, 24 May 1985.

[64] Design to Cost, DoD Directive 4245.3, 6 April 1983.

[65] Production Readiness Reviews, DoD Instruction 5000.38, 24 January 1979.

[66] Industrial Modernization Incentives Program (IMIP), DoD Directive 5000.XX. 
Appendix A

DESIGN SYNTHESIS 


\section{DESIGN SYNTHESIS}

Design is defined as the arrangement of elements that obey laws so that an environment is created in which elemental interactions produce a desired result. Employed in the design process are synthesis and analysis. Synthesis may be described as the creative or divergent phase, where a fitting together of parts or separate concepts takes place to produce an integrated whole. Analysis is an examination of a complex system, its elements, and their interactions.

\section{A. AEROSPACE SYSTEM DESIGN}

In the engineering sense, the term "design" has many interpretations. Engineering design may be thought of as the arrangement of elements that make up a machine or other man-made system. Gillmer [Ref. A-2] describes design as "a total creative process that progresses from an original concept to its final reality ... design must always be a unified procedure with the sole purpose of interpreting and communicating the basic concept, however simple or complex, to the builder." The following five stages of design are considered during the traditional aerospace design process:

(1) Feasibility Studies establish cost/performance trends, i.e., cost of speed, endurance, payload, etc.

(2) Conceptual Design considers trade offs at the aircraft design level.

(3) Preliminary Design focuses on the subsystem level.

(4) Contract Design deals with definition of the aircraft for the builder.

(5) Detail Design entails preparation of working drawings and numerical control (NC) tapes.

The process of rational aerospace design is traditionally exemplified by the design spiral concept developed by Evans [Ref. A-3]. The design progresses in an orderly fashion through a system of technologies that address each aspect of the aerospace system's geometry and performance. In this concept, the design process, which is iterative by nature, moves in a spiral fashion to a balanced conclusion. The various system 
technologies that are adoressed, as well as the phases of aerospace system design, are shown in Figure A-1.

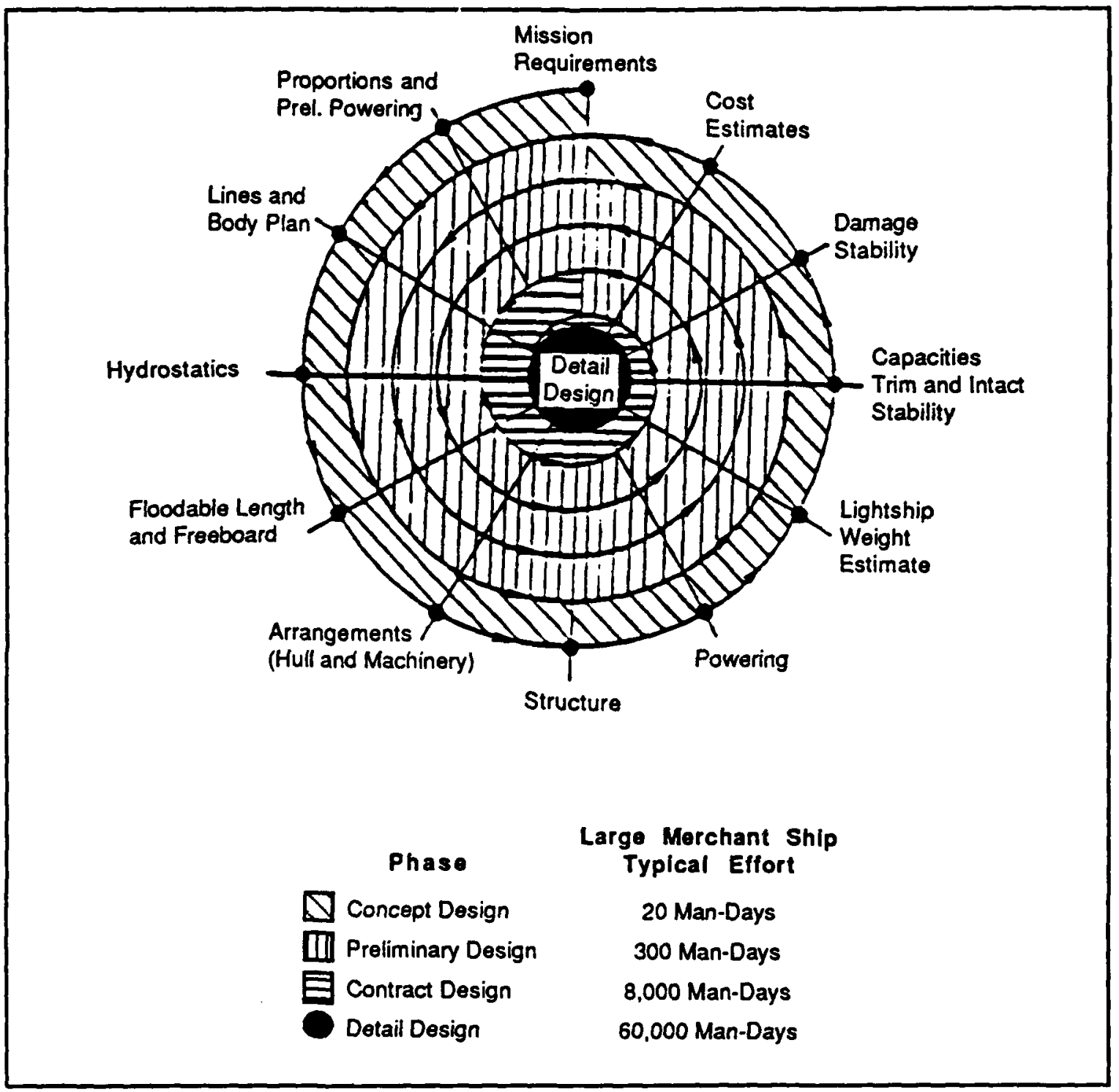

Figure A-1. Evan's Design Spiral

Andrews [Ref. A-4] proposes a design spiral concept in which the traditional design spiral is seen as a section through a conical solid (Figure A-2). In this concept, the many constraints on the designer can be shown as fundamentally affecting the design process. Andrews' three-dimensional design spiral concept includes the time required to progress through the spiral to completion--the axial coordinate represents time. Evan's 


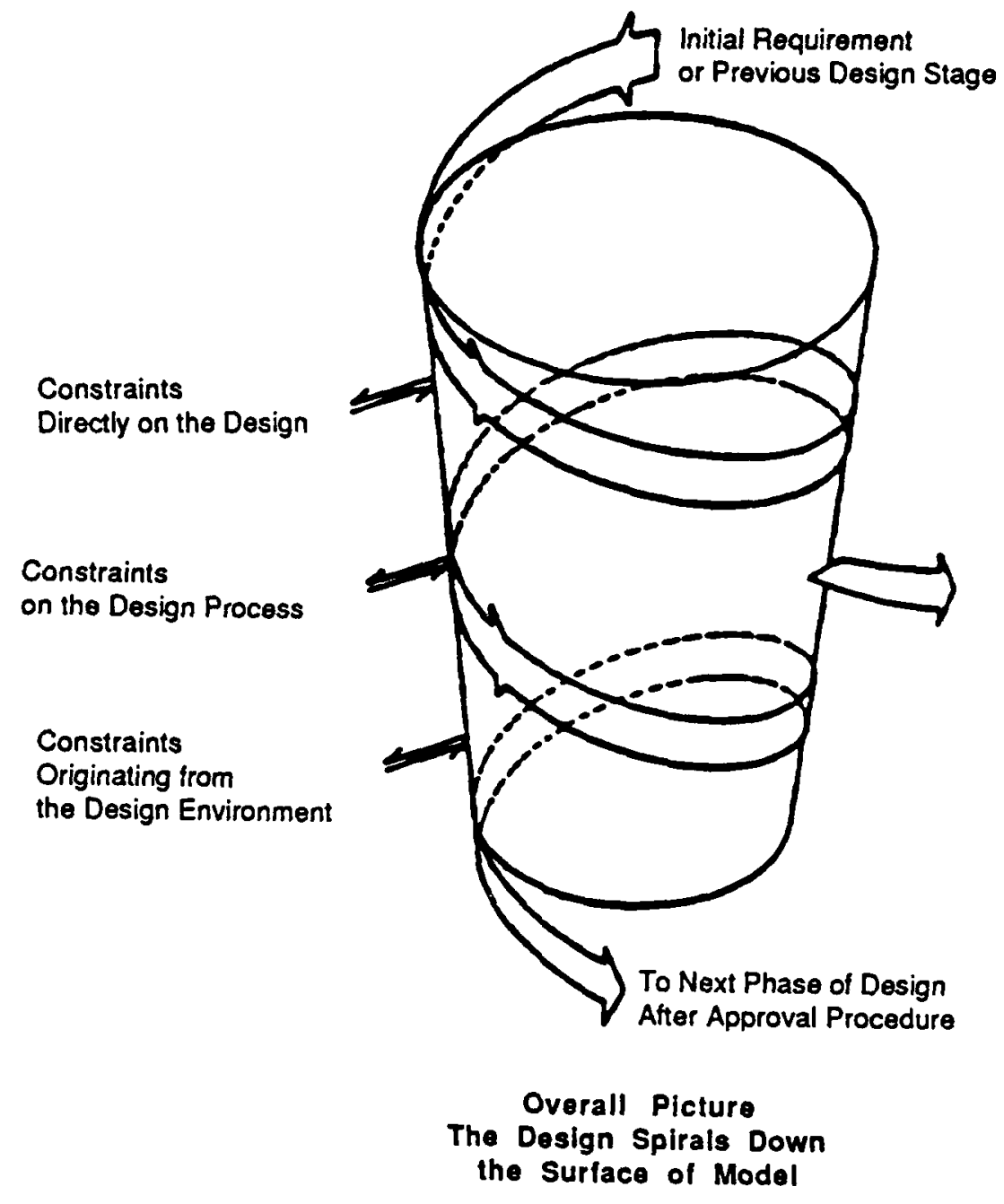

\section{Figure A-2. Andrews' Three-Dimensional Design Spiral}

model does not include this feature. Any efforts to increase the efficiency of the aerospace designer during the design process will result in a decrease in the time coordinate, thus resulting in an increase in productivity.

\section{B . SYNTHESIS MODEL ARCHITECTURE}

Synthesis models are computer programs with architecture that emulates the design process; that is, they comprise both synthesis and analysis aspects. Synthesis model technology has developed historically in the marine and aeronautical industries. The design 
of an aircraft or ship is a well-defined exercise in systems design. Synthesis models have been developed that combine aspects of geometry synthesis (CAD) and performance analysis (CAE). These synthesis models, which address the feasibility study and conceptual design phases, are used to evaluate or estimate ship or aircraft characteristics.

\section{Aeronautical Synthesis Models}

The following paragraphs describe synthesis models developed in the aeronautical industry:

The General Aviation Synthesis Program (GASP) was developed at the National Aeronautics and Space Administration (NASA) Ames [Ref. A-5]. GASP has an interactive graphics capability, with specific parameters for defining the aircraft geometry used as the input to the program. GASP has five analysis modules including aerodynamics, propulsion, weight and balance, mission performance (taxi, take off, climb, cruise and landing), and economics.

The Aerospace Vehicle Interactive Program (AVID) includes an executive program with a communication database [Ref. A-6]. AVID comprises six technology/utility programs that may be executed individually or linked in the automatic sequence mode. These programs include graphics, mass/sizing, aerodynamics, propulsion, flight performance, and economics.

The Configuration Development System (CDS) is an interactive graphics aircraft design, analysis, and loft program for the development of three-dimensional geometry [Refs. A-7, A-8, A-9]. CDS allows the designer to rapidly build aircraft concepts and provide sufficient three-dimensional information required for analysis. The system stores all surface and internal components as three-dimensional shell bodies of arbitrary shape defined by stacked parallel cross sections. Geometry primitives, such as the fuselage and wing, allow the user to create these entities with only one section defined and a few global parameters, such as fineness ratio, nose area, and tail area. Biquartic surface patch mathematics are employed for smooth, lofted components.

For irregularly shaped components, CDS stores actual surface points. The component data bank contains such primitives as engines, ejection seats, weapons, landing gear types, radars, and airfoils. CDS, which is used for conceptual design only, may be interfaced with analysis programs including a wave drag calculation and optimization 
module, an aerodynamic preliminary analysis module, a weight, balance and inertial module, a cost module, a mission-sizing module, a tail-sizing module, and a tire- and strutsizing module. CDS may also be interfaced with outside analysis programs such as NASTRAN.

The Naval Airship Program for Sizing and Performance (NAPSAP) was developed for the preliminary design and performance analysis of lighter-than-air vehicles such as rigid airships and conventional Zeppelin types [Ref. A-10]. NAPSAP comprises seven modules (subroutines) including initialization, atmospheric characteristics, vehicle sizing and geometry, aerodynamic characteristics, propulsion system sizing, total vehicle weights, and generalized vehicle performance. Program options include sensitivity studies, mission profile analysis, and parametric design variable studies. The initialization module is used to size the vehicle and determine its overall physical and geometrical characteristics.

The Space Vehicle Configuration Development System (SVCDS) is an extension of CDS, developed by Rockwell for the Air Force Flight Dynamics Laboratory [Ref. A-11]. SVCDS was developed for the three-dimensional geometry creation and layout of space vehicles. It was used to simulate systems operations for the evaluation of human factors considerations. Three modules within SVCDS include geometry, display, and rapid analysis.

The Hypersonic Aerospace Vehicle-Synthesis Program Integration (HAV-SPRINT) is used for hypersonic vehicle sizing and sensitivity studies [Ref. A-12]. Six technology modules include Configuration, Weights, Aerodynamics, Propulsion, Aerothermodynamics, and Trajectory analysis. The user may select any module and combine them in any order to perform a number of functions including iteration constraint and optimization. The program may be used to develop a configuration defined in three-view form to compute the required geometrical information based on a description of the input shape distribution of the fuselage.

The first generation of Preliminary Design Tools (PD Tools), developed by Mitchell, are used for air-to-air integral rocket-ramjet missiles, single-stage, solid rocket surface-to-surface missiles, and miniature kinetic-energy interceptors [Ref. A-13]. The first generation of PD Tools do not incorporate CAD; however, the second generation does. The second generation PD Tools include a module GEOGEN which is used for geometry generation as a front end for a commercial mechanical CAD (MCAD) program [Ref. A-14]. The MCAD program in turn allows the development of three-dimensional 
solids models. The resulting geometric data can also be transferred to CAE programs, such as a commercial finite element modeler (FEM). A second program TECGEN provides the link between design and analysis. It serves as a front end to a domain of CAE programs including AERGEN, an aerodynamics generator; MAPGEN, a mass properties generator; and FEMGEN, a finite element model generator.

\section{Generic Synthesis Model Architecture}

An examination of the technology modules that make up the various synthesis models in the aerospace field indicates that the architectures of each are similar. Three basic components comprise the aeronautical and marine synthesis models--initialization, synthesis, and analysis [Figure A-3]. The initialization component is based on a data base of prior designs. They are used to develop parametric relations that enable the designer to make initial estimates of design parameters such as the geometry form parameters, weights, and vehicle sizing. The synthesis component builds on the initialization component, by allowing the designer to modify the initial parameters that define the geometry configuration or to develop the exterior geometry from the beginning, as in the CDS model. The analysis component then evaluates the performance state of the synthesized design through the various technology modules.

Table A-1 compares the aeronautical synthesis models by technology module breakdown. It should be noted that not every synthesis model has each of the technology modules shown in Figure A-3 for the aeronautical synthesis model. Also two of the models, CDS and PD Tools, are heterogeneous in that they also interface to application programs outside of their basic structure, such as a CAD and a FEM program. The marine synthesis models are similar (Figure A-3), but with their own distinct technology modules. Without exception, they are all homogeneous in architecture.

A logical extension of the synthesis model is automated design, wherein the computer is used to find an optimum. The optimization code allows the designer to make trade offs and reduces the number of iterative cycles in the design spiral. Although the information generated is helpful, the output will still be simply a number that the designer can accept or reject. The automated process is ultimately efficient only if the designer can recognize the optimum. While the optimization code handles the numerical aspects of the problem, computer graphics are needed to help the designer visualize the process. 


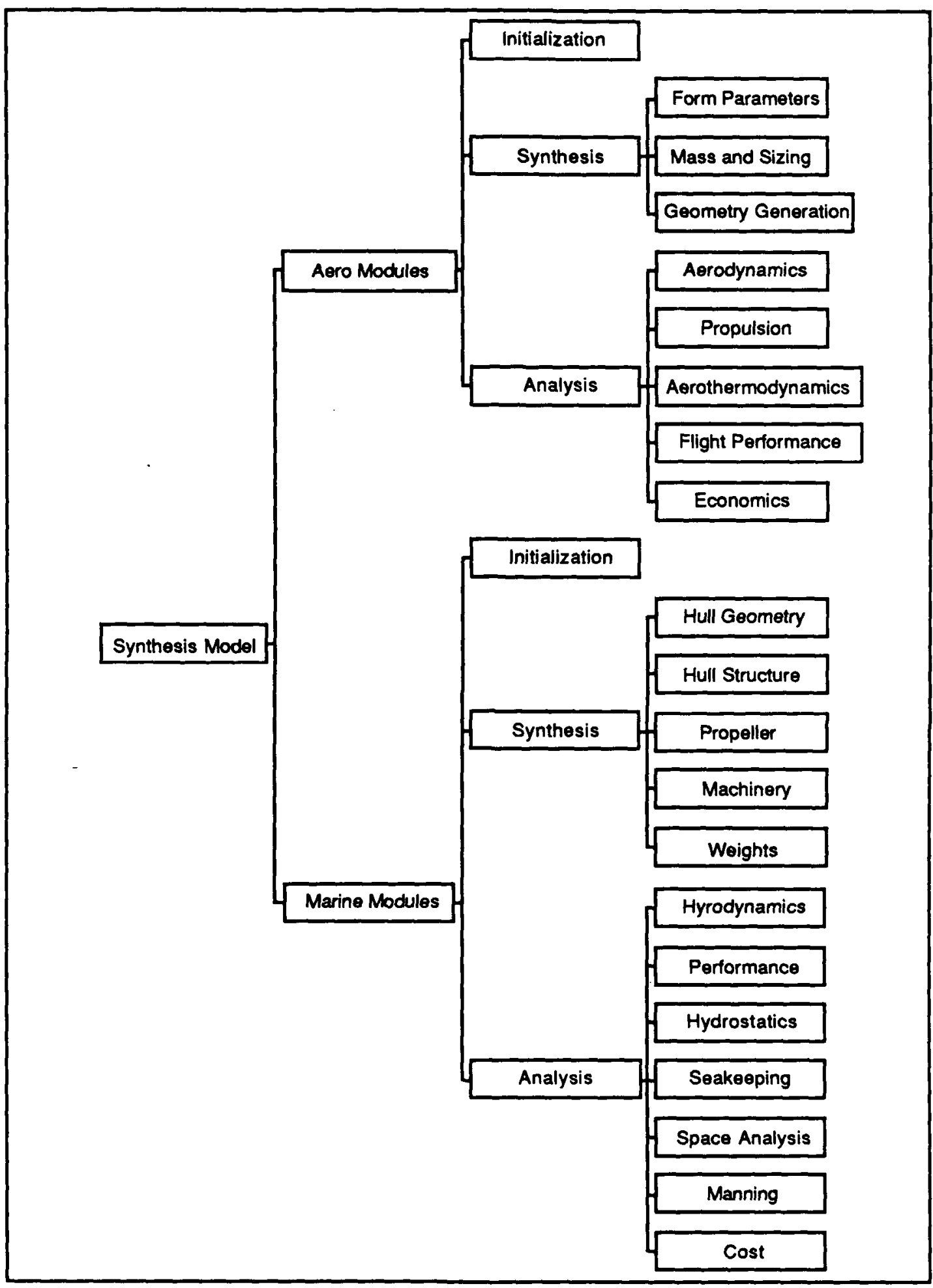

Figure A-3. Aeronautical and Marine Synthesis Models 
Table A-1. Aeronautical Synthesis Model Architecture

\begin{tabular}{|c|c|c|c|c|c|c|c|}
\hline TECHNOLOGY & GASP & AVID & $\cos$ & NAVSAP & SVCDS & HAV-SPRINT & PD TOOL \\
\hline INITIALIZATION & & & & $x$ & & & \\
\hline $\begin{array}{l}\text { SYNTHESIS } \\
\text { Form Parameters } \\
\text { Mass and Sizing } \\
\text { Geometry Generation }\end{array}$ & $\begin{array}{l}x \\
x\end{array}$ & $x$ & $\begin{array}{l}x \\
x\end{array}$ & $\begin{array}{l}x \\
x \\
x\end{array}$ & $\begin{array}{l}x \\
x\end{array}$ & $\begin{array}{l}x \\
x\end{array}$ & $\begin{array}{l}x \\
x\end{array}$ \\
\hline $\begin{array}{l}\text { ANALYSIS } \\
\text { Aerodynamics } \\
\text { Propulsion } \\
\text { Aerothermodynamics } \\
\text { Flight Performance } \\
\text { Economics }\end{array}$ & & $x$ & $\begin{array}{l}x \\
x \\
x \\
x\end{array}$ & $\begin{array}{l}x \\
x \\
x \\
x\end{array}$ & $\begin{array}{l}x \\
x \\
x \\
x\end{array}$ & $\begin{array}{l}x \\
x\end{array}$ & $\begin{array}{l}x \\
x \\
x \\
x\end{array}$ \\
\hline $\begin{array}{l}\text { FINTTE ELEMENT } \\
\text { MODELING (FEM) }\end{array}$ & & & $x$ & & & & $x$ \\
\hline $\begin{array}{l}\text { COMPUTER-AIDED } \\
\text { DESIGN (CAD) }\end{array}$ & & & $x$ & & & & $x$ \\
\hline
\end{tabular}

\section{CURRENT TECHNOLOGIES FOR DESIGN}

\section{Computer-Aided Technology}

Computer-aided technology uses interactive computer graphics and database management techniques for the design process. It is generally considered to comprise four major areas, including CAD, CAE, drafting, and manufacturing. Of importance to the synthesis model are the following:

\section{a. Computer-Aided Design}

Computer-Aided Design (CAD) is the process of geometric modeling, including the conception and synthesis of a system, such as an aircraft, using interactive graphics techniques to display and view the design. Three-dimensional wire-frame models are the typical display format, with fully shaded color raster models a developing alternative. The designer describes the shape of a structure with a geometric model constructed graphically on the CRT screen. The representation is based on a mathematical model that is stored in the computer database for later use. The model may be used for other CAD functions, or it may be recalled and refined by the engineer at any point in the design process. 


\section{b. Computer-Aided Engineering}

Computer-Aided Engineering (CAE) is the engineering analysis of the design concept or geometric model, which was created using CAD. With keyboard commands, the user may have the computer calculate, for example, weight, volume, surface area, moment of inertia, or center of gravity of a part. Other analyses might include stresses and deflections, surface pressures and velocities, and system time and frequency domain dynamics. Computer-Aided Technology is related to the engineering design process. CAD is used in the the design concept formulation synthesis stage, while CAE is used in the evaluation and optimization and presentation stage.

Advanced technologies that may be integrated into the design process include the High Level Computer Graphics (HLCG) enhanced user environment, automated optimization design techniques, supercomputers, and knowledge-based systems. These technologies are not yet available in commercial CAD/CAM systems; however, applications research continues and to some extent they are beginning to appear in the marketplace.

\section{High Level Computer Graphics User Environment}

Advances in computer graphics hardware have produced new methods for portraying complex processes, data, and spatial relationships in new forms [Ref. A-15]. Computer graphics workstations are able to render complex images in real or near real time. These images can be of three-dimensional spaces, such as the exterior geometry of an aircraft; they can show the interactions of several variables in complex dynamic processes, such as the aerodynamic pressures on an aircraft hull surface; or they might present an interpretation of data.

HLCG are characterized by the following capabilities of the real time manipulation of realistically rendered images of three-dimensional cbjects:

- Ability to display three-dimensional objects

- Real-time image manipulation of the three-dimensional objects

- Color-shaded object surfaces

- Icon-driven user interfaces

- Multiple window operating environment.

The advent of sophisticated computer graphics hardware and graphics software techniques offers several advantages. The use of a computer graphics-based interface 
between the user and computer program eahances the transfer of information to the user, allowing the user to assess, assimilate, and analyze multiple channels of information. By accelerating information transfer, a computer graphics-based interface also allows the designer to evaluate more options in less time; the design time is made more productive. In addition, the visual representation of input data often provides the user with the means to detect and correct data input errors far more readily than tabular output.

Graphics interfaces generally operate in an interactive environment, which can assist users in pursuing creative and intuitive possibilities (or even guesses) without the distractions and loss of concentration that would occur in a slower batch-oriented mode of computer utilization. The usefulness of an interactive computing environment and computer graphics to increase the transfer of information to the user has been frequently asserted and almost universally accepted; in addition, research efforts have been conducted that lend scientific validity to this claim [Ref. A-16].

\section{Automated Optimum Design}

In automated optimum design, the computer is used for as much of the design process as possible to reduce the man-machine interface to a minimum [Ref. A-17]. If the design concept, design constraints, and optimization goals are clearly established and can be stated in quantitative form, the design process can be represented in the form of a mathematical programming problem. The innermost cycle of the design process can be programmed for solution by the computer.

Optimizing the design process requires an objective function, which is some defined figure of merit used to choose from among alternate designs and constraints. The constraints may be regarded as limits to be imposed on the design and result from physical laws and limitations or compatibility conditions on individual variables. They include functional constraints, which result from relations among the design variables, regional constraints, which are imposed by the specific details of the problem, and an analytical method, which requires the definition of the mathematical equations and techniques to be used.

\section{Supercomputers/Parallel Processing}

The supercomputer offers a significant increase in processing speed through the combined advantages of multiprocessing and multitasking, which improve the execution 
time of computer programs. Multitasking permits the partitioning of a program among multiple processors, enabling different parts to execute at the same time. The effectiveness of the multitasking is a function of the number of central processors available, the degrce of parallel processing in the program, and the overhead inherent in multitasking. Typical supercomputer applications include computational fluid mechanics, structural engineering, and mechanical engineering.

\section{EMERGING TECHNOLOGIES FOR DESIGN}

The following sections describe some emerging technologies, tools and techniques that have application potential for integration into the design process.

\section{Design Support Systems}

The concept of a design support system has been explored by Rouse [Ref. A-21], who examines whether knowledge-based systems can be developed to enhance rather than hinder the designer's creativity. Rouse does not define creativity; instead he attempts to determine how creative behavior can be supported. Characterization of those behaviors associated with individuals judged to be creative provides a basis for defining the functionality of a design support system. Individuals judged to be creative tend to mix algorithmic reasoning and heuristic searching. They also combine conceptual thinking and graphic coding. Rouse proposes the following conceptual requirements for a design support system:

- Provide access to information across disciplines (multiple databases)

- Provide access to information across individuals (networking)

- Support multiple modes of thinking (graphic and algorithmic utilities)

- Support pursuit of multiple solutions (windowing and pull-down menus)

- Provide sense of ownership of design solutions (open-ended advice rather than narrow prescriptions).

Monaghan discusses a support system that represents knowledge of the conceptual design process. The following knowledge would be required:

- Domain--Knowledge of subsystems and components. Domain knowledge is classified into a hierarchy of subsystems and components into which successive levels of detail are introduced. Heuristic search techniques are used for exploration. 
- Constraint--Constraints imposed by standards and regulations. Constraints describe the requirements that must be satisfied in the final design.

- Procedural--Knowledge of the design procedure. The fundamental parts of the design process are the selection and/or addition of components. These are not independent processes, and the selection of components depends on the state of the developing system.

- Analysis Algorithms--Knowledge of how to evaluate and analyze developing and final solutions. The analysis algorithms are used for analyzing, evaluating, and comparing the performance of the developing and final solutions.

- Solution--Knowledge of the developing solution(s). Graphical and textural descriptions are used to represent the developing system.

These foregoing approaches to knowledge representation are modular and hierarchical. The decisionmaking procedures at nodes within a hierarchy and the condition/ action format of the procedural and constraint knowledge is suitable for implementation in production rules.

Popplestone [Ref. A-23] describes the development of a design support system that is visualized as an animated textbook with a catalog collection. The design support system would have the following elements:

- A history of the engineering domain supported by the design support system, referred to as the Encyclopedia. The knowledge forms in the Encyslopedia are classed as

- English (symbolic to English translator)

- Tabular (empirical)

- Graphical

- Mathematical, such as algebra (not procedural knowledge)

- Heuristic (mathematical constraints that are flagged as being advisory rather than mandatory)

- A means of creating a design description document that contains information relevant to a particular design activity.

\section{Object-Oriented Programming}

Object-oriented programming is a technique that allows hierarchies of classes of objects with similar attributes and characteristics to be constructed. These objects may have 
the common family characteristics, and characteristics that distinguish one object from other objects in the family. Object-oriented programming is used to distinguish generic parts and components. Models of the design are made up of descriptions of parts and objects, rules and formulas, and any kind of relationship that determines attributes.

An object is an intelligent package of programming code (software) and descriptive data that completely describes a physical object and its relationship with the physical world. An object-oriented data structure is developed through the definition of classes and subclasses of objects. Individual objects contain all of the intelligence defined by class above the object in the hierarchy. Because of inheritance, new objects can be created that are specializations of other objects and that automatically contain all of the intelligence and features inherent in the original object. Applications may be developed by taking advantage of previously developed objects and all of the intelligence inherent in them. Modular program design allows programs to be modified and enhanced without affecting other parts of the program. All modifications are made to objects and the relationships contained within them.

The control of the configuration geometry of an aircraft requires an appropriate representation of the design configuration through a modeling of its components and subcomponents. Object-oriented programming techniques offer this representation [Ref, A-24]. An object-oriented representation of the configuration of an aircraft is described by Kolb [Ref. A-25], while an object-oriented representation of the aircraft analysis process is developed by Elias [Ref. A-26]. An object-oriented description of an aerospace system would provide the ability to rapidly implement design changes, while maintaining a consistent configuration.

\section{Coupled Symbolic/Procedural Knowledge-Based Systems}

Mitchell describes a knowledge-based system called the Expert Designer [Ref. A-13]. The Expert Designer integrates three systems: Expert Executive, Technology Information Management Expert, and Expert Menu Interface to Design.

The Expert Executive reasons how to solve a design and analysis problem from the knowledge available on relevant $\mathrm{CAD}$ and $\mathrm{CAE}$ resources. It then manages the sequence it has drawn up of program executions and data input-output flow until the problem is solved. The Technology Information Management Expert, a "smart" catalog of CAD and CAE resources, communicates with the Expert Executive or directly with the user. The 
Expert Menu Interface, a "smart" engineering handbook, stores deeper engineering knowledge on design and analysis required to aid engineers who use the Expert Designer.

The integration of knowledge-based expert systems with aircraft design technology codes is further discussed by Mitchell and Chalfan [Ref. A-27] and Chalfan [Ref. A-28]. The design analysis of an aerospace vehicle within an organization is usually fragmented among numerous CAE programs, such as those for weight, aerodynamics, propulsion, and flight performance. The Expert Executive (EE), a program that integrates large computational programs (technology codes), was developed at Boeing Computer Systems to integrate these functions. Symbolic computing offers a new approach to the problem of integrating the technology codes. Kitzmiller [Ref. A-29] describes a class of coupled software systems that integrate knowledge-based and numerical processes into a single unified program. The coupled or hybrid system architecture forms the basis of the EE.

Given the facts about the input/output structure of the relevant CAE programs, and the locations of the executable programs, the system understands the objectives of the analyst and executes the programs necessary to analyze the design. The Expert Executive uses the following paradigm:

To run a program, if all the inputs are present, execute the program and return the result. Otherwise find all the required input variables whose values are not known and consult the analyst for starting values. Then, if all the needed inputs are still not present, but are there in another program, the outputs of which provide the missing inputs, run that program first. [Ref. A-29]

Dannenhoffer [Ref. A-30] also describes a hybrid or coupled system that is applied to computational fluid dynamics problems. At the center of the hybrid system is the database that contains all of the information to be shared among the procedures. Typically, the data consist of global parameters that describe the current problem state, as well as arrays that describe distributions. A number of independent procedures that are algorithmic and numeric surround the database. The expert system controls the flow of execution through the system, passing control information out of the various procedures.

\section{Decomposition Techniques}

A multifaceted decomposition of a nonlinear constrained optimization problem describing the preliminary design process has been made by Rogan [Ref. A-31]. Decomposition techniques are used to define the elements of the design process (design 
tasks or subproblems) and the interfaces between these elements. It is shown that the decomposition techniques define how the iteration inherent in the design process is to be performed. The design process decomposition is used to plan, schedule, and control the design effort so that system integration is achieved.

The technique, called linear decomposition, is an iterative scheme for converging a network of design optimization subproblems, which was developed by Sobieski [Ref. A-32]. Sobieski [Ref. A-33] has suggested that linear decomposition may be used to iterate through the system hierarchy, using reoptimization with optimal sensitivity constraints to resolve conflicting design requirements between system elements.

\section{Hypertext (Hypermedia)}

Hypertext is an interactive system in which text and graphics are dynamically linked in electronic documents. Hypertext manages information in a multisequential way, in contrast to the traditional manner of presenting information in an orderly sequence of ideas. The concept of Hypertext was developed by Nelson [Ref. A-34] as a means of linking information in an interconnected system. Electronic documents in hypertext are designed to be read directly from the screen without the limitations of paper and page formats.

Hypermedia is information processing in forms that go beyond the traditional list and database report methods. Following a predetermined organization scheme when searching for information is no longer required; instead, one can branch instantly to related facts. A hypermedia program allows the user to establish, maintain, and use such sets of linked data. The term hypermedia is used, rather than hypertext, because the data need not be limited to text. The data may be graphical, sound, photographic, or a video from a video disk or CD ROM. The CD ROMs will make hypermedia programs particularly useful by permitting the storage of literally hundreds of megabytes of data possible on a workstation. Hypermedia will provide the pathway through this information.

\section{E. SYNTHESIS MODEL DESIGN ENVIRONMENT ARCHITECTURE}

\section{Design Environment}

A design support system would include a system of hardware, software, and knowledge or intelligence into a total design environment (Figure A-4). The emerging technologies for design provide the basis for developing this design environment. The 


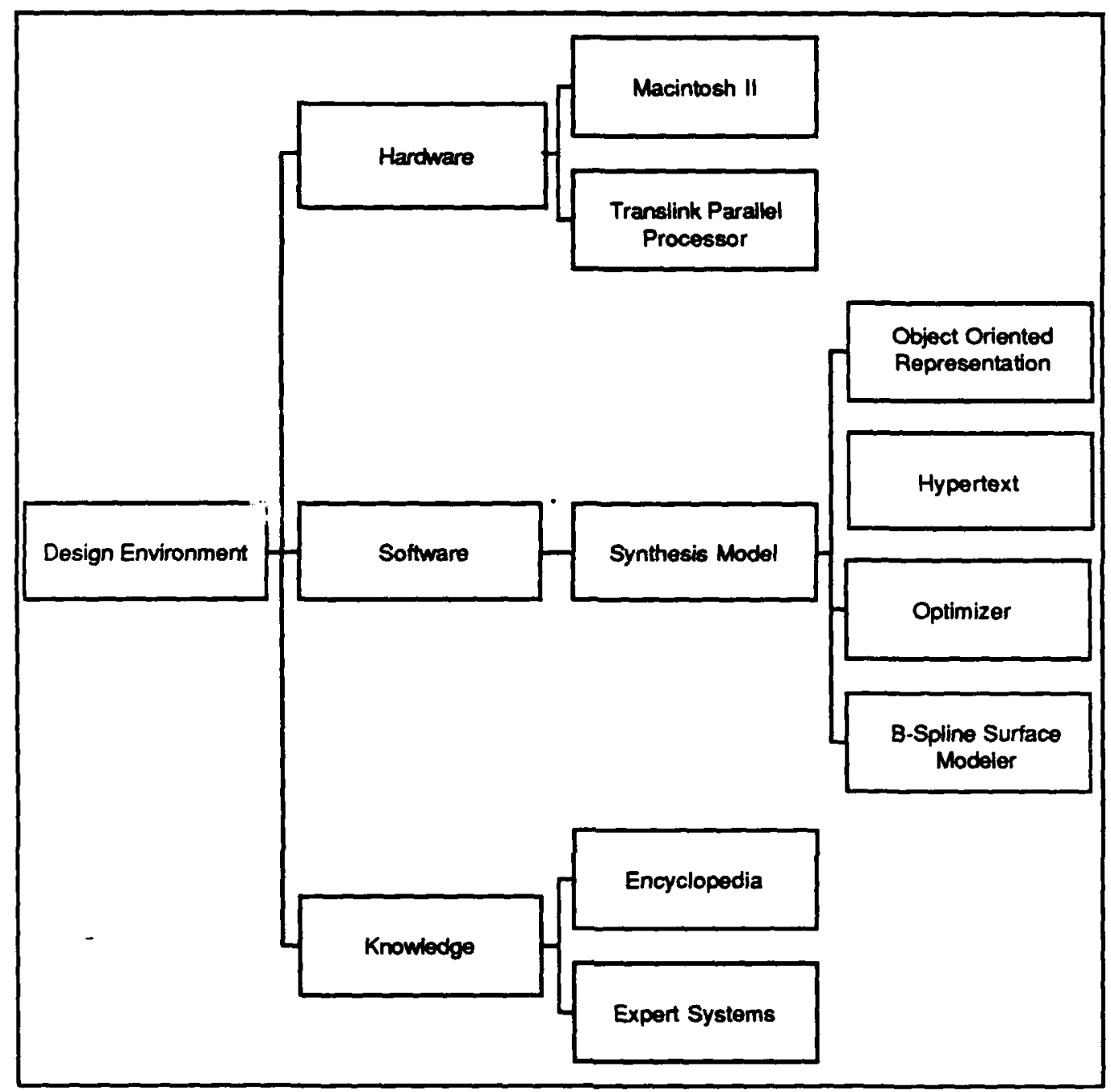

Figure A-4. Design Environment for the Designer

kernel of this design environment would be the synthesis model procedural algorithm, which provides the knowledge base for the actual design process. A proposed generic synthesis model for ship design is shown in Figure A-5. The flow chart is structured to represent the computational time flow through the synthesis model.

The initialization module may provide the incipient configuration design based on past design experiences embedded in the historical database. Geometry form parameters and mass and sizing define this design. The designer then has the option of generating a hull form geometry from the beginning using the three-dimensional geometry generation program. The high level computer graphics interface environment provides the designer 


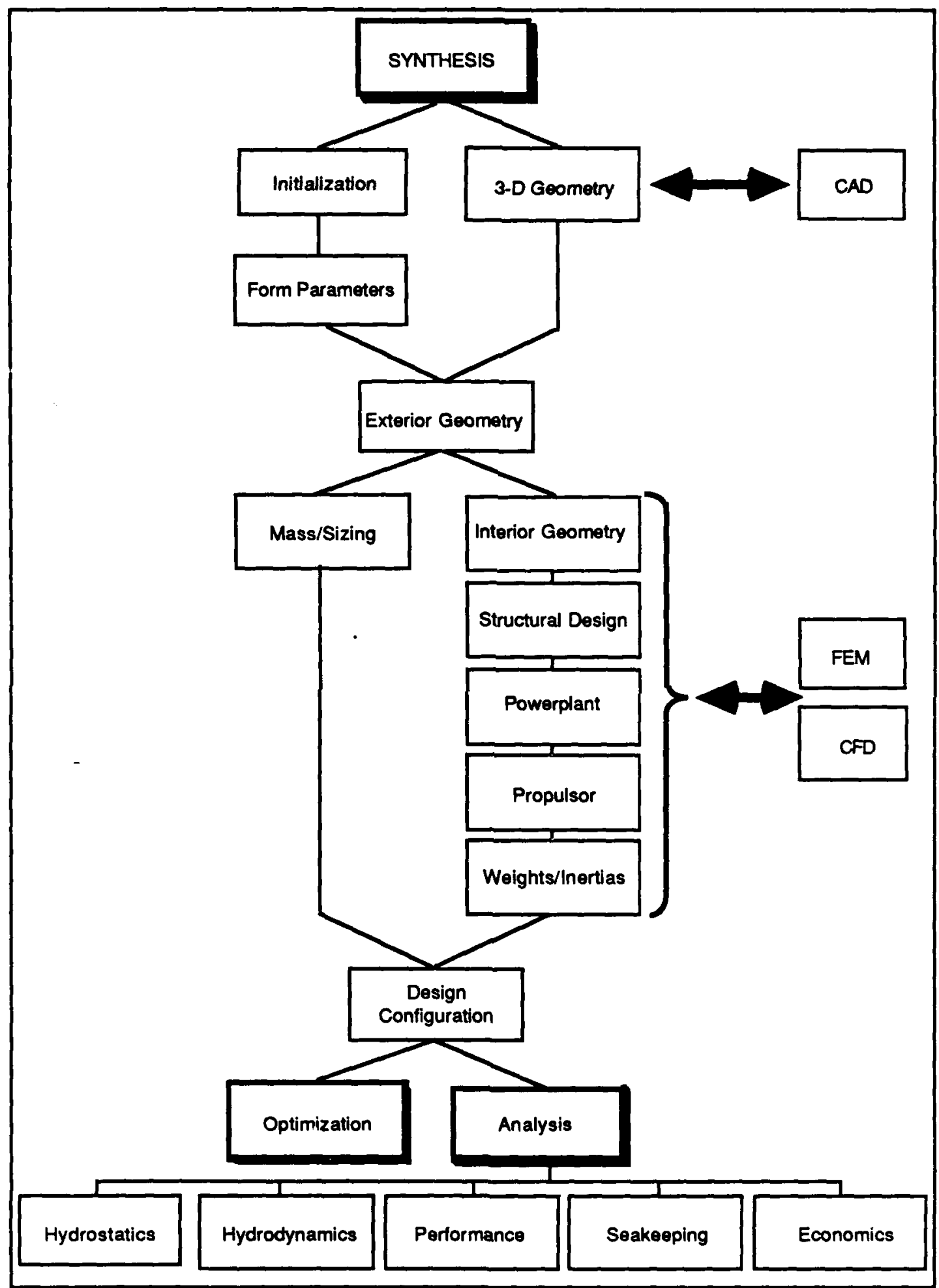

Figure A-5. Proposed Marine Generic Synthesis Model 
with the ability to generate a complex hull form in much less time than was previously needed. Interactive modification of the hull form in real-time provides this increase in productivity.

After the exterior geometry is complete, the designer then configures the interior geometry. The main weight items, such as power plant and propulsion, are then added and arranged interactively on the screen. After the final positioning is achieved, the weights and balance statements are prepared, and mass and inertias computed. Synthesis is then complete, and the serial processing aspects of the design process now proceed to the parallel processing aspects, analysis.

Once the exterior geometry is established, the performance analysis may proceed in a parallel or independent fashion. The individual technology modules may be integrated tightly into a homogeneous synthesis model, as has been done in the past, or may be interfaced through an expert system to a heterogeneous environment with exterior large independent programs, such a Finite Element Model (FEM) or a Computational Fluid Dynamics (CFD) model. The processing speeds of the supercomputer environment will allow the designer access to the homogeneous model for early stage design or the heterogeneous environment for preliminary design.

\section{Optimization}

The integration of an optimization module into the synthesis model would require the use of the decomposition techniques described by Rogan [Ref. A-31]. This would include the functional (design analysis disciplines) decomposition and the system (configuration) hierarchy decomposition. The multiple window environment of high level computer graphics will allow the designer to simultaneously display both geometry space and arbitration space. Arbitration space will display the objective function and related design variables as three-dimensional surfaces.

\section{Hybrid Knowledge System}

The architecture of the hybrid expert system environment is shown in Figure A-6. The hybrid expert system should include both the procedural algorithms that comprise the synthesis model and the optimizer, and the expert systems, which include the integrated knowledge data bases and the encyclopedia of reference material. Expert systems would 


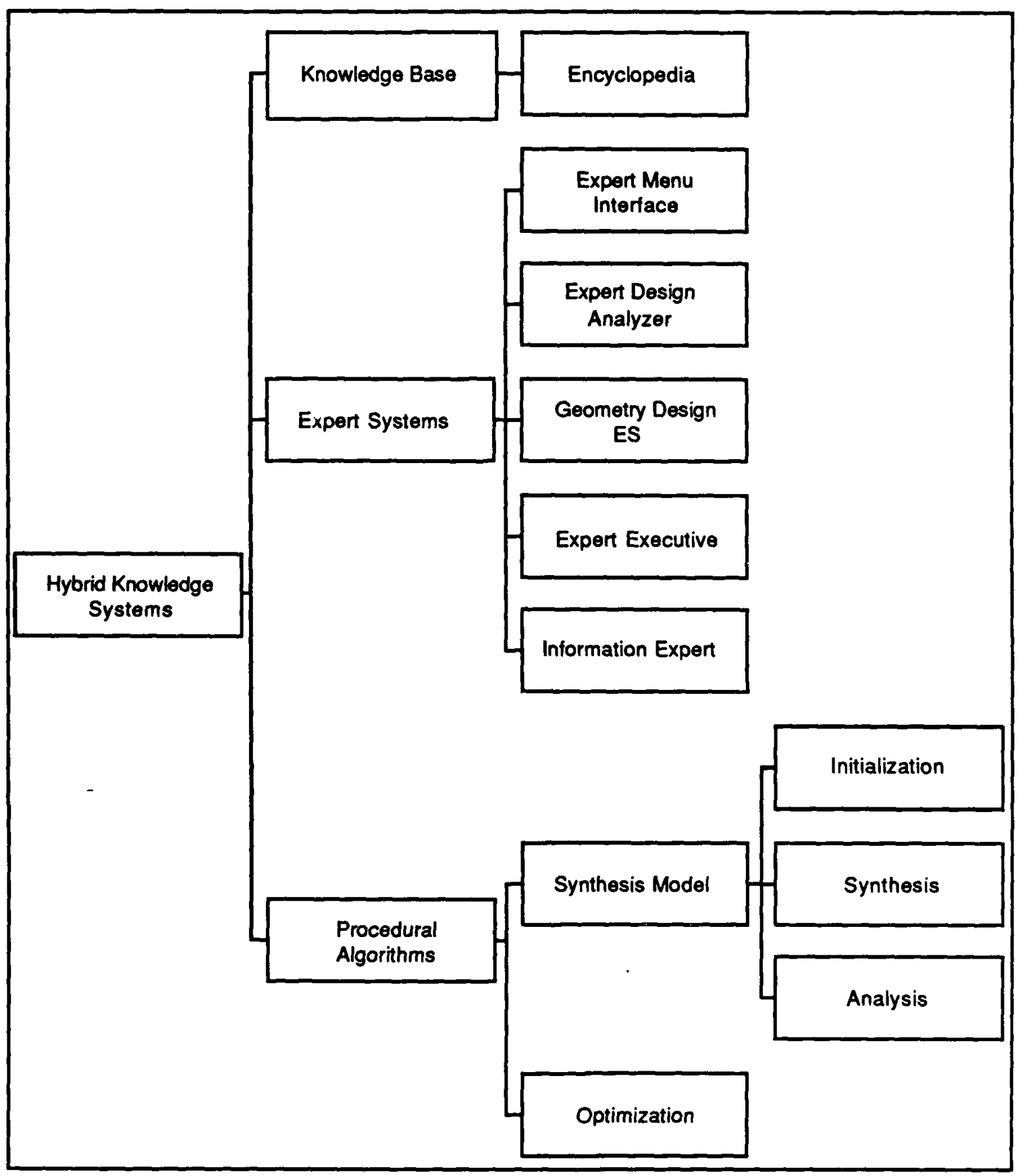

Figure A-6. Hybrid Expert System Environment 
include modules similar to those described by Mitchell [Ref. A-13], Chalfan [Ref. A-28], and Nakasone [Ref. A-35]:

- Expert Menu Interface (smart engineering handbook)

- Expert Design Analyzer (domain specific design knowiedge)

- Geometry Design Expert System (geometry design)

- Expert Executive (CAD/CAE interface)

- Information Expert (CAD/CAE resource catalog).

\section{Object-Oriented Representation}

An object-oriented representation of the actual design process, proposed by Rogan [Ref. A-31], combines an object-oriented representation of both the configuration and the analysis process, as well as the complete design process. The representation would include sub-problem managers, optimization handlers, and documentation facilities, which result in a design system capable of managing realistic design problems from conceptual design through the final states of advanced preliminary design. Object-oriented programming would provide for ship configuration control by means of the design description document.

\section{Hypermedia}

The hypermedia electronic document would form the basis of the Encyclopedia, which would be comprised of a series of linked documents. Text, graphics, and video media would be used to provide an instant access to the reference knowledge database for the designer. The designer would be able to access text files such as regulations or rules and guidelines. Vendor brochures and catalogs would be available for details and specifications on power plants, for example. Graphics databases would include the data sheets, e.g., a catalog of hull form lines and form parameters. 


\section{REFERENCES}

[A-1] Sandor, G.N., "The Seven Stages of Engineering Design," Mechanical Engineering, 86, No. 4, April 1964, pp. 21-25.

[A-2] Gillmer, T.C., "Modern Ship Design," US Naval Institute, Annapolis, MD, 1970.

[A-3] Evans, J.H., "Basic Design Concepts," American Society of Naval Engineers Journal, Vol. 71, No. 4, 1959.

[A-4] Andrews, D., "Creative Ship Design," The Naval Architect, Royal Institution of Naval Architects, November 1981.

[A-5] Galloway, T.L. and M.R. Smith, "General Aviation Design Synthesis Utilizing Interactive Computer Graphics," SAE 760476, Society of Automotive Engineers Business Aircraft Meeting, April 1976.

[A-6] Wilhite, A.W., "AVID: A Design System for Technology Studies of Advanced Transportation Systems," NASA, AIAA 79-0872, NASA Langley Research - Center, 1979.

[A-7] Raymer, D.P., "Developing an Aircraft Configuration Using a Minicomputer," Astronautics and Aeronautics, November 1979, pp. 26-34.

[A-8] Raymer, D.P. and S.K. Albrecht, "CDS-The Designer's Media, The Analyst's Model," Astronautics and Aeronautics/ICAS Conference, 1982.

[A-9] Raymer, D.P., "CDS Grows New Muscles," Astronautics and Aeronautics, June 1982, pp. 22-31.

[A-10] Lancaster, J.W. and D.B. Bailey, "Naval Airship Program for Sizing and Performance (NAPSAP)," AIAA Journal of Aircraft, Vol. 18, No. 8, August 1981, pp. 677-682.

[A-11] Tice, S.E., J.L. Zelon, and R.A. Repic, "SDVCDS-An Evolutionary CDS for Preliminary Space Vehicle Design, Analysis, and Simulation," Aircraft Design Systems and Operations Meeting, AIAA 84-2393, AIAA/AHS/ASEE, October 1984. 
[A-12] Burgess, M.A., E.S. Schreffler, J.C. Hill, P.G. Osterbeck, and G.E. Woodhead, "HAV-SPRINT: A Conceptual Design Computer Code for Hypersonic Vehicle Synthesis and Optimization," Aircraft Design, Systems and Operations Meeting, AIAA 87-2956, AIAA/AHS/ASEE, September 1987.

[A-13] Mitchell, A.R., "Market Supremacy Through Engineering Automation," Aerospace America, January 1987, pp. 24-27.

[A-14] Mitchell, A.R., S.S. Bryan, and M.D. Hall, "Design Technologies for Aerospace Vehicles," Structures, Structural Dynamics, and Materials Conference, AIAA 8707151, AIAA , 6-8 April 1987.

[A-15] Calkins, D.E., J.L. Garbini, and J.M. Isimaru, "Interactive Wire Frame Ship Hull Form Generation and Display," Computer-Aided Geometry Modeling Symposium, NASA Langley Research Center, Hampton, VA, April 1983.

[A-16] Haber, R. Norman and L. Wilkinson, "Perceptual Components of Computer Displays," IEEE Computer Graphics and Applications, 1982.

[A-17] Calkins, D.E., "A Study in Computer-Aided Aerospace Vehicle Design," Master of Science Thesis in Aerospace Engineering, San Diego State College, January 1969.

[A-18] Booth, M. and K. Misegares, "Microtasking: A New Way to Harness Processors, Gray Channels," Cray Research, Inc., Summer 1986.

[A-19] Dixon, J.R., "Computers That Design: Expert Systems for Mechanical Engineers," Computers in Mechanical Engineering, November 1983, pp. 10-18.

[A-20] Luby, S.C., J.R. Dixon, and M.K. Simmons, "Creating and Using a Features Data Base," Computers in Mechanical Engineering, November 1986, pp. 25-33.

[A-21] Rouse, W.B., "A Note on the Nature of Creativity in Engineering: Implications for Supporting System Design," Information Processing and Management, Vol. 22, No. 4, 1986, pp. 279-285.

[A-22] Monaghan, P.F. and J.G. Doheny, "Knowledge Representation in the Conceptual Design Process for Building Energy Systems," Department of Mechanical Engineering, University College Galway, Galway, Ireland.

[A-23] Popplestone, R., T. Smithers, J. Corney, A. Koutsou, K. Millington, and G. Sahar, "Engineering Design Support Systems," Department of Artificial Intelligence, University of Edinburgh.

[A-24] Abelson, H., G.J. Sussman, and J. Sussman, "Structure and Interpretation of Computer Programs," The MIT Press, Cambridge, MA, 1985.

[A-25] Kolb, M.A., "Rubber Airplane, A Paradigm for Computer-Aided Preliminary Design Based on Component-Modeling," Ph.D thesis proposal, Department of Aeronautics and Astronautics, MIT, Cambridge, MA, 1986. 
[A-26] Elias, A.L., "Knowledge Engineering of the Aircraft Design Process, Knowledge Based Problem Solving," J.S. Kowalik, Ed., Prentice-Hall, Englewood Cliffs, NJ., 1985.

[A-27] Mitchell, A.R. and K.M. Chalfan, "An Integration Tool for Design Analysis and Life-Cycle Engineering," The Boeing Co., 1987.

[A-28] Chalfan, K.M., "A Knowledge System that Integrates Heterogeneous Software for a Design Application," The AI Magazine, Summer 1986, pp.80-84.

[A-29] Kitzmiller, T. and J.S. Kowalik, "Coupling Symbolic and Numeric Computing in Knowledge-Based Systems," The AI Magazine, Summer 1987, pp. 85-90.

[A-30] Dannenhoffer, J.F. and J.R. Baron, "A Hybrid Expert System for Complex CFD Problems," Massachusetts Institute of Technology, AIAA 87-1111-CP, AIAA 8th Computational Fluid Dynamics Conference, Honolulu, Hawaii, June 1987.

[A-31] Rogan, J.E., R.P. McElveen, and M.A. Kolb, "Application of Decomposition Techniques to the Preliminary Design of Transport Aircraft," Lockheed-Georgia Co., AIAA-86-2617, Aircraft Systems, Design and Technology Meeting, AIAA/AHS/ASEE, Dayton, OH, October 1986.

[A-32] Sobieski, J., "A Linear Decomposition Method for Large Optimization ProblemsBlueprint for Development," NASA, TM-83248, February 1982.

[A-33] Sobieski, J., J.F. Barthelemy, and G.L. Giles, "Aerospace Engineering Design by Systematic Decomposition and Multifaceted Optimization," ICAS-84-4.7.3, September 1984.

[A-34] Nelson, T.H., "Computer Lib," Microsoft Press, 1987.

[A-35] Nakasone, J.K., "An Expert System Based Parametric Geometry Generation Method," MS Thesis, Department of Mechanical Engineering, University of Washington, Seattle, WA, August 1987. 


\section{Appendix B}

\section{ANNOTATED BIBLIOGRAPHY}




\section{ANNOTATED BIBLIOGRAPHY}

\section{TEXTS}

(1) Product Design for Assembly

Authors: Boothroyd, Geoffrey (U. of Rhode Island, Dept. of Ind. and Mfg. Engr.); Dewhurst, Peter (U. of Rhode Island, Dept. of Ind. and Mfg. Engr.)

Publisher: Boothroyd Dewhurst, Inc.

Date: 1987

Keywords: assembly methods, design efficiency, assembly cost estimation

(2) Manufacturing Engineering, An Introduction to the Basic Functions Authors: Tanner, John P. (McDonnell Douglas Astronautics)

Publisher: Marcel Dekker, Inc.

Date: 1985

Keywords: producibility management, production management

(3) Producibility/Machinability of Space-Age and Conventional Materials

Author: Howe, Raymond, ed.

Publisher: American Society of Tool and Manufacturing Engineers

Date: 1968

Keywords: producibility, machinability, machining costs

(4) Designing for Production

Authors: Niebel, Benjamin W.; Baldwin, Edward N.

Publisher: Richard D. Irwin, Inc.

Date: 1963 
(5) Group Technology

Author: Ranson, G. M.

Publisher: McGraw-Hill

Date: 1972

(6) Understanding the Manufacturing Process

Author: Harrington, Joseph, Jr.

Publisher: Marcel Dekker, Inc.

Date: 1984

(7) The Management of Engineering Production

Author: King, John R.

Publisher. Frances Printer

Date: 1985

(8) Introduction to Quality Engineering: Designing Quality into Products and Processes

Author: Taguchi, Genichi

Publisher: Unipub-Krause International Publications

Date: 1986

Keywords: quality in manufacturing, consumer tolerance, loss function

(9) Manufacturing, The Formidable Competitive Weapon

Author: Skinner, Wickham (Harvard University, Grad. School of Business)

Publisher: John Wiley \& Sons

Date: 1985

(10) Modern Production Management Systems

Author: Kusiak, Andrew, Ed. (U. of Manitoba, Dept. of Mech. and Ind. Engr.)

Publisher: North-Holland

Date: 1987

(11) Military Handbook, Design Guidance for Producibility (MIL-HDB K-727)

Author. Army Materials and Mechanics Research Center

Publisher: Department of Defense

Date: April 1984

Keywords: producibility objectives and considerations 
Abstract: The task of the design engineer is to design a product that satisfies the requirements for functioning, i.e., ensure that it works. Implicit in this design is the fact that the technology and materials exist to fabricate the design. Only later-during production engineering--is thought given to modifying the basic design to permit ease and efficiency in production. This sequential approach is at best a "band-aid" approach, i.e., curing problems that were unconsciously designed into the product initially. The consideration of producibility in the initial design would reduce the possibility of altering its functional characteristics as a result of a change to satisfy producibility and would eliminate, or reduce, the incorporation of a design feature making producibility difficult to achieve.

(12) Fundamentals of Pattern Recognition

Author: Patrick, Edward A. (Dept. of Elec. Engr., Purdue U.)

Publisher: Prentice-Hall, Inc., Englewood Cliffs, NJ

Date: 1972

(13) Proceedings of the 3rd Conference on Product Design for Manufacture and Assembly

Author: Troy Conferences (subsidiary of Troy Engineering), Boothroyd and Dewhurst, Inc.

Publisher: Troy Conferences, Rochester, Michigan

Date: June 1988

Keywords: DFA, DFM (design for manufacture and assembly)

Abstract: The conference focuses on three major elements crucial for improved product development programs: (1) methodologies for improving products at the early design stage--when costs are low and design flexibility the greatest, (2) CAD systems for accelerating and improving the quality of the design effort, and (3) successful implementation techniques for sustaining an aggressive product design effort. The Product Design for Manufacture and Assembly Conference continues to serve as a worldwide forum for alerting participants to the largest achievements in this key area.

(14) "Producibility"..excerpt from Department of Defense Manufacturing Management Handbook for Program Managers, 2nd ed.

Publisher: Defense Systems Management College, Ft. Belvoir, VA

Date: July 1984

Keywords: producibility planning and considerations

(15) Best Practices--How to Avoid Surprises in the World's Most Complicated Technical Process--The Transition from Development to Production

Publisher: Department of the Navy, NAVSO P-6071

Date: March 1986

Keywords: critical path templates, risk assessment 
Abstract: This manual attempts to enhance the enlightenment of both government and industry by identifying specific practices in current use and their potentially adverse consequences in terms of cost, schedule, performance, and readiness. It then describes proven best practices which avoid or alleviate these consequences, and provides enough background information to understand their rationale. Enlightenment follows better understanding.

(16) Transition from Development to Production (DoD 4245.7M)

Author: Department of Defense Research and Engineering

Publisher. US Department of Defense

Date: April 1985

Keywords: critical path templates, risk assessment

(17) Department of Defense Manufacturing Management Handbock for Program Managers, 2nd ed.

Publisher: Defense Systems Management College, Ft. Belvoir, VA

Date: July 1984

Keywords: producibility requirements, producibility techniques for analysis 


\section{JOURNAL ARTICLES}

(1) Cover Story: Smart Design, Quality is the New Style

Authors: Nussbaum, Bruce; Port, Otis; Brandt, Rich; Carson, Teresa; Wolman, Karen; Kapstein, Jonathon

Publisher: Business Week

Date: April 11, 1988

Pages: 102-117

Keywords: quality design, style trends, design trends

(2) Manufacturing and Design, A Symbiosis

Author: Whitney, Daniel (Charles Stark Draper Laboratory, Inc.)

Publisher: IEEE Spectrum

Date: May 1987

Pages: 47-54

Keywords: automation, manufacture simplification

(3) Design-for-Manufacturability Guidelines and Tools Make Designers Think Through Product Development

Author: None

Publisher: CAD/CIM Alert

Date: June 1987

Keywords: design-for-manufacturability (see "The Strategic Approach to Product Design")

(4) The Effect of Product Design on Product Quality and Product Cost Author: Daetz, Douglas

Publisher: Quality Progress Journal

Date: June 1987

Pages: 63-67

Keywords: assemblability, design for quality, design and cost, manufacturing and cost 
Authors: Luby, Steven C. (Cognition, Inc.); Dixon, John R. (U. of Mass.); Simmons, Melvin K. (General Electric, Schenectady)

Publisher: Computers in Mechanical Engineering

Date: November 1986

Pages: 25-33

Keywords: features, manufacturability evaluation, expert systems

Abstract: Symbolic programming can help computers take over the job of evaluating a design's manufacturability. Researchers have developed a data base of features, written in a Lisp dialect, that automatically evaluates designs. Such a system could strengthen the link between CAD and CIM.

(6) Optimizing a Design for Production, Inspection, and Operation

Authors: Corser, T. (U. of Wisconsin, Dept. of Mech. Engr.); Seireg, Ali A. (U. of Wisconsin, Dept. of Mech. Engr.)

Publisher: Computers in Mechanical Engineering

Date: September 1985

Pages: $18-27$

Keywords: design optimization

Abstract: High speed computers and sophisticated data bases now enable an engineer to optimize the design of a mechanical system or component on the basis of the total cost of performing a specified task. Significant gains can be realized when the optimization algorithm incorporates not only performance of the design but also its production and inspection.

(7) Producibility--The Road to Increased Productivity

Author: Gimigliano, R. F.

Publisher: RCA Engineer

Date: Jan/Feb 1983

Pages: $25-28$

Keywords: producibility planning, engineering aids for producibility

Abstract: Producibility, a comerstone of efficient long-run production for many years, has become an important factor in one-of-a-kind high-technology development as well. This paper describes the application of producibility concepts to advanced radar system development at MSR in Moorestown. Three specific areas treated are (1) formation of interdisciplinary teams to plan and implement producibility approaches, (2) use of work centers in manufacturing engineering to promote producibility, and (3) application of mock-ups and mechanized assembly techniques to the production process. 
Publisher: Astronautics and Aeronautics, Vol. 21

Daxe: May 1983

Pages: $66-70$

Keywords: engineering productivity

(9) Computer Support for Group Versus Individual Decisions

Authors: Turoff, Murray; Hiltz, Starr Roxanne

Publisher: IEEE Transactions on Communications, Vol. Com-30, No. 1

Date: January 1982

Pages: 82-90

Abstract: Most decision support systems use computers to support interaction between individuals and a structured model, analytic routine, or a data base. However, many problems are unstructured or at best semistructured, and are dealt with by groups of managers within organizations. When dealing with nonroutine problems, the decision-making groups are often geographically and organizationally dispersed. Thus, a decision support system for these groups must include communications, structured to support the decision-making process among members of the group.

This paper gives several examples of computerized conferencing systems (CCS's) which have served as group decision support systems (DSS's). In addition, the results of a controlled experiment comparing the process and outcome of group decision-making in a face-to-face versus a CCS mode are discussed. Finally, preliminary results are presented from a second controlled experiment which explored how a CCS may best be structured to serve as a group DSS for a specific type of managerial task.

(10) The Use of Functional Cost Analysis in the Design of New Products

Authors: Kapinus, E. E.; Sosnovski, Ya. Sh.

Publisher: Soviet Electrical Engineering

Date: 1982

Pages: No. 3, pp. 56-57

Abstract: Proposals are put forward for the use of functional cost analysis in the development stage of a new product. An algorithm is presented for the conversion of the development requirements into functions of the components and parts based on variants of a design and process model. The interrelationship between the development stages of a new product and the FCA stages is demonstrated. 
Author: Baron, J. A.

Publisher: Chartered Mechanical Engineer

Date: September 1981

Pages: $44-46$

Keywords: production phases

Abstract: Designing for production, like most things in business, cannot be done in isolation. It is essential that all other related departments within the company, e.g., purchasing, quality, industrial engineering, production and marketing, are consulted to determine the best and most efficient methods of production and procurement of materials. Only by achieving this total involvement will the new product be successfully launched on time and at the right price. This article sets out to highlight the general requirements of production, with specific illustrations related to mechanical, electro-mechanical, and electronic instrumentation associated with the motor-car industry.

(12) Balancing the Scale Between Innovation and Manufacturability

Author: Welch, John F., Jr.

Publisher: The Bridge

Dare: Winter 1986

Pages: $10-12$

Keywords: manufacturability, competitiveness

(13) - Top-Down Construction of 3-D Mechanical Object Shapes from Engineering Drawings

Authors: Yoshiura, Hiroshi (Hitachi); Fujimura, Kikuo (U. of Tokyo); Kunii, Tosiyasu (U. of Tokyo)

Publisher. Computer

Date: December 1984

Keywords: natural language processing, constructive solid geometry

Abstract: Many CAD/CAM systems are commercially available today, but there are numerous ways in which they should be made more efficient. Previous research has demonstrated that more efficient methods exist for carrying out operations between objects such as intersection calculations between surfaces. Currently, the man/machine interface is itself a major obstacle to raising the productivity of CAD/CAM systems. 
(14) An Interpreter for a Language for Describing Assemblies Authors: Popplestone, R. J. (U. of Edinburgh); Ambler, A. P. (U. of Edinburgh); Bellos, I. M. (U. of Edinburgh)

Publisher: Artificial Intelligence 14 (1980)

Pages: 79-107

Date: 1980

(15) A Geometric Modeling System for Automated Mechanical Assembly Authors: Wesley, M. A.; Lozano-Perez, T.; Lieberman, L. I.; Lavin, M. A.; Grossman, D. D.

Publisher: IBM Joumal of Research and Development

Date: January 1980

Keywords: computer representation of parts and assemblies, AUTOPASS

Abstract: This paper describes a computer-based system for modeling threedimensional objects. The initial motivation for this research was to create models for a very high level programming language for mechanical assemblers. The result has evolved into a general purpose system for describing parts both in terms of their three-dimensional geometry and their mechanical properties.

(16) With Group Technology, No One Reinvents the Wheel

Author: Baer, Tony

Publisher: Mechanical Engineering

- Date: November 1985

Pages: 60-69

Keywords: group technology, coding/classifications

(17) Just-In-Time Production Systems: Replacing Complexity With Simpicity in Manufacturing Management

Author: Schongerger, Richard (U. of Nebraska-Lincoln)

Publisher. Industrial Engineering

Date: October 1984

Pages: 52-63

Keywords: JIT, flexible manufacturing, continuous flow manufacturing 
(18) The Decision-Support Problem Technique in Engineering Design Author: Muster, D. (Dept. of Mech. Engineering, U. of Houston); Mistree, F. (Dept. of Mech. Engineering, U. of Houston)

Publisher: International Joumal of Applied Engineering

Date: 1988

Pages: 23-33

Keywords: design process, synthesis and decision support

(19) Design Activity Models: Worldwide Emergence and Convergence Author: Pugh, Stuart (Dept. of Engr. Design, U. of Strathclyde, Glascow, UK)

Publisher: Design Studies, Vol. 7, No. 3

Date: July 1986

Keywords: design models, engineering, architecture

Abstract. This discussion paper was prompted by seeing the proceedings of the International Design Participation Conference. In particular, there seemed to be evidence of a convergence towards a design activity model which would be an acceptable basis for most, if not all, design professions. This topic is pursued here, by cross-referring from some of the Participation Conference papers to deductions made from the marine and general engineering fields.

(20) The Seven Stages of Engineering Design

Author: Sandor, G. N.

- Publisher: Mechanical Engineering

Date: April 1964

Pages: 21-25

(21) Basic Design Concepts

Author: Evans, J.H.

Publisher: American Society of Naval Engineers Journal, Vol. 71, No. 4

Date: 1959

\section{Developing an Aircraft Configuration Using a Minicomputer}

Author: Raymer, D. P.

Publisher: Astronautics and Aeronautics

Date: November 1979

Pages: 26-34 
CDS Grows New Muscles

Author: Raymer, D. P.

Publisher: Astronautics and Aeronautics

Date: June 1982

Pages: 22-31

(24) Naval Airships Program for Sizing and Performance

Authors: Lancaster, J. W.; Bailey, D. B.

Publisher: AIAA Journal of Aircraft, Vol. 18, No. 4

Date: August 1981

Pages: 677-682

(25) Market Supremacy Through Engineering Automation

Author: Mitchell, A. R.

Publisher: Aerospace America

Date: January 1987

Pages: 24-27

(26) A Note on the Nature of Creativity in Engineering: Implications for Supporting System Design

Author: Rouse, W. B.

= Publisher: Information Processing \& Management, Vol. 22, No. 4

Date: 1986

Pages: 279-285

(27) A Knowledge System that Integrates Heterogeneous Software for a Design Application

Author: Chalfan, K. M.

Publisher: The AI Magazine

Date: Summer 1986

Pages: $80-84$

(28) Coupling Symbolic and Numeric Computing in Knowledge-Based Systems

Authors: Kitzmiller, T.; Kowalik, J. S.

Publisher. The AI Magazine

Date: Summer 1987

Pages: 85-90 


\section{TECHNICAL PAPERS}

(1) Program Management Guidelines for Producibility Engineering and Planning (PEP)

Authors: Adler, Fred L.; Alducin, Donald G.; Glass, David V., Gunkel, Richard A.

Publisher: Logistics Management Institute--Gov. Accession \# AD-A153 730

Date: January 1985

Keywords: producibility planning and engineering

Abstract: Acquisition of a weapon system goes through five stages: design, development, test, production, and support. To acquire a producible weapon system requires a design that can be executed within affordability and design-tocost limits. Throughout acquisition, therefore, producibility and related manufacturing considerations must be interwoven with design as part of a program of producibility engineering and planning (PEP) that assures both feasibility of production and production at least cost.

(2) Why Some Weapon Systems Encounter Production Problems While - Others Do Not: Six Case Studies

Author: Comptroller General of the United States

Publisher: General Accounting Office: GAONSLAD-85-34

Date: May 24, 1985

Keywords: transition from development to production, production problems

Abstract: Experience has shown that new weapon systems regularly encounter great difficulties as they begin production, such as a high percentage of components that must be scrapped or reworked. These give rise to significant cost increases and schedule delays. Through an examination of six weapon system case studies, GAO found that such problems occur in programs where efforts to prepare weapons for production were insufficient. GAO found further that technical performance concerns, program management and staff, and funding and quantity instability greatly influenced these preparations during the weapons development.

DoD has issued two directives which should improve production preparations in future programs. GAO makes recommendations on applying these directives to individual programs to both improve production preparations and reduce the effects of other program influences on such preparations. 
Utilization in Industry of ICAM "Manufacturing Cost/Design Guide" (MC/DG) for Composite Structures

Authors: Klivans, Dean S. (Rockwell International Corp., Los Angeles, CA); Noton, Bryan R. (Batelle's Columbus Laboratories, Columbus, $\mathrm{OH}$ )

Publisher: 26th National SAMPE (Society of Advanced Materials and Process Engineering) Symposium

Date: April 28-30, 1981

Pages: 593-600

Keywords: manufacturing costs for composite fuselage shear panel

Abstract: Utilizing the MC/DG, trade studies have been conducted on advanced composite fuselage shear panels. The configurations included lightweight/high complexity; moderate weight/moderate complexity; and high weight/low complexity configurations. The panels were of single curvature and were assembled using mechanical and cocuring methods. The graphite/epoxy selected was AS/3502-6. The configurations studied included hat and J-sections for the frames, and the manufacturing manhours were determined for each. The results are presented in diagrams indicating the weight and manufacturing manhours for each configuration. The MC/DG formats were used to develop the design employing a step-by-step approach to support the cost of the concept. The final cost was accurate, and the objectives of the MC/DG program were demonstrated.

(4) ICAM "Manufacturing Cost/Design Guide" (MC/DG) Background, Metallic and Nonmetallic Demonstration Sections

Authors: Noton, Bryan R. (Batelle's Columbus Laboratories, Columbus, $\mathrm{OH}$ ); Preston, Richard R. (Capt., Materials Laboratory, Wright-Patterson AFB)

Publisher: 26th National SAMPE (Society of Advanced Materials and Process Engineering) Symposium

Date: April 28-30, 1981

Pages: 593-600

Keywords: manufacturing cost guides, weight/cost trade studies, cost drivers

Abstract: The "Manufacturing Cost/Design Guide" (MC/DG) is under development for the Computer Integrated Manufacturing Laboratory, WPAFB, Ohio. The objective is to enable aircraft designers to achieve lowest cost by conducting trade-offs between manufacturing cost and design factors, such as minimum weight. The model of the MC/DG has been developed as well as sections for sheet metal, aerospace sheet metal discrete parts, mechanicallyfastened assemblies, advanced composite fabrication, castings, test, inspection and evaluation (TI\&E), and also for certain emerging manufacturing technologies. The manufacturing operational sequences have been studied for base parts; i.e., structural elements in their simplest form, and also with designer-influenced cost elements (DICE) such as cut-outs and heat treatment. It is therefore also possible to identify the cost-driving operational sequences which are candidates for computer-aided manufacturing (CAM). In the case of composites, typical DICE are fiber materials, number of plies, and quality requirements. 
The Manufacturing Cost/Design (MC/DG) Computerization Program-Manufacturing Cost Design System (MCDS)--A Program Update

Authors: Rachowits, Bernard I.; Loshiigian, Henry; Judson, David

Publisher: 26th National SAMPE (Society of Advanced Materials and Process Engineering) Symposium

Date: 1981

Pages: 620-629

Keywords: life cycle development and cost

Abstract: In the early 1970s, the Air Force initiated development of a Manufacturing Cost/Design Guide. The Guide's data development is continuing by the Coalition Team headed by the Battelle Corporation. While the basic guide is useful in a manual sense, the Air Force recognized the need for a computerized system that can be integrated with other ICAM and CAD systems. In order to accomplish this task, the Manufacturing Cost Design System (MCDS) is being developed. This paper provides a brief overview of the development of the MCDS.

The paper will first review the background leading toward the current effort describing the overall Air Force basic ICAM program and describing the specific tasks involved in the MCD's development along with a review of concepts and outputs through Phase I. By the time this paper is given, additional data will be available on Phase II implementation and with appropriate approvals will be presented.

(6) Producibility Technology Studies--Supersonic Cruise Aircraft

Author: Van Hamersveld, John (Lockheed-California)

Publisher: Bicentennial of Materials Progress, SAMPE (Society of Advanced Materials and Process Engineering) Series, Vol. 21

Date: 1976

Pages: 138-155

Keywords: fabrication technologies for titanium structure

Abstract: This paper contains the results of producibility technology studies conducted for NASA on a supersonic titanium structure arrow wing design configuration with a design and manufacture go-ahead at the end of 1980 . The proposed structure design concepts were titanium skin-stiffened chordwise and spanwise arrangements, and biaxial stiffened honeycomb sandwich configurations. A hybrid structure with composite reinforced spars was the lowest weight and met the long-range requirements.

(7) Designing Composites for Producibility

Author: Becker, Wayne (Plastic Fabricating Co., Wichita, KS)

Publisher: SAE (Society of Automotive Engineers) Paper \#850903

Date: 1985 
Keywords: sandwich panel composites, producibility guidelines for composites

Abstract: A composite created by the synthetic assembly of two or more components, can offer results which cannot be achieved with any of the components acting alone. While many design configurations provide satisfactory product performance, care should be taken to design the part so that it is manufacturable with ease.

Sandwich panel construction, comprised of fibrous skins and honeycomb core, a significant aerospace structure, is selected for focus. Autoclave processing is highlighted. The effectiveness of sandwich panels is cited and its various elements identified. Discussion relative to simplifying production by designing for producibility is shared.

(8) Designing for Producibility: Design-Influenced Production Cost Program

Author: Brooks, Doyle T. (LTV Aerospace Corp.)

Publisher: SAE (Society of Automotive Engineers) Paper $\# 710747$

Date: 1971

Keywords: target cost, program planning

Abstract: Whether or not a product is producible is largely determined during the initial design phase. Further, producibility can usually be measured in terms of cost, which is the approach in this paper.

Presented here is a plan for tracking and controlling the end-product costs which are influenced by design decisions, while those decisions are being made. This is accomplished by creating accurate cost targets at the beginning of design, from base-cost modules established prior to design, then tracking the influence of design decisions against those targets as the design progresses. The key here is the technique of rapidly creating the cost target.

(9) Producibility Considerations in Production Planning for New Aircraft

Author: Torget, Sofus J. (Boeing Commercial Airplane Co.)

Publisher: SAE (Society of Automotive Engineers) Paper \#710746

Date: 1971

Keywords: preliminary planning, logistics planning, program scheduling

Abstract: This paper describes some aspects of aircraft producibility at the Boeing Company and discusses the functions of design engineering and manufacturing organizations in achieving a producible airplane. The make-up and function of the product team prior to corporate go-ahead, as well as their objectives and timing, are defined. Producibility aspects in both preliminary design and production phases of the aircraft program are identified and described. Specifically, producibility considerations during the preliminary design phase in the provisioning of facilities, subcontracting, and scheduling, as well as production-phase design verification, production planning, subcontractor 
coordination, materials handling, and plant layout and equipment are discussed. The effects of design changes on producibility are noted. A discussion of motivation as a factor in producibility is included.

Producibility in Design

Author: Petronio, George (Grumman Aerospace Corp.)

Publisher: SAE (Society of Automotive Engineers) Paper \#710748

Date: 1971

Keywords: cost control, manufacturing plan, trade studies

Abstract: Producibility, an input to aircraft design techniques, reduces production cost and increases product profitability. Concurrently with all stages of design, a joint engineering and manufacturing team continuously analyzes fabrication methods and materials to minimize costs and optimize product performance. This analysis may strongly influence aircraft design. During design of the F-14 fighter aircraft, for example, producibility analysis permitted significant savings in weight, time, and money.

\section{Producibility of Helicopter Power Transmission Systems}

Authors: Bowen, C. W. (Bell Helicopter Co.); Braddock, C. E. (Bell Helicopter Co.)

Publisher: SAE (Society of Automotive Engineers) Paper \#680675

Date: 1968

Keywords: Huey transmission, transmission design

Abstract: This paper summarizes the production history of Bell Helicopter Co.'s

Model UH-1 (Huey) helicopter transmission, compares the producibility of the Huey transmission system with the estimated producibility of new conventional and unconventional systems, and outlines the responsibilities of the transmission designer in adding producibility to his usual design considerations of weight, efficiency, reliability, and cost.

(12) A New Development Concept for Gas Turbine Engine--Optimize Life Cycle Costs

Authors: Cowie, W. D.; Abell, E. E.; Horn, E. W.

Publisher: 3rd International Symposium on Air Breathing Engines

Date: 1976

Pages: 27-38

Abstract: The life cycle development and management process for turbine engines is being revised to provide more durable, reliable, and lower life cycle cost engines to the military services. Greater attention is being given earlier in the life cycle to the cost trades between performance, producibility, and operability/supportability; i.e., during the technology, conceptual, and validation phases of the development process. The full-scale development phase has been restructured to emphasize structural durability and to provide formal demonstrations of useful engine life limits; operational and logistic characteristics; 
and validation of the engine life management process to provide economic management rationale for the production hardware acquisition, operational usage, and logistic support phases.

(13) Design to Cost and Life Cycle Cost.-AGARD Conference Proceedings No. 289 (book contains 27 papers)

Authors: Various

Publisher: NATO-AGARD (Advisory Group for Aerospace Research and Development)

Date: May 1980

Keywords: LCC, design to cost

(14) Introduction to Preliminary Aircraft Design

Author: Weissman, C. C.

Publisher: From AGARD Lecture Series No. 65, Preliminary Aircraft Design (book-NATO)

Date: May 1974

Keywords: design requirements

(15) Modern Engineering Methods in Aircraft Preliminary Design

Author: Huff, W. W. Jr. (LTV Aerospace)

Publisher: From AGARD Lecture Series No. 65, Preliminary Aircraft Design (book-NATO)

- Date: May 1974

Keywords: computerized design synthesis

Abstract: This lecture addresses the impact of computer technology on modem engineering methods used in preliminary design. Computerized design synthesis programs are usually constructed in a modular fashion. As preliminary design follows program evolution from tentative requirements through release of a type specification, data resources consistent with the program stage are input to the computer modules. Application of Vought's Aircraft Synthesis and Analysis Program, ASAP, to the early Program Definition Phase of preliminary design is discussed in detail. When requirements are confirmed, concept formulation begins. Synthesis and analysis activities accept new sources of data such as developmental test results and especially design manned simulator programs. During contract definition, preliminary design objectives are directed to optimization for high value specification criteria. A typical air superiority fighter program is selected to illustrate the lecture theme. Movie film strips intersperse the lecture to graphically portray these new tools of the trade. Nondimensional technical material is frequently used and certain artistic license is taken for reasons of security. Methods discussed and engineering tools described are factual. 
The Team Leader's Role in "Design to Cost" Proliminary Design Author: Josephs, Lyman C. (General Dynamics)

Publisher: From AGARD Lecture Series No. 65, Preliminary Aircraft Design (book-NATO)

Date: May 1974

Keywords: preliminary design engineering organization

(17) Product Design for Manufacture and Assembly

Authors: Huthwaite, Bart (Troy Engineering)

Publisher: Society of Manufacturing Engineers

Date: November 23-24, 1987

Keywords: assembly methods, design efficiency, assembly cost estimation

Abstract: A product's design is the primary "driver" of its manufactured cost. Simplifying a product's design in the early development stage results in reduced tooling, material, and labor cost. Product launches are faster and less painful. Capital equipment costs are lower. Quality risks are fewer. Customer needs are met sooner and with more flexibility and reliability.

Product Design for Manufacture and Assembly (DFMA) is an engineering management strategy that merges a "team effort" philosophy with quantitative analysis to resolve manufacturing problems "up front," in the early design stage. Total company cycle time shrinks as problems are identified--and solved sooner and with far less cost in time and money. Time required to respond to customer needs is sharply reduced, yielding a better competitive position. Time required to - manufacture the product drops, resulting in lower cost products.

(18) The Taguchi Approach to Parameter Design

Authors: Byme, Diane M. (Eaton Corporation, Southfield, MI); Taguchi, Shin (American Supplier Institute, Dearborn, MI)

Keywords: quality, parameter design, loss function

(19) Product Design for Assembly

Author: Huthwaite, Bart (Troy Engineering)

Publisher: Society of Manufacturing Engineers

Date: 1987

Keywords: assembly methods, design efficiency, assembly cost estimation

(20) A Machinability Knowledge Based System

Author: Jardine, T. J. (Boeing Artificial Intelligence Center)

Publisher: Boeing Computer Services

Keywords: machinability 
Abstract. In this chapter, we present a distillation of the results of an experiment. This experiment involved the construction of a knowledge-based system linked to an analytical software model performing machinability computations. We first outline the nature of the manufacturing problem, focusing on sufficient information to provide a context for the machinability computation task. Following this, we describe the experiment by discussing the specific problem to be addressed, our approach to solving this problem, the design of the knowledgebased system, and an analysis of the results of the experiment to date.

(21) OFD (Quality Function Deployment) Results

Publisher: Ernst \& Whitney Co. (Ronald M. Fortuna, Manager)

Keywords: Failure Mode and Effects Analysis (FMEA), Fault Tree Analysis (FTA), Taguchi

(22) Status of Producibility Analysis, Maintainability Evaluation, and Trade-Off Studies

Author: Maybell, J. L.

Publisher: Assurance Technology Relates to Today's World (Annals of Reliability and Maintainability, Vol. 10)

Date: 1971

Pages: 409-411

(23) Computer Integration of Engineering Design and Production

Authors: Committee on the CAD/CAM Interface; Manufacturing Sciences Board; Commission on Engineering and Technical Systems; National Research Council

- Publisher: National Academy Press, Washington, DC

Date: 1984

Analysis of Expert Systems in Manufacturing Design

Authors: Heragu, Sunderesh S.; Kusiak, Andrew

Publisher: IEEE Transactions on Systems, Man, and Cybernetics, Vol. SMC-17, No. 6

Date: November/December 1987

Pages: 898-912

Keywords: expert systems, manufacturing system design

Abstract: Features of expert systems applied in manufacturing design are presented. Three issues in expert systems, namely, knowledge representation, knowledge acquisition, and inference strategy, are briefly discussed. The tandem architecture of expert systems that allows for close interaction of the inference engine with a set of models and algorithms is outlined. Four design problems in manufacturing systems, namely, part design, process planning, equipment selection, and facility layout, are identified. Existing expert systems developed for the design problems are surveyed. 
Utilization in Industry of ICAM "Manufacturing Cost/Design Guide" (MC/DG) for Metallic Structures

Author: Pillera, Anthony J. (Lockheed-California)

Publisher: 26th National SAMPE Symposium

Date: April 28-30, 1981

Pages: 601-606

Abstract: The MC/DG has been utilized for structural performance/manufacturing cost studies of seven titanium fuselage panel designs for an SST project. Various structural concepts with varying skin thicknesses, frames, and stringer count, were studied. An engineering team conducting the trade studies included design, stress, weight, and producibility engineers. Detailed engineering drawings were utilized providing realistic applications of the MC/DG. The study enabled the selection of the most cost-effective concept by determining the cost of weight saved for each panel. The use of the MC/DG was fully demonstrated in developing a cost/weight effective design by utilizing the manufacturing cost methodology developed. This provided program dollar costs (including materials, labor, and tooling).

\section{Expert Systems for Mechanical Design: A Program of Research}

Authors: Dixon, John R. (U. of Massachusetts, Dept. of Mech. Engr.); Simmons, Melvin K. (General Electric, Schenectady, NY)

\section{Publisher: American Society of Mechanical Engineers Paper \#85-det-78}

Date: 1985

Keywords: expert systems, model of design

- Abstract: A program of research into the application of artificial intelligence to mechanical design is described. The objectives of the program are (1) to explore the use of "design with features" as a means for creating a design data base that will serve manufacturing process planning as well as design and analysis needs, (2) to leam how to develop expert systems in CAD environments that can do online evaluation of designs for their manufacturability, (3) to develop a new language for knowledge acquisition and representation in design that will facilitate the construction of expert systems for mechanical design.

The research consists of a $1:$ mber of active subprojects, each developing a working expert system. The subprojects have been selected to provide understanding of major theoretical and practical issues in manageable steps. Specific topics include design of heat sinks, design and analysis of injection molded parts, design of plastic extrusions, casting design and analysis, casting process selection, plastic materials selection, and a domain independent iterative redesign program.

(27) Knowledge Representation in Mechanical Design Systems: Issues and Examples

Authors: Dixon, J. R.; Jones, C. D.; Libardi, E. C., Jr.; Luby, S. C.; Nielsen, E. H.

Publisher: Society of Automotive Engineers Paper \#860335 
Date: 1986

Keywords: knowledge representation, features, manufacturing evaluation

Abstract: A brief introduction to the key role of knowledge in knowledge-based and expert systems is presented. Knowledge representation issues for mechanical design are then discussed. What types of knowledge must be represented? What representation methods are available?

Next, specific examples are presented from research being done in the Program in Artificial Intelligence Applied to Mechanical Design and Manufacturing at the University of Massachusetts, Amherst. These include a representation of design geometries, manufacturability knowledge, redesign knowledge, and knowledge of analytical procedures.

(28) Recent Developments in Representation in the Science of Design

Author: Eastman, Charles (Camegie-Mellon University)

Publisher: 18th Design Automation Conference (sponsored by IEEE)

Date: 1981

Abstract: A recent goal in computer aided design is the representation of a design artifact sufficient to support all analyses and to determine that the design is realizable. Some aspects of a theory of design representations are presented. Benefits of developing such a theory are discussed.

(29) Computer-Aided Production Engineering--International Conference

Author: McGeough, J. A., ed.

Publisher: Mechanical Engineering Publications Ltd. for the Institution of

- Mechanical Engineers

Date: 1986

(30) Proceedings of the 6th Annual Conference on Design Engineering

Author: Davies, B. J., ed.

Publisher: IFS (Publications) Ltd. and North-Holland Publishing Company

Date: October 1983

(31) The Taguchi Approach to Quality Control and Enhancement: A Primer

Authors: Elmaghraby, Salah E. (North Carolina St., Raleigh); Fathi, Yahya (North Carolina St., Raleigh); Ferrell, William G. (North Carolina St., Raleigh)

Publisher: US Army Research Office, Report \#ARO 22835.1-MA

Date: November 1986

Keywords: quality control, loss-function, parameter design, robust design

Abstract: A quiet revolution in the field of quality control and enhancement has been in progress in Japan for some 25 years, and has recently come ashore to the United States. It has been identified with the name of $G$. Taguchi, an engineer 
cum statistician, who advocated a radical departure from the prevailing culture of the detection of "assignable causes" of variation with the view of eliminating them, to the engineering of quality, where the emphasis is on the design of the product to be robust against such causes of variation.

This paper reviews the basic tenets of the Taguchi approach, and contrasts them with classical well-entrenched approaches such as "response surface" and "evolutionary operation." The paper also raises the issue of the possible extension of the Taguchi approach to process (rather than product) quality control.

For ease of reading, the paper is divided into two parts. The first is discursive and non-mathematical and is aimed at the reader who wishes to gain a deeper understanding of "what it is all about" without the detailed mathematical formalism. The second presents the mathematical underpinnings of the approach, which are rather elementary. No statistical methodology is expounded upon because we assume the reader to be cognizant of the requisite statistical background.

\section{(32) Group Technology Assessment}

Author: Case and Company, Inc., Chicago, Raymond J. Levulis, Senior Partner

Publisher: US Army Material Command, Gov. Accession \#AD-A152 045

Date: January 1985

Keywords: group technology (GT), process planning, cellular manufacturing, procurement, manufacturing costs/benefits, classification and coding systems, standardization

Abstract: Because some independent efforts toward the use of group technology

- (GT) within AMC have been made in the past, and more are expected in the future, it was deemed timely to assess these efforts; determine current interest, potential, and issues and begin to outline a strategy for the future use of GT at US Army manufacturing facilities, government owned-government operated (GOGO) and government owned-contractor operated (GO-CO).

The findings of this project revealed that since GT efforts began in 1979, little meaningful progress has been made. This is generally attributed to a lack of top management support, a scarcity of GT experience and knowledge within the various AMC organizations, difficulties encountered in the justification of funding, and certain organizational constraints. In the few instances where successful applications have been made, it was evident that a clear purpose, strong leadership, and a good understanding of GT concepts are essential.

From this assessment, it has been concluded that a significant potential for cost savings exists in the application of GT in the functions of manufacturing, design, and procurement at certain Army plants, arsenals, and depots. To obtain this potential will require an improved management awareness, the development of a more complete GT strategy, the commitment of resources, the initiation of key projects, and the maintenance of continuity. 

Technology, Benefits, and Strategies for the US Army Material Command

Authors: Willis, Roger G. (Arthur Anderson \& Co., Chicago); Piatt, John P. (Arthur Anderson \& Co., Chicago); Dimitriyev, Steven R. (Arthur Anderson \& Co., Chicago)

Publisher: US Army Material Command: Gov. Accession \# AD-A176 754

Date: December 1986

Keywords: CIM, factory automation, product/process design, manufacturing planning/control, international systems support architecture

Abstract: CIM is the coordinated application of technology to the process of design manufacturing, distribution, and maintenance for a product or group of products. The approach taken to perform the study was to logically group and define CIM technologies as a foundation for further analysis and as a basis for defining high-payback strategies for future Army CIM efforts. The next step was to assess the current state of Army efforts in CIM development and implementation. This was accomplished by researching industry and government technology data bases and interviewing knowledgeable individuals within the Army Material Command. After relevant programs and projects were identified, the current strategies were analyzed and compared to those of other government agencies, private commercial organizations, and universities. Finally, alternate strategies were identified along with related risks and benefits.

(34) Methods of Incorporating Design for Production Considerations into Concept Design Investigations

- Authors: Bong, H. S. (Daewoo Shipbuilding and Heavy Machinery, Ltd., Korea); Hills, William (U. of Newcastle upon Tyne, UK); Caldwell, John B. (U. of Newcastle upon Tyne, UK)

Publisher: The Society of Naval Architects and Marine Engineers

Date: June 1988

Abstract: The paper describes a method of incorporating knowledge and data of the production process into a concept design model in a way which provides a flexible and powerful structural design tool.

Interactive graphics is shown to be a useful design aid when defining geometry and scantlings particularly when combined with a data base of information on standardization, build methods, and production technology.

The total build cost, including labor, materials, and overhead is used as the criterion in a series of studies which demonstrate the application of the method to total cost to changes in various parameters of design and production.

Life Cycle Cost in the Conceptual Design Process

Author: Johnson, Vicki S. (NASA Langley Research Center, Hampton, VA)

Publisher: AIAA Paper \#87-2889

Date: September 1987 
Keywords: LCC, conceptual design optimization, cost modeling

Abstract. The inclusion of life cycle costs as early as possible in the conceptual design process is needed because of the strong impact the early design effort has on the total cost of an aircraft program. A methodology is proposed which will incorporate life cycle cost in the conceptual design process. The need for this methodology is identified by examining the history of the conceptual design process and previous efforts to include cost in conceptual design. After establishing the need for the proposed methodology, characteristics of a good systems analysis process and cost modeling techniques are identified. Finally, a methodology is proposed which could make it possible to identify an aircraft concept which will meet the mission requirements and have the lowest life cycle costs. Direct operating costs, acquisition costs, and return on investment will be considered. The proposed methodology is composed mainly of existing computer codes and cost models appropriate for subsonic commercial aircraft. The proposed methodology could also be useful in illustrating the sensitivities of aircraft concepts to economic, conceptual design, and technology level variables.

(36) A CAD Approach to Cost Estimating Composite Aircraft

Authors: Camin, R. A. (General Dynamics, Ft. Worth Division); McKenzie, C. L. (General Dynamics, Ft. Worth Division)

Abstract: Cost justification has always been a primary consideration in the Department of Defense procurement process. As such, accurate detailed cost estimates of proposed defense acquisitions have become a requirement in defenserelated projects. Collectively, these formalized cost identification and tracking programs are known as Design-to-Cost (DTC) and Design-to-Life-Cycle-Cost (DTLCC). These design constraints place increasing emphasis on producing not only technically superior designs, but cost-effective designs as well. Because of

- relative infancy of advanced computer technology, a gap exists between the need to determine high cost areas and current capabilities to analyze aircraft costs at an early stage in the design process at a detailed level.

(37) Automated Reliability Expert Systems--ARES

Author: Etzel, Julius M. (Lockheed Electronics Co., Plainfield, NJ); Brandau, Richard; Fischer, Charles W.; Oakes, James

Publisher: AIAA and Lockheed Electronics Co.

Date: 1987

Abstract: Many analyses are performed by reliability engineers to improve a design/s reliability, safety, and quality. These analyses include: Failure Mods and Effects Analysis (FMEA), Criticality Analysis, Worst Case Tolerance Analysis, Reliability/Maintainability Predictions, and Nuclear Radiation Effects analysis. These reliability tasks require iterations of circuit analyses, and when performed manually are tedious, time consuming, and costly. In order to meet the objectives of the Department of Defense to design and manufacture more reliable weapon systems with lower logistics support costs there is a need to make these analyses less costly to perform and to enhance the capability of making design modifications early in the design phase based on the results of such analyses. As weapon systems become larger and more complex, the reliability engineer needs the means to perform all of these analyses in a timely and more 
cost effective manner than can be achieved by manual methods. The automated Reliability Expert System (ARES) project is developing a computerized, integrated system of analyses which will provide reliability, design and logistic engineers with the necessary resources to meet the increasing demands on system requirements for reliability, maintainability, safety, and logistics support.

Do We Really Understand Maintenance?

Author: Matteson, T. D.

Publisher: AIAA Paper \#87-2943

Date: September 1987

Abstract: The total concentration of engineering curricula on design and the associated "ilities" has resulted in a general lack of engineers' knowledge about maintenance. Maintenance is not maintainability, a quality of design. It is a separate technology based on a separate body of knowledge. Many traditional beliefs about maintenance are erroneous. It is most effective when supported by inductive reasoning and analysis based on operating experience, not on dogma and industrial folklore. Maintenance is the means for ensuring that the initial investment in the design will provide the value expected. It merits specific attention as a technology by engineers interested in the ultimate success of their designs, as well as by maintainers interested in maximizing the benefits of preventive maintenance.

\section{(39) The Strategic Approach to Product Design}

Author: Whitney, D. E. (Charles Stark Drapei Laboratory, Cambridge, MA); Nevins, J. L.; De Fazio, T. L.; Gustavson, R. E.; Metzinger, R. W.; Rourke, J. M.; Seltzer, D. S.

Publisher: Charles Stark Draper Laboratory, Inc.

Date: December 1986

Keywords: group technology, concurrent design, design for producibility

What Progressive Companies are Doing to Raise Productivity

Authors: Nevins, J. L. (Charles Stark Draper Laboratory, Cambridge, MA); Whitney, D. E.

Publisher: Charles Stark Draper Laboratory, Inc.

Date: October 1986

Keywords: see "(40) The Strategic Approach to Product Design"

Abstract: Advanced technology has long been the hope of companies wishing to raise their productivity, but now there is growing agreement that technology cannot accomplish this alone. This paper describes several strategies that stress integration of product design, process design, and total involvement of design and production employees. Such strategies allow rational mixes of technological and non-technological methods to be designed and justified. 
(41) Identification of Bottlenecks and Capacity Constraints

Authors: Cabuk, Joe G., Jr. (Col., USAF); Duncan, Thomas J. (Capt., USN); Hoffman, Irving L. (LTC, USAF); Nowlin, David V. (LTC, USAF)

Publisher: Defense Logistics Agency, Alexandria, VA - AD \#A134-629

Date: April 1983

Keywords: long lead items, suggestions for production surge

Abstract: This paper examines the aerospace industry capacity for surge production of tactical fighter aircraft in response to a national emergency. It provides a conceptual overview of the aerospace industry, some general industrial production factors, and a discussion of 1966-67 F-4 production surge. A vertical slice study of each of the four aircraft under consideration is then provided, followed by a horizontal slice study which addresses major critical production factors and ongoing corrective actions.

(42) Integrating Producibility Tools into a CAE Design Environment Author: Hawiszczak, Robert (Texas Instruments)

Publisher: Third International Conference on Design for Manufacture and Assembly

Date: March 1988

Keywords: producibility, design environment, methodologies and tools

(43) Relating Technology to Acquisition Costs: Aircraft Turbine Engines

- Author: Nelson, J. R.; Timson, F. S.

Publisher: National Technical Information Service (NTIS) AD \#780 636; also Rand Corp. R-1288-R

Date: March 1974

(44)

\section{Aircraft Configuration Optimization Including Optimized Flight Profiles}

Author: McClullers, L. A. (Kentron International, Inc., Hampton, VA)

Publisher: Multidisciplinary Analysis and Optimization - Part I. NASA CP-2327 (\#N87-11743)

Date: 1985

Pages: $395-412$

Keywords: flight optimization, optimized flight profiles 


\section{A New Method for Estimating Current and Future Transport Aircraft Operating Economics}

Author: American Airlines

Publisher: NASA CR-145190, \#N78-13027

Date: 1978

Keywords: airline operational cost assessment

Abstract: A methodology has been developed by which the operating cost associated with variations in aircraft design and technology characteristics can be assessed. This methodology addresses aircraft related operating cost elements and is based on an in-depth examination of American Airlines operating experience and relevant operating data collected by the Boeing Company from its customers.

The assessment method produces a base line estimate of the operating cost elements relating to such design specification features as seat capacity, avionic equipment, design range, and design definition features such as maximum takeoff gross weight and number of engines. Means for determining the deviations from this base line of the design or technological difference at the specific ATA system level are provided.

The methodology has been applied to assess the operating cost of one potential future advanced technology transport aircraft. An analysis has been included to show the relative sensitivity of the operating cost to design parameters.

Areas of potential future research on operating cost related technologies are identified.

(46) - Department of Defense Directive 4245.7: Transition From Development to Production

Author. Department of Defense

Publisher: Department of Defense

Date: January 19, 1984

Keywords: DoD production policies and procedures

\section{Department of Defense Directive 4245.6: Defense Production Management}

Author: Department of Defense

Publisher: Department of Defense

Date: January 19, 1984

Keywords: DoD production policy, procedure, and production management 

Reviews

Author: Department of Defense

Publisher: Department of Defense

Date: January 24, 1979

Keywords: production readiness guidelines

Ship Synthesis Model Morphology

Author: Calkins, D. E. (Dept. of Mech. Engr., U. of Washington)

Publisher: SNAME 11th Ship Technology and Research Symposium, Pittsburgh, PA

Date: June 1988

Keywords: Design Synthesis, CAE/CAD

Abstract: The classical process of designing a ship may be conceived of as an iterative spiral. The design process progresses in an orderly fashion through a system of technologies that address each aspect of the ship's geometry specification and performance analysis. Programs known as "Synthesis" models have been developed that emulate this design spiral. Synthesis models are defined as computer programs, the architecture of which emulates the design process; that is, they comprise both synthesis and analysis aspects. Synthesis model technology has developed historically in the marine industry for ship design and in the aeronautical industry for aircraft and aerospace vehicle design. The research that is described focuses on the development of the methodologies and architecture of ship synthesis models for design. The architecture of existing marine and aeronautical Synthesis models are reviewed to develop a "generic" Synthesis model. The applicability of several current, as well as emerging, design technologies will then be evaluated as enhancements to the Synthesis model architecture to increase the amount of information transferred and its speed of perception. The architecture of a "ship design environment" based on these technologies is proposed as a shell for the Synthesis model to increase the designers' productivity.

(50) Issues and Answers on Transition from Development to Production Author: Markham, Gerard R. (Textron Lycoming, Stafford, CT)

Publisher: personal document of Gerard Markham

Keywords: transition from development to production considerations

Chapter 10:: The Low Risk Transition System

Keywords: see Transition for Development to Production...Solving the Risk Equation 
Publisher: in "2nd International Conference on Product Design for Manufacture and Assembly" by Troy Conferences

Date: April 6-8, 1987, Newport, RI

Keywords: world class design characteristics and four ways to improve them

(53) Integrating Systems Producibility into the Design Process

Author: Bogard, Timothy V. (Texas Instruments, Inc.)

Publisher: in "2nd International Conference on Product Design for Manufacture \& Assembly" by Troy Conferences

Date: April 6-8, 1987, Newport, RI

Keywords: producibility methodologies, producibility within major corporations

(54) The Hatachi Assemblability Evaluation Method (AEM)

Authors: Miyakawa, Seii (Hitachi Ltd., Japan); Ohashi, Toshijiro (Hitachi Ltd., Japan)

Publisher: in "International Conference on Product Design for Assembly" by Troy Conferences

Date: April 15-17, 1986, Newport, RI

Keywords: Hitachi Assemblability Evaluation Method (AEM)

(55) - Design for Producibility

Author: Hurd, Gary L. (Cipher Data Products)

Publisher: in "2nd International Conference on Product Design for Manufacture \& Assembly" by Troy Conferences

Date: April 6-8, 1987, Newport, RI

Keywords: producibility guidelines, producibility attitudes

Giving Your Designs a "Producibility Checkup"

Author: Hock, Gerard

Publisher: in "2nd Intemational Conference on Product Design for Manufacture \& Assembly" by Troy Conferences

Date: April 6-8, 1987, Newport, RI

Keywords: producibility, product quality, design simplicity 


\section{Early Cost Estimating in Product Design}

Authors: Dewhurst, P. (Dept. of Industrial and Mfg. Engr., U. of Rhode Island); Boothroyd, G. (Dept. of Industrial and Mfg. Engr., U. of Rhode Island)

Publisher: in "2nd International Conference on Product Design for Manufacture \& Assembly" by Troy Conferences

Date: April 6-8, 1987, Newport, RI

\section{After 5 Years, What Has GE Learned From Design for Assembly?} Author: Hock, Gerard (General Electric, Bridgeport, CT)

Publisher: in "International Conference on Product Design for Assembly" by Troy Conferences

Date: April 15-17, 1986, Newport, RI

Keywords: design for assembly, quality in design

\section{Better Than Taguchi Orthogonal Tables}

Authors: Shainin, Dorian (Shainin Consultants, Inc., Manchester, CT); Shainin, Peter (Shainin Consultants, Inc., Manchester, $\mathrm{Ct}$ )

Publisher: in "Quality and Reliability Engineering International," Vol. 4, John Wiley \& Sons, Ltd.

Date: February 1988

Pages: 143-149

Abstract: There has been a great amount of publicity about Taguchi orthogonal tables. This paper will evaluate the pros and cons of that approach. In addition an American approach, having the same initial goals of the Taguchi approach, will be presented in detail, representing a significant improvement in meeting those goals without confounding interactions with any main effect or with other interactions. In addition, this constructive alternative generally requires a much smaller number of tests.

(60) An Explanation and Critique of Taguchi's Contributions to Quality Engineering

Authors: Box, George (Dept. of Industrial Engr., U. of Wisconsin); Bisgard, Soren (Dept. of Industrial Engr., U. of Wisconsin); Fung, Conrad (Dept. of Industrial Engr., U. of Wisconsin)

Publisher: in "Quality and Reliability Engineering International, Vol. 4, John Wiley \& Sons, Ltd.

Date: February 1988

Pages: 123-131

Abstract: Recently there has been much interest and some controversy concerning the statistical methods employed by Professor Genechi Taguchi of Japan for improving the quality of products and processes. These methods include the use of fractional factorial designs and other orthogonal arrays, parameter design to 
minimize sensitivity to environmental factors, parameter design for minimizing transmitted variation, signal-to-noise ratios, loss functions, accumulation analysis, minute analysis, and the analysis of life test data. This paper explains some of Taguchi's contributions to quality engineering and also provides a critical evaluation of statistical methods. Our conclusion is that although on the one hand Professor Taguchi's quality engineering ideas are of great importance and should become part of the working knowledge of every engineer, on the other hand many techniques of statistical design and analysis he employs to put these ideas into practice are often inefficient and unnecessarily complicated and should be replaced or appropriately modified. In this short article only an overview is attempted, but references are appended where these matters are discussed in greater detail.

(61) Characterizing and Optimizing Multi-Response Processes by the Taguchi Method

Authors: Logothetis, N. (Hirst Research Centre, Middlesex, UK); Haigh, A. (Ferranti Electronics, Oldham, UK)

Publisher: in "Quality and Reliability Engineering International," Vol. 4, John Wiley \& Sons, Ltd.

Date: February 1988

Pages: 159-169

Abstract: In this paper we demonstrate the ability of the Taguchi technique accurately to characterize and successfully to optimize complicated multi-response processes with the minimum of experiments, provided one uses simple statistical techniques which can ensure valid and definitive results. We point out the usefulness of suitable data-transformations, and we suggest a systematic procedure for establishing the optimal operating conditions and for carrying out confirmatory experiments. For the particular case detailed in this paper (which is typical of multi-response processes) the Taguchi technique achieved an improvement in uniformity of a factor of 2 together with optimized process control.

(62) The Role of Data Transformation in Taguchi Analysis

Author: Logothetis, N. (Hirst Research Centre, Middlesex, UK)

Publisher: in "Quality and Reliability Engineering International," Vol. 4, John Wiley \& Sons, Ltd.

Date: February 1988

Pages: 49-61

Abstract: This paper reports on the usefulness of data transformation in a proper application of the "Taguchi method" for off-line quality control. With the joint aim of establishing a meaningful measure of performance variability and reducing the risk of incorrectly assuming no interactions in the performance model, a simple method of choosing appropriate data transformations is presented. This provides the basis for suggested general procedure for carrying out Taguchi analyses. The technique is assessed by considering how it performs on data taken from previously published applications of the Taguchi method. 
Author: Ganter, William A. (Production Automation, Inc., Boulder, CO)

Publisher: in "Quality and Reliability Engineering International," Vol. 4, John Wiley \& Sons, Ltd.

Date: February 1988

Pages: 46

Abstract: This paper attempts to define a quality engineering role in the product design process. The product design is also placed within the modern quality system. Methods of experimentation and modeling in design are emphasized and an example is described.

(64) US Manufacturing Firms Adopt Taguchi Method to Improve Quality, Reduce Costs

Author: None

Publisher: CAD/CIM Alert; The Monthly Newsletter of the All-Systems User Group

Date: June 30, 1988

Keywords: Taguchi method

(65) What is Statistical Process Control?

Author: ITT Research Institute

Publisher: from Statistical Process Control and Quality Productivity Improvement

Keywords: statistical process control, quality-productivity improvement

Management Methods for Quality Improvement Based on Statistical Process Control: A Literature and Field Survey

Authors: Houston, Archester; Shettel-Neuber, Joyce; Sheposh, John P.

Publisher: Navy Personnel Research and Development Center, San Diego (NTIS AD \#A169 083)

Date: June 1986

Keywords: SPC Demings' Approach, Juran's Approach, Crosby's Approach

Abstract: This report presents the findings of a study on statistical process control (SPC) management approaches. SPC management approaches are intended to improve an organization's productivity and product or service quality by reducing variation in the work process. The study was conducted to identify similarities and distinctions among SPC management approaches, evaluate the use of commercial training packages in normal industrial facilities, and attempt to identify requirements and barriers to implementing SPC management systems in naval industrial facilities. 

Evaluation

Authors: Sakata, I. F. (Lockheed-California Co.); Davis, G. W. (LockheedCalifornia Co.)

Publisher: NASA Report \#CR-132575-1 (Microfiche \#N76-28219)

Date: August 1976

Keywords: Arrow Wing Structural Design Concepts

Abstract. An analytical study was performed to determine the structural approach best suited for the design of a Mach 2.7 arrow wing supersonic cruise aircraft.

(68) The Organization of Design: An Interdisciplinary Approach to the Study of People, Process and Contexts

Authors: Morley, Ian E.; Pugh, Stuart

Publisher: International Conference on Engineering Design, Boston, MA

Date: August 17-20, 1987

Keywords: design models

Abstract: This paper brings together the works of Morley and Pugh in the context of total design, considering the evolution of the understanding of leadership skills in parallel with the emerging understanding of engineering design. Models of design have brought about effective communication between the authors and industry, and they are used as the catalyst to focus upon the difference in design team characteristics required in differing design situations. These differences are elaborated through a consideration of products being either conceptually static or dynamic. It concludes by firmly establishing a sound relationship between the work on the two areas.

(69) Further Development of the Hypothesis of Static Dynamic Concepts in Product Design

Author: Pugh, Stuart (Dept. of Engr. Design, U. of Strathclyde, Glascow, UK)

Publisher: International Symposium on Design and Synthesis, Tokyo

Date: July 11-13, 1984

Keywords: Dynamic and Static Concepts, Systematic Design

Abstract: The paper considers the questions of conventional and nonconventional products in relation to the hypothesis of static/dynamic product concepts. In the conventional case, the emergence of a generic base is highlighted and discussed in the terms of the hypothesis--randomness of approach to design in the conventional area is seen as being inefficient. In the non-conventional case it is again shown that randomness of approach, combined with rapidly advancing technology, can make the major issues and the emergence of the generic base. It is argued that in both cases a systematic design activity needs to be adopted, and that within such activity alternative concepts to a given need situation, as defined in the Product Design Specification (PDS), require to be synthesized. Examples given in both conventional and non-conventional product areas may, in fact, be conceptually highly dynamic. 
(70) Total Design, Partial Design, A Reconciliation

Author: Pugh, Stuart (Dept. of Engr. Design, U. of Strathclyde, Glascow, UK)

Publisher: International Conference on Engineering Design, Boston, MA

Date: August 17-20, 1987

Keywords: design education, total design, partial design

Abstract: This paper considers and contrasts the design requirements of Industry with those of Education. By considering design teaching in education as being traditionally and necessarily elemental and therefore partial, it demonstrates how products are composed of a summation of many partial design inputs--to give Total Design. It concludes by describing briefly a new course at the University of Strathclyde--designed to cross traditional departmental boundaries and reconcile partial design teaching with the Totality of Industrial requirements.

(71) Modern Ship Design

Author: Gillmer, T. C.

Publisher: US Naval Institute, Annapolis, MD

Date: 1970

(72) Creative Ship Design

Author: Andrews, D.

Publisher: The Naval Architect, Royal Institution of Naval Architects

Date: November 1981

(73) - General Aviation Design Synthesis Utilizing Interactive Computer Graphics

Authors: Galloway, T. L.; Smith, M. R.

Publisher: SAE 760467, Society of Automotive Engineers Business Aircraft Meeting

Date: April 1976

(74) AVID: A Design System for Technology Studies of Advanzed Transportation Systems

Author: Wilhite, A. W.

Publisher: AIAA 79-0872, NASA-Langley Research Center

Date: 1979

(75) CDS--The Designer's Media, The Analyst's Model

Authors: Raymer, D. P.; Albrecht, S. K.

Publisher: Astronautics and Aeronautics/ICAS Conference

Date: 1982 
SDVCDS--An Evolutionary CDS for Preliminary Space Vehicle Design, Analysis, and Simulation

Authors: Tice, S. E.; Zelon, J. L.; Repic, R. A.

Publisher: AIAA 84-2393, AIAA/AHS/ASEE Aircraft Design Systems and Operations Meeting

Date: October 1984

(77) HAV-SPRINT: A Conceptual Design Computer Code for Hypersonic Vehicle Synthesis and Optimization

Authors: Burgess, M. A.; Schreffler, E. S.; Hill, J. C.; Osterbeck, P. G.; Woodhead, G. E.

Publisher: AIAA 87-2956, AIAA/AHS/ASEE Aircraft Design, Systems and Operations Meeting

Date: September 1987

(78) Design Technologies for Aerospace Vehicles

Authors: Mitchell, A. R.; Bryan, S. S.; Hall, M.D.

Publisher: AIAA 87-0715, AIAA Structures, Structural Dynamics, and Materials Conference

Date: April 6-8, 1987

(79) Interactive Wire Frame Ship Hull Form Generation and Display

Authors: Calkins, D. E.; Garbini, J. L.; Ishimaru, J. M.

- Publisher: Computer-Aided Geometry Modeling Symposium, NASA-Langley Research Center, Hampton, VA

Date: April 1983

(80) Perceptual Components of Computer Displays

Authors: Haber; Norman, Ralph; Leland, Wilkinson

Publisher: IEEE Computer Graphics and Applications

Date: 1982

(81) A Study in Computer-Aided Aerospace Vehicle Design

Author: Calkins, D. E.

Publisher: Master of Science Thesis in Aerospace Engineering, San Diego State University

Date: January 1969 
(82) Microtasking: A New Way to Harness Processors

Authors: Booth, M.; Misegares, $\mathrm{K}$.

Publisher: Cray Channels, Cray Research, Inc.

Date: Summer 1986

(83) Knowledge Representation in the Conceptual Design Process for Building Energy Systems

Authors: Monaghan, P. F.; Doheny, J. G.

Publisher: Department of Mechanical Engineering, University College Galaway, Galaway, Ireland

(84) Engineering Design Support Systems

Authors: Popplestone, R.; Smithers, T.; Corner, J.; Koutsou, A.; Millington, K.; Sahar, G.

Publisher: Department of Artificial Intelligence, University of Edinburgh

(85) Structure and Interpretation of Computer Programs

Authors: Abelson, H.; Sussman, G. J.; Sussman, J.

Publisher: The MIT Press, Cambridge, MA

Date: 1985

(86) Rubber Airplane, A Paradigm for Computer-Aided Preliminary Design Based on Component-Modeling

- Author: Kolb, M. A.

Publisher: Ph.D. thesis proposal, Dept. of Aeronautics and Astronautics, MTT, Cambridge, MA

Date: 1986

(87) Knowledge Engineering of the Aircraft Design Process, Knowledge Based Problem Solving

Authors: Elias, A. L.; J. S. Kowalic, Ed.

Publisher: Prentice-Hall, Englewood Cliffs, NJ

Date: 1985

(88) An Integration Tool for Design Analysis and Life-Cycle Engineering

Author: Mitchell, A. R.

Publisher: The Boeing Co.

Date: 1987 
A Hybrid Expert System for Complex CFD Problems Authors: Dannenhoffer, J. F.; Baron, J. R.

Publisher: MIT, AIAA 87-1111-CP, AIAA 8th Computational Fluid Dynamics Conference, Honolulu, HI

Data: June 1987

(90) Application of Decomposition Techniques to the Preliminary Design of Transport Aircraft

Authors: Rogan, J. E.; McElveen, R. P.; Kolb, M. A.

Publisher: Lockheed-Georgia Co., AIAA 86-2617, AIAA/AHS/ASEE Aircraft Systems Design and Technology Meeting, Dayton, $\mathrm{OH}$

Date: October 1986

(91) A Linear Decomposition Method for Large Optimization Problems-Blueprint for Development

Author: Sobieski, J.

Publisher: NASA TM-83248

Date: February 1982

(92) Aerospace Engineering Design by Systematic Decomposition and Multifaceted Optimization

Authors: Sobieski, J.; Barthelemy, J. F.; Giles, G. L.

Publisher: ICAS-84-4.7.3

Date: September 1984

(93) Computer Lib

Author: Nelson, T. H.

Publisher: Microsoft Press

Date: 1987

(94) An Expert System Based Parametric Geometry Generation Method Author: Nakasone, J. K.

Publisher: MS thesis, Department of Mechanical Engineering, University of Washington, Seattle, WA

Date: August 1987 


\section{DISTRIBUTION \\ IDA PAPER P-2151}

\section{AEROSPACE SYSTEM UNIFIED LIFE CYCLE ENGINEERING: PRODUCIBILITY MEASUREMENT ISSUES}

\section{Copies}

Number of

Copies

\section{Department of Defense}

\section{OUSD(R\&AT)/ET}

Rm. 3D1089, Pentagon

Washington, DC 20301-3080

ATTN: Dr. Leo Young

Col. Larry Griffin

OASD(P\&L) WSIG

Rm. 2B322, Pentagon

Washirtgton, DC 20301-8000

Dr. Jacob T. Schwartz

Defense Advanced Research Projects Agency

Information Science and Technology Office

1400 Wilson Boulevard, 7th Floor

Arlington, VA 22209

Defense Technical Information Center

Cameron Station

Alexandria, VA 223046145

Department of the Army

Dr. Michael Kaplan

Director, Basic Research

US Army Research Institute

5001 Eisenhower Avenue

Alexandria, VA 22333-5600 
Mr. Geza Papp

Chief of Technology

U.S. Army AMCCOM

Building 62

Picatinny Arsenal

Dover, NJ 07806-5000

\section{Department of the Air Force}

Logistics and Human Factors Division Air Force Human Resources Laboratory Area B, Building 190

Wright-Patterson AFB, OH 45433-5000

ATTN: Col. Donald Tetmeyer, Director Ms. Wendy Campbell

Capt. Raymond Hill

Mr. Mark Hoffman

Capt. Michael Hanuschik

Mr. Al Herner

WRDC/MTC

Wright-Patterson AFB, OH 45433

Industrial and Academic Organizations

Dr. Geoffrey Boothroyd

Boothroyd Dewhurst, Inc.

212 Main St., Suite C-3

Wakefield, RI 02879

D. E. Calkins, D. Eng., P.E.

Department of Mechanical Engineering University of Washington

Mechanican Engineering Bldg., FU-10

Seattle, WA 98195

Mr. Richard S. Gaevert

Department of Mechanical Engineering

University of Washington

Mechanican Engineering Bldg., FU-10

Seattle, WA 98195

Mr. Robert S. Hawiszczak

Manager, Producibility Engineering

Electro-Optics Systems Defense

Systems and Electronics Group

Texas Instruments

P.O. Box 600246, MS 3115

Dallas, TX 75266 
Mr. Bart Huthwaite

Institute for Competitive Design

134 University Drive

Rochester, MI 48063

Mr. Anthony W. Kim

Manager, Aircraft Performance Methods

General Electric Company

1 Neumann Way MD A326

Cincinnati, OH 45215-6301

Mr. C. T. Kitzmiller

Boeing Computer Services

The Boeing Advanced Technology Center for Computer Sciences

P.O. Box 24346, MS 7L-64

Seattle, WA 98124-0346

Mr. Stephen A. Meyer

McDonnell Douglas Helicopter Company

Building 530/B220

5000 East McDowell Road

Mesa, AZ 85205-9797

Mr. Frederick J. Michel

8409 Felton Lane

Alexandria, VA 22308

Dr. Farrokh Mistree

Department of Mechanical Engineering

University of Houston

Houston, TX 77009

Dr. Michael Pecht, P.E.

Director, CALCE

Department of Mechanical Engineering

University of Maryland

College Park, MD 20741

Dr. Daniel Schrage

School of Aerospace Engineering

Georgia Institute of Technology

Atlanta, GA 30332-0150

Dr. Michael J. Wozny

Director, Rensselaer Design Research Center

Rensselaer Polytechnic Institute

Troy, NY 12180-3590 
Institute for Defense Analyses

1801 N. Beauregard Street

Alexandria, VA 22311

Gen. William Y. Smith

Mr. Philip L. Major

Dr. Robert Roberts

Dr. William J. Schultis

Dr. Victor A. Utgoff

Dr. Jeffrey H. Grotte

Dr. Frederick R. Riddell

Mr. William E. Cralley

Dr. Karen J. Richter

Mr. David A. Dierolf

Mr. G. Watts Hill

Dr. Jim Pennell

Control and Distribution 